[Aus dem hygienischen Institut der Universität Gießen.]

(Direktor: Prof. Dr. Kossel.)

\title{
Die Verunreinigung der Lahn und der Wieseck durch die Abwässer der Stadt Gießen, mit besonderer Berücksichtigung der Brauchbarkeit der üblichen Methoden zur Untersuchung von Flußverunreinigungen. \\ Von
}

Dr. K. Kisskalt,

Privatdozent und Assistent am Institut.

(Hierzu Taf. III n. IV.)

Allgemeine Verhältnisse. Die Stadt Gießen leitet bisher ihre Abwässer mit Ausschluß der Fäkalien teils direkt, teils durch Vermittlung der die Stadt durchflieBenden Bäche in die Lahn. Die Abwässer sind fast rein städtische; von industriellen kommen fast nur solche der Brauereien in Betracht, doch können diese schon unter die Kategorie der städtischen mitgezählt Jverden, da wohl jede Stadt in Deutschland ihre Brauerei besitzt. Größere Fabriken von der Art, wie sie anderwärts viel zur FluBrerunreinigung beitragen, gibt es in der Stadt nicht. - Die Einwohnerzahl beträgt etwa 28000; der Wasserverbrauch pro Kopf und Tag ca. 80 Liter. Das Wasser stammt aus Quellen im Basalte des Vogelsberges; die meisten Häuser sind angeschlossen, Hausbrunnen nur wenige vorhanden.

Von den Abwässern gelangen bisher die Hausabwässer, sowie das Regenwasser teils oberirdisch, teils durch Kanäle in die Wasserläufe; die Fäkalien werden in Gruben gesammelt und abgefahren und gröBtenteils von den Bauern abgeholt, jedenfalls nicht der Lahn übergeben. Doch besitzt ein nicht geringer Teil der Gruben noch widerrechtlich angelegte Überläufe nach den Kanälen. 
Die Wasserläufe, in die die Abwässer eingeführt werden, sind die Lahn, die Wieseck und die Stadtbäche.

Die Lahn hat bei GieBen einen etwa $90 \mathrm{~km}$ langen Lauf hinter sich. In ihrem obersten Teile erhält sie ihr Wasser aus den Sandsteinen, Tonschiefern und Grauwacken des Unterdevons, den Kalken und Diabasen des Mittelderons, den Tonschiefern and Sandsteinen des Mittel- und Oberdevons und den Sandsteinen, Arkosen und Konglomeraten des Kulm. Die in der Gegend von Marburg einmündende $\mathrm{Ohm}$ bringt Wasser aus

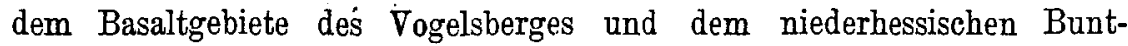
sandsteingebiet; ferner aus tonigen Bestandteilen des Tertiär. Die zwischen Marburg und Gießen einmündenden Bäche führen dasselbe Wasser wie die Lahn (westlich) bezw. die Ohm (östlich). Die Wassermenge der Lahn bei Gießen wird bei niederstem Wasserstand auf $3.1 \mathrm{cbm}$ in der Sekunde geschätzt. Ihre Geschwindigkeit schwankt erheblich entsprechend den stark wechselnden Querprofile zwischen 8 and $72^{\mathrm{cm}}$ in der Sekunde an der Wasseroberfläche; an der Stelle unterhalb Gießens, wo von uns Untersuchungen vorgenommen wurden, betrug sie bei dem sehr niederen Pegelstand ron 0.41 an der Oberfläche $33.3 \mathrm{~cm}$ in der Sekunde.

Verunreinigungen werden dem Flusse oberhalb Gießens besonders

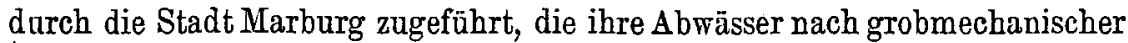
Reinigung einläBt. Von den Abwässern der $12.5^{\mathrm{km}}$ unterhalb Gießens gelegenen Stadt Wetzlar geht ein Teil völlig ungereinigt, ein Teil ebenfalls nach Reinigung mittels Rechen in den Fluß. Eine Benutzung des Lahnwassers als Trink- und bäusliches Brauchwasser findet seitens der in dieser Gegend gelegenen Gemeinden nicht statt. Die Labn wird nach hessischem Rechte bis Gießen als Bach, von da an als schiffbarer FluB betrachtet (1, S. 111). ${ }^{1}$ Die Genehmigung zur Einleitung von Abwässern in Bäche wird in Hessen durch den KreisausschuB, in Flüsse durch die Wasserbauämter erteilt. -

Die Wieseck kommt nach etwa $25 \mathrm{~km}$ langem Laufe nach Gießen. Sie entspringt aus den Basaltgebieten des Vogelsbergs und nimmt unterwegs Wasser ans tonigen Bestandteilen des Tertiär auf. Während die Lahn von dem gröBten Teil der Stadt durch einen Eisenbahndamm getrennt ist, durchfließt sie die Wieseck im rechten Winkel in. der Art, daB auf ihrem rechten Ufer der gröBere Teil der tiefgelegenen, auf ihrem linken Ufer der gröBte Teil der hochgelegenen Partie ist. Unter dem erwähnten Eisenbahndamm tritt sie aus der Stadt aus und mündet nach weiteren $50^{\mathrm{m}}$ in die Lahn, mit der sich ihr Wasser schnell rermischt.

${ }^{1}$ Die erste Ziffer gibt die Zahl im Literaturverzeichnis, die zweite. die Seitenzahl der betreffenden Angabe an. 
Ihre Wassermenge schwankt schon oberhalb Gießens in weiten Grenzen. Bei niederem Stande dürfte sie etwa $0.1^{\mathrm{cbm}}$ pro Sekunde betragen; in der Stadt wird sie noch dadurch stark beeinfluBt, daB ihr willkürlich wechselnde Mengen von Lahnwasser zugeführt werden könpen, daB als „Stadtbach" die Stadt durchflossen hat. Als Gesehwindigkeit wurde an der oberen Entnahmestelle 0.5 und $0.2 \mathrm{~m}$ in 1 Sekunde gemessen. Verunreinigungen finden unterwegs in mehreren Dörfern und in manchen Jahreszeiten durch die Wiesenbewässerung statt.

Von den Abwässern GieBens wird nur ein kleiner Teil direkt in die Lahn eingeführt. Ein gröBerer Teil flieBt zunächst der Wieseck zu, und zwar sind auf dem ganzen Laufe innerhalb der Stadt in kurzen Abständen die Ausmündungen der Kanāle sichtbar. Den gröBten Teil der Verunreinigungen erbält die Wieseck erst etwa $50^{\mathrm{m}}$ oberhalb ihrer Mündung durch die Stadtbäche.

Diesen wird ihr Wasser durch eine schmale Abzweigung der Lahn, das „Eingerinne" zugefülrt. Das Eingerinne teilt sich in mehrere Arme, die teils die innere Stadt als eigentliche Stadtbäche durchfließen (und zwar quer durch die Häuserblocks), teils als Stadtringräben oder ,Schoorgräben" der früheren Umwallung folgen; kurz vor der Einmündung in die Wieseck vereinigen sie sich zum "Ausgerinne". Auf diese Weise wird schließlich der Wieseck der meiste und der Lahn der sämtliche schwemmbare Unrat der Stadt Gießen außer den Fäkalien zugeführt.

Es ist klar, daB dadurch die Wassserläufe in verschiedener Weise verunreinigt werden. - Die Lahn kommt nach GieBen als reiner FluB; ihr Wasser ist klar, solange keine besonderen Umstände vorliegen (Grünfärbung im Hochsommer, Trübung bei Hochwasser); ein Einfluß der Marburger Abwässer ist nicht zu bemerken. Aber auch nach Einführung sämtlicher Abwässer zeigt sich trotz des schlechten Gefälles keine Verunreinigung: das Wasser erscheint dem Beschauer ebenso klar wie oben, der Grund ist braun und an den Ufern gut zu sehen. Auch der Zustand der Wieseck oberhalb GieBens gibt zu Beanstandungen keinen AnlaB. Dagegen machen sich Übelstände schon bald nach ihrem Eintritt in die Stadt bemerkbar, besonders unterhalb der Einmündung des Klingelbaches, der die Abwässer einer Brauerei mitbringt. Im Hochsommer schwimmen Schlammbrocken auf dem Wasser; dieses ist trübe, der Boden, soweit sichtbar, ist schwarzgrau gefärbt und läßt Gasblasen aufsteigen. Im Herbste bessert sich dieser Zustand, indem nur noch eine schwarzgraue Verfärbung des Wassers und des Bodens zurückbleibt. Im Winter findet bei dem starken Anschwellen des Baches eine natürliche Reinigung statt, so daB im Frühjahr das Aussehen ein besseres ist. 
Besonders unerträgliche Zustände führt die Verschmutzung des Stadtbaches herbei. Seine Geschwindigkeit ist gering, die Veruureinigung sehr stark; die Folge ist, daB sich im Sommer eine schwarzgraue, mit Papier und anderen Schwimmstoffen durchsetzte Schlammdecke bildet, so $\mathrm{daB}$ flieBendes Wasser an vielen Stellen kaum sichtbar ist. Der Geruch bildet eine ständjge Klage der Anwohner, wie wir besonders bei Gelegenheit einer kürzlich veranstalteten Wohnungsenquête erfahren konnten. Nach der Verunreinigung durch den Stadtbach verschlimmert sich das Aussehen der Wieseck beträchtlich; doch führen die $50^{\mathrm{m}}$, die sie dann noch zurückzulegen hat, durch unbewohntes Gebiet.

Die Verunreinigung, die die Lahn durch die zugeführten Abwässer erhält, dürfte dem Baumeisterschen Verunreinigungskoüffizienten $\mathbf{2 . 9}$ entsprechen [2]; dabei ist angenommen, daß Fäkalien „nicht planmäBig“ eingeführt werden.

Über die in Hessen derzeit für die Beurteilung von Flußrerunreinigungen maßgebenden Gesichtspunkte hat die großherzogliche Regierung vor kurzem im Landtage auf eine dahingehende Anfrage Auskunft erteilt (3).

Vorbemerkungen zu den Untersuchungen. Die Untersuchung der Verunreinigung der Lahn und der Wieseck bot nach mehreren Seiten hin Interesse. Zunächst als Beitrag zur Frage der FlnBverunreinigungen überhaupt. Ferner wird in kurzer Zeit die Kaualisation von Gießen beendet sein und es wird dann interessant sein, festzustellen, inwiefern dadurch der Reinheitsgrad der beiden Gewässer geändert wird. Schließlich war es von Wichtigkeit, daß gleichzeitig ein stark verunreinigter Bach and ein schwach verunreinigter FluB zur Untersuchung kamen. Es war dadurch die Möglichkeit gegeben, die erhaltenen Zahlen miteinander $\mathrm{zu}$ vergleichen und dadurch $\mathrm{zu}$ prüfen, $\mathrm{ob}$ die angewandten Methoden sämtlich gute Resultate ergaben, besonders ob die erhaltenen Zahlen bei starker Verschmutzung wesentlich höher waren als bei geringer. Dieser Teil der Arbeit wurde noch durch Vergleich mit anderen in der Literatur niedergelegten Untersuchungen erweitert; leider sind diese in so vielen Zeitschriften zerstreut, daB unmöglich alle berücksichtigt werden konnten.

Die Entnahme geschah rom Juli 1904 bis Juni 1905 in jedem Monat 1 bis 2 mal und zwar stets za derselben Tageszeit. Gegen $9 \mathrm{Uhr}$ wurde an der Brücke am Philosophenwald, etwa $1 \mathrm{~km}$ oberhalb GieBens, Wasser entnommen. Die Entnahme geschah aus der Tiefe ron $20^{\mathrm{cm}}$ in der Art, daß zwei Flaschen mit zusammen $1300^{\mathrm{cem}}$ Inhalt durch Schöpfen mit einem Becherglas in kurzen, zeitlichen Abständen gefüllt wurden. Auf diese Weise sollten möglichst Durchschnittsproben genommen werden. - 
Außerdem wurde das, Wasser zur Sauerstoffbestimmung mit einer Flasche von etwa $300 \mathrm{~cm}$ entnommen, sofort mit den betreffenden Chemikalien versetzt und die Flasche mit Glasstöpsel und wassergefüllter Gummikappe fest verschlossen; ferner zur Bestimmung der Sauerstoffzehrung ebensoviel in eine Flasche gebracht und ebenso verschlossen. Das Wasser zur bakteriologischen Untersuchung wurde vermittelst steriler Reagenzgläser entnommen; im Sommer wurden zuerst an Ort und Stelle Platten gegossen, später die Proben in Eis rerpackt ins Laboratorium transportiert.

Die Entnahme der Proben aus der Lahn oberhalb Gießens geschah etwa eine halbe Stunde später, anfangs von einem Wehr neben oiner Mühle aus an einer Stelle, wo das Wasser noch keinerlei verunreinigende Stoffe aufgenommen hatte, später von einem ron der Stadt zur Verfügung gestellten Kahne aus unmittelbar oberhalb dieser Stelle. Das Wasser HoB dort infolge des großen Querschnittes sehr langsam. - Kurz darnach wurde nochmals Wasser aus der Wieseck entnommen, etwa $20^{\mathrm{m}}$ unterhalb der Einmündung des Stadtbaches, $30^{\mathrm{m}}$ oberhalb ihrer Mündung in die Lahn. Bis dorthin hatte eine völlige Vermischung mit diesem infolge der Verengerung des Querschnittes unter einer Brücke und einer starken Krümmung bereits stattgefunden. - In einer Tabelle (XV) sind auch Resultate von Wasser angeführt, das direkt oberbalb der Einmündung des Stadtbaches entnommen wurde. - Die Proben wurden darauf ins Laboratorium gebracht und sofort die bakteriologische Untersuchung vorgenommen; darauf der wesentlich weitere Gang zo der $2.5 \mathrm{~km}$ unterhalb der Einmündung der Wieseck liegenden Kleinlindener Brücke gemacht. Hier geschah die Entnahme vom Ufer aus. Einigemale wurde das Wasser ron beiden Ufern gemischt, doch zeigte sich in mehreren Untersuchungen, da $B$ zwischen beíden ein Unterschied nicht einmal bei Anwendung der feinsten Probe, der Keimzählung, gefunden werden konnte. - Die Entnahme geschah hier so weit unterhalb, damit nicht nur die durch die Wieseck, sondern auch die weiter unten in den Fluß gelangenden Abwässer mituntersucht werden konnten.

Mit der Entnahme wurde zugleich die Inspektion der Gewässer und ihrer Ufer verbunden, wobei sich besonders die von $\mathrm{Mez}(4$, S. $365 \mathrm{ff}$.) gegebenen Ratschläge wertvoll erwiesen, - Da die Entnahmestellen weit voneinander entfernt lagen, war es nicht möglich, größere Mengen von Wasser als die eingeführten mitzunehmen.

Die physikalische Untersuchung erstreckte sich vor allem auf Bestimmung der Durchlesbarkeit und der Lichtabsorption (5). Erstere wurde in der Weise ausgeführt, daß Glaszylinder dureh ZugieBen solange mit Wasser gefüllt wurden, bis die darunter gehaltene Leseprobe Snellen I rerschwand. Da sie. zu unsichere Resultate ergab, wurde sie später weg- 
gelassen. Die letztere genügte allen Anforderungen. Eine Untersuchung, in welcher Tiefe eine weiße Scheibe noch zu sehen sei (Forel 6, S. 141; Fischer 7, S. 40) konnte leider nicht gemacht werden, da die Wieseck meist zu seicht und an der Lahn unterhalb GieBens eine Beurteilung vom Ufer aus nicht möglich war.

Die chemische Untersuchung wurde nach Farnsteiner, Buttenberg und Korn (8), Lehmann (9) u. a. vorgenommen. Im einzelnen sei dazu noch folgendes bemerkt:

Die Reaktion wurde mit Rosolsäure untersucht, auf Schwefelwasserstoff durch Eintauchen von Bleipapier. - Der Ammoniak wurde leider nicht immer quantitativ bestimmt, da die Mehrzahl der bisher vorgenommenen Arbeiten davon absieht; nach unseren Ergebnissen dürfte jedoch großes Gewicht darauf zu legen sein. Es wurden deshalb am Schluß an einigen Tagen Proben nur auf Ammoniak untersucht (Tabelle 15 und 17). Meist geschah dies kolorimetrisch, anfangs auch durch Titrieren des nach Zusatz ron Magnesia erhaltenen Destillates mit 1/10 normal Schwefelsäure, die aber für genauere Bestimmung zu stark war. Zur Erkennung der salpetrigen Säure wurde anfangs Jodzinkstärke allein, später auch das viel feiner reagierende Erdmannsche Reagens (10, S. 105) benutzt. Die Möglichkeit, daß darauf noch andere Stoffe reagieren (8), kann man dadurch ausschalten, daB man Harnstoff zusetzt, wodurch (K. B. Lehmann) die salpetrige Säure zerstört wird; in mehreren von uns untersuchten Proben trat dän nách Zusatz der Reagens keine Rotfärbung mehr ein.

Die Bestimmung der Salpetersäure geschah mittels Diphenylamin, die des freien Sauerstoffs nach Winkler. Zur Ermittlung der Oxydierbarkeit wurden $100^{\mathrm{cm}}$ unverdünnten Wassers benutzt. . Zur Bestimmung der suspendierten Bestandteile wurden mindestens $300 \mathrm{~cm}$ Wasser genommen, die durch ein gewogenes Filter filtriert wurden.

Diese sämtlichen Untersuchungen wurden am Tage der Entnahme gemacht. Am nächsten Tage wurde noch aus dem Filtrate Gesamtrückrückstand, Glühverlust und Glührückstand und Chlor bestimmt; ferner an diesem oder dem dritten Tage die Untersuchung der Sauerstoffzehrung nach Spitta (11) gemacht.

Die Bestimmung der „Fäulnisfähigkeit" wurde in der Weise vorgenommen, daB etwa 300 com in der Literflasche stehen gelassen wurden; der Stopfen wurde nach verschieden langer Zeit geöffnet und der Gauch geprüft.

Die bakteriologische Untersuchung geschah teils mit Agargelatine, teils mit Jodkaliumkartoffelgelatine; die ersteren Platten wurden nach 2 Tagen, die letzteren nach 3 Tagen gezählt. Außerdem wurde die 
Bestimmung der Kolititers nach Petruschky und Pusch (12) vorgenommen.

Eine genaue Untersuchung des Schlammes hätte jedenfalls sehr interessante Resultate ergeben; doch mußte davon einstweilen noch abgesehen werden.

\section{Abkürzungen in den Tabellen:}

Wieseck I = Entnahmestelle an der Brücke am Philosophenwald vor Einfluß in die Stadt Gießen.

Wieseck II = Entnahmestelle $30^{\mathrm{m}}$ oberhalb der Mündung.

Lahn I = Entnahmestelle oberhalb Gießens.

Lahn II $=$ Entnahmestelle unterhalb Gießens an der Kleinlindener Brücke.

Bei den Angaben der salpetrigen Säure bedeutet $\mathrm{J}$ : Nachweis mit Jodzinkstärke; E: Nachweis mit dem Erdmannschen Reagens.

Bei der Sauerstoffzehrung ist stets besonders angegeben, $o b$ die Ermittlung nach 24 oder 48 Stunden erfolgte.

Die Zahlen bedeuten, wo nicht anders angegeben, mg in 1 Liter; die Oxydierbarkeit ist in mg Sauerstoff für 1 Liter, der freie Sauerstoff in ccm bei $0^{\circ}$ und $760 \mathrm{~mm}$ Druck angegeben. Aus dem Sauerstoffgehalt wurden nach den Winklẹschen Tabellen das Sauerstoffdefizit bezw. der Überschuß in Prozenten berechnet.

Tabelle $\mathbf{I}$.

Montag, 18. Juli 1904.

Seit Wochen heißes Wetter. Barometer 751.5; Lahnpegel 0.27.

\begin{tabular}{|c|c|c|c|c|}
\hline & \multicolumn{2}{|c|}{ Wieseck } & \multicolumn{2}{|c|}{ Lahn } \\
\hline & I & II & I & U \\
\hline $\begin{array}{c}\text { Aussehen } \\
\text { a) der Wasser- } \\
\text { läufe }\end{array}$ & $\begin{array}{c}\text { sehr seicht; } \\
\text { Wasser ziemlich } \\
\text { klar; Wiesen- } \\
\text { bewässerung }\end{array}$ & $\begin{array}{l}\text { schwärzlich, teil- } \\
\text { weise fettiger } \\
\text { Überzug; vielè } \\
\text { schwarzeu.grüne } \\
\text { Schlammbrock.; } \\
\text { viele Pilzfäden; } \\
\text { Gestank }\end{array}$ & dunkelgrün & braun \\
\hline $\begin{array}{l}\text { b) des ent- } \\
\text { nommenen } \\
\text { Wassers }\end{array}$ & $\begin{array}{l}\text { opaleszent mit } \\
\text { vielen feinen } \\
\text { Flöckchen und } \\
\text { fein.hellbraunem } \\
\text { Niederschlag }\end{array}$ & $\begin{array}{l}\text { opaleszent; ge- } \\
\text { ringer schwärzl. } \\
\text { Niederschlag }\end{array}$ & $\begin{array}{c}\text { fast klar, } \\
\text { etwas grünlich }\end{array}$ & wie I \\
\hline
\end{tabular}


K. KISSKALT:

Tabelle I. (Fortsetzung.)

\begin{tabular}{|c|c|c|c|c|}
\hline & \multicolumn{2}{|c|}{ Wieseck } & \multicolumn{2}{|c|}{ Lahn } \\
\hline & I & II & I & II \\
\hline $\begin{array}{l}\text { Temperatur } \\
\text { des Wassers }\end{array}$ & $21 \cdot 25$ & $22 \cdot 5$ & 25 & 25 \\
\hline $\begin{array}{c}\text { Durch- } \\
\text { lesbarkeit }\end{array}$ & $10^{\mathrm{cm}}$ & $8 \mathrm{~cm}$ & $24 \mathrm{~cm}$ & $23 \mathrm{~cm}$ \\
\hline Geruch & erdig & urinös-fäkalisch & $\begin{array}{l}\text { nach Wasser- } \\
\text { pflanzen }\end{array}$ & $\begin{array}{l}\text { wie I, etwas } \\
\text { stärker }\end{array}$ \\
\hline $\begin{array}{l}\text { Fäulnis- } \\
\text { fähigkeit }\end{array}$ & $\begin{array}{c}\text { nach } 8 \text { Tagen } \\
\text { hellbrauner, } \\
\text { grobkrümeliger } \\
\text { Bodensatz }\end{array}$ & $\begin{array}{c}\text { nach } 2 \text { Tagen } \\
\text { schwarzer Boden. } \\
\text { satz; Geruch hat } \\
\text { zugenommen, } \\
\text { n. } 8 \text { Tag. ebenso }\end{array}$ & $\begin{array}{c}\text { nach } 8 \text { Tagen } \\
\text { feiner grüner } \\
\text { Bodensatz }\end{array}$ & $\begin{array}{c}\text { nach } 8 \text { Tagen } \\
\text { feiner } \\
\text { hellbrauner } \\
\text { Bodensatz }\end{array}$ \\
\hline Reaktion & alkalisch & alkalisch & alkalisch & alkalisch \\
\hline Rückstand. & 260 & 340 & 280 & 270 \\
\hline Glühverlust & 140 & 170 & 160 & 150 \\
\hline $\begin{array}{c}\text { Glüh }-^{-} \\
\text {rückstand }\end{array}$ & 120 & 170 & 120 & 120 \\
\hline $\mathrm{H}_{2} \mathrm{~S}$ & 0 & 0 & 0 & 0 \\
\hline Chlor & 18 & 54 & 12 & 16 \\
\hline Ammoniak & 0 & $4 \cdot 08$ & 0 & 0 \\
\hline $\begin{array}{l}\text { Salpetrige } \\
\text { Säure }\end{array}$ & 0 & J.: vorhanden & 0 & 0 \\
\hline Salpetersänre & 0 & 0 & 0 & 0 \\
\hline $\begin{array}{c}\text { Oxydierbar- } \\
\text { keit }\end{array}$ & $6 \cdot 1$ & $9 \cdot 2$ & $5 \cdot 5$ & $5 \cdot 5$ \\
\hline $\begin{array}{c}\text { Freier } \\
\text { Sauerstoff }\end{array}$ & $5 \cdot 15$ & $1 \cdot 13$ & $8 \cdot 23$ & $7 \cdot 36$ \\
\hline $\begin{array}{l}\text { Sanerstoff- } \\
\text { defizit bzw: } \\
\text { Überschu in } \\
\text { Prozenten }\end{array}$ & -17 & -81 & +42 & +27 \\
\hline $\begin{array}{l}\text { Suspendierte } \\
\text { Bestandteile }\end{array}$ & 43 & 47 & unwägbar & 10 \\
\hline KeimzahI & 4000 & 104000 & 318 & 2640 \\
\hline
\end{tabular}

Tabelle II. Montag, 25. Juli 1904.

Fortdauer des heißen Wetters. Barometer 741.0; Lahnpegel 0.33. \begin{tabular}{c||c|c|c|}
$\stackrel{\text { A ussehen }}{\text { a) Wasserlänfe }}$ & wie Tabelle I & wie Tabelle I & $\begin{array}{c}\text { wie Tabelle I } \\
\text { grün durchAlgen, }\end{array}$
\end{tabular} b) des entnom. $\quad \begin{gathered}\text { die schon nach } \\ \text { 2 std. Stehen sich }\end{gathered}$ opaleszent, \begin{tabular}{l|l|l|l|l} 
& & wie Tabelle I & $\begin{array}{c}\text { in dem unteren } \\
\text { Teile d. Flüssig- } \\
\text { keit ansammeln }\end{array}$ & $\begin{array}{c}\text { Bodensatz, } \\
\text { Filterrück- }\end{array}$
\end{tabular} keit ansammeln. 
Tabelle II. (Fortsetzung.)

\begin{tabular}{|c|c|c|c|c|}
\hline & \multicolumn{2}{|c|}{ Wieseck } & \multicolumn{2}{|c|}{ Lahn } \\
\hline & I & II & I & II \\
\hline $\begin{array}{c}\text { Temperatur } \\
\text { des Wassers }\end{array}$ & 26 & $22 \cdot 5$ & $25 \cdot 5$ & $25 \cdot 5$ \\
\hline $\begin{array}{c}\text { Durch- } \\
\text { lesbarkeit }\end{array}$ & $16^{\mathrm{cm}}$ & $12^{\mathrm{cm}}$ & $31 \mathrm{~cm}$ & $26 \mathrm{~cm}$ \\
\hline $\begin{array}{c}\text { Licht. } \\
\text { absorption } \\
\text { bei } 5^{\mathrm{cm}} \text { Dicke }\end{array}$ & 22 Prozent & 31 Prozent & 11 Prozent & 12 Prozent \\
\hline Geruch & erdig & $\begin{array}{l}\text { urinös-fäkalisch } \\
\text { schwächer als } \\
\text { am 18. VII. }\end{array}$ & $\begin{array}{l}\text { nach Wasser- } \\
\text { pflanzen }\end{array}$ & wie I \\
\hline $\begin{array}{l}\text { Fänlnis } \\
\text { fähiglit }\end{array}$ & $\begin{array}{l}\text { nach } 6 \text { Tagen } \\
\text { hellbrauner, } \\
\text { grobkrümeliger } \\
\text { Bodensatz }\end{array}$ & $\begin{array}{c}\text { nach } 6 \text { Tagen } \\
\text { starkerschwarzer } \\
\text { Bodensatz; } \\
\text { Geruch stark }\end{array}$ & $\begin{array}{c}\text { nach } 6 \text { Tagen } \\
\text { klar mit grünem } \\
\text { Bodensatz }\end{array}$ & $\begin{array}{c}\text { nach } 6 \text { Tagen } \\
\text { klar mit } \\
\text { braunem } \\
\text { Bodensatz }\end{array}$ \\
\hline Peaktion & alkalisch & alkalisch & alkalisch & alkalisch \\
\hline Rückstand & 230 & 360 & 220 & 260 \\
\hline Glühverlust & 110 & 180 & 90 & 140 \\
\hline $\begin{array}{l}\text { Glüh- } \\
\text { rückstand }\end{array}$ & 120 & 180 & 130 & 120 \\
\hline $\mathrm{H}_{2} \mathrm{~S}$ & 0 & 0 & 0 & 0 \\
\hline Chlor & 12 & 50 & 14 & 16 \\
\hline Ammoniak & 0 & $4 \cdot 08$ & 0 & 0 \\
\hline $\begin{array}{l}\text { Salpetrige } \\
\text { Säure }\end{array}$ & 0 & 0 & 0 & 0 \\
\hline Salpetersäare & 0 & 0 & 0 & 0 \\
\hline $\begin{array}{c}\text { Oxydierbar- } \\
\text { keit }\end{array}$ & $6 \cdot 4$ & $14 \cdot 4$ & $5 \cdot 2$ & $7 \cdot 9$ \\
\hline $\begin{array}{c}\text { Freier } \\
\text { Sauerstoff }\end{array}$ & 6.7 & $0 \cdot 3$ & $9 \cdot 2$ & $6 \cdot 8$ \\
\hline $\begin{array}{l}\text { Sauerstoff- } \\
\text { defizit bzw. } \\
\text { ÜberschuB } \\
\text { in Prozenten }\end{array}$ & +18 & -95 & +61 & +20 \\
\hline $\begin{array}{l}\text { Suspendierte } \\
\text { Bestandteile }\end{array}$ & 17 & 40 & 10 & 13 \\
\hline Keimzahl & 2384 & 156800 & 132 & 10400 \\
\hline
\end{tabular}


Tabelle III.

Mittwoch, 24. August 1904.

Nach langer regenloser Zeit am Tage vorher starker Regen.

Barometer $745 \cdot 1$; Lahnpegel 0.39.

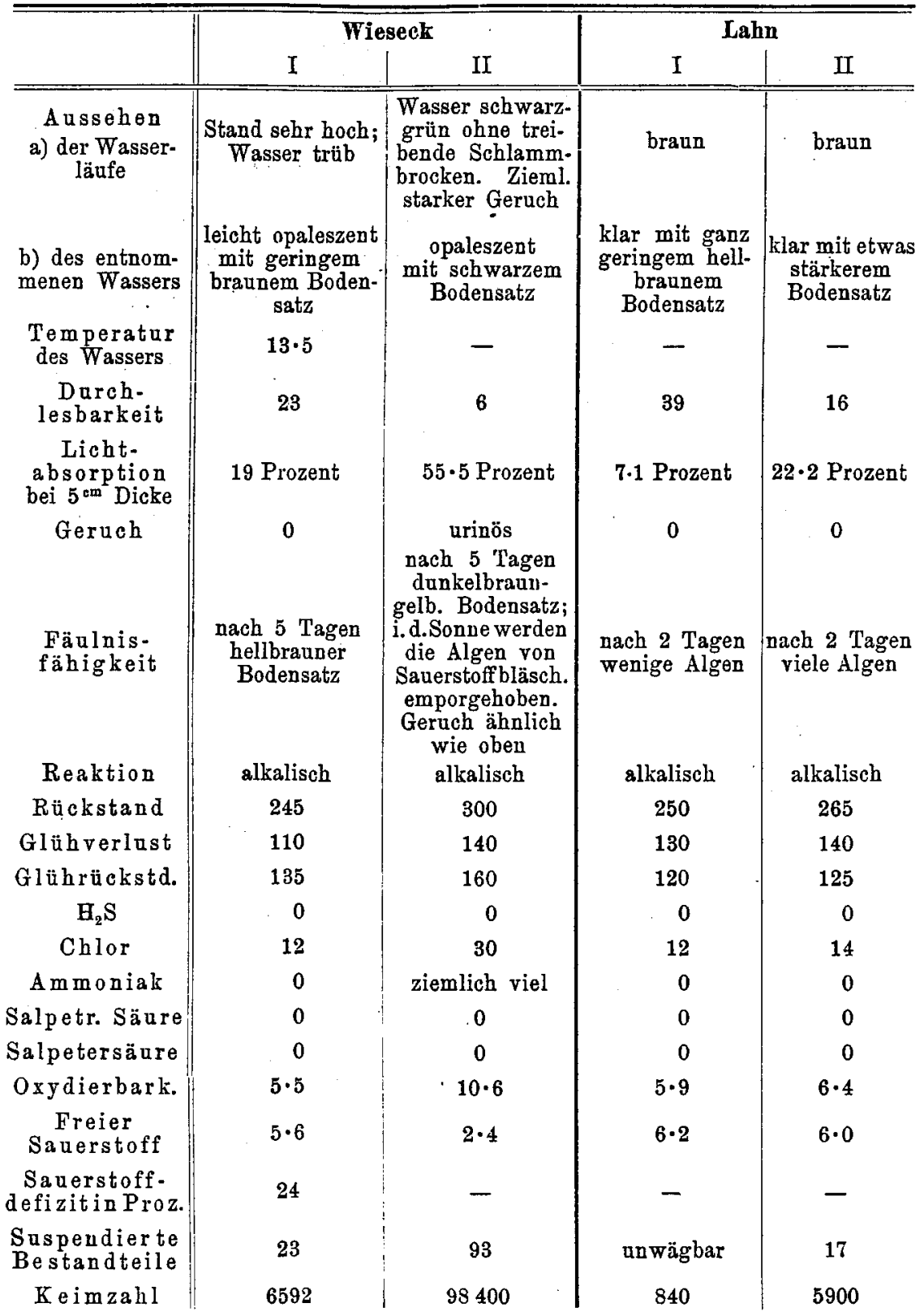


Tabelle IV.

Dienstag, 4. Oktober 1904.

Seit einigen Wochen häufig Regen; am Entnahmetage Sonne. Barometer 752.2; Lahnpegel 0.33.

\begin{tabular}{|c|c|c|c|c|}
\hline & \multicolumn{2}{|c|}{ Wieseck } & \multicolumn{2}{|c|}{ Lahn } \\
\hline & $\mathrm{I}$ & II & I & II \\
\hline $\begin{array}{c}\text { Aussehen } \\
\text { a) der Wasser- } \\
\text { läufe }\end{array}$ & $\begin{array}{l}\text { Stand sehr hoch; } \\
\text { Wasser grau }\end{array}$ & $\begin{array}{l}\text { schwarzgrau mit } \\
\text { zahlreichen Pilz- } \\
\text { fäden; Geruch } \\
\text { ziemlich stark }\end{array}$ & $\begin{array}{l}\text { sehr durch- } \\
\text { sichtig; braun }\end{array}$ & $\begin{array}{c}\text { ziemlich } \\
\text { durchsichtig; } \\
\text { brann }\end{array}$ \\
\hline $\begin{array}{l}\text { b) des entnom- } \\
\text { menen Wassers }\end{array}$ & $\begin{array}{c}\text { opaleszent; } \\
\text { mäBiger hell- } \\
\text { braun. Bodensatz }\end{array}$ & $\begin{array}{l}\text { opaleszent; klein. } \\
\text { schwarze Par- } \\
\text { tikelchen; zieml. } \\
\text { starker schwarz. } \\
\text { Bodens.; Pilzfäd. }\end{array}$ & $\begin{array}{l}\text { sehr geringe } \\
\text { Opaleszenz; } \\
\text { minimaler } \\
\text { Bodensatz }\end{array}$ & $\begin{array}{l}\text { geringe } \\
\text { Opaleszenz; } \\
\text { minimaler } \\
\text { Bodensatz }\end{array}$ \\
\hline $\begin{array}{l}\text { Temperatur } \\
\text { des Wassers }\end{array}$ & $13 \cdot 0$ & $13 \cdot 0$ & $14 \cdot 0$ & $14 \cdot 0$ \\
\hline der Luft & 14.5 & $15 \cdot 5$ & $15 \cdot 5$ & $16 \cdot 5$ \\
\hline $\begin{array}{l}\text { Durch- } \\
\text { lesbarkeit }\end{array}$ & $19^{\circ \mathrm{m}}$ & $9^{\mathrm{cm}}$ & $39^{\mathrm{em}}$ & $27 \mathrm{~cm}$ \\
\hline $\begin{array}{l}\text { Licht: } \\
\text { absorption } \\
\text { bei } 5 \mathrm{~cm} \text { Dicke }\end{array}$ & 14 Prozent & $38 \cdot 3$ Prozent & 4.5 Prozent & 8.7 Prozent \\
\hline Gerach & 0 & $\begin{array}{c}\text { schwach } \\
\text { moderig-urinös }\end{array}$ & 0 & 0 \\
\hline $\begin{array}{l}\text { Fäulnis: } \\
\text { fähigkeit }\end{array}$ & $\begin{array}{l}\text { nach } 4 \text { Tagen } \\
\text { keine Verände- } \\
\text { rung; nach } \\
4 \text { Wochen braune } \\
\text { Fäden am Boden }\end{array}$ & $\begin{array}{c}\text { nach } 4 \text { Tagen } \\
\text { brauner Boden- } \\
\text { satz; kein Geruch, } \\
\text { nach } 4 \text { Wochen } \\
\text { braune Klümp- } \\
\text { chen (Diatomeen, } \\
\text { Pilze nsw.) am } \\
\text { Boden }\end{array}$ & $\begin{array}{c}\text { nach } 4 \text { Tagen } \\
\text { sehr geringer } \\
\text { brauner Boden- } \\
\text { satz; nach } \\
4 \text { Wochen etwas } \\
\text { - stärker }\end{array}$ & $\begin{array}{c}\text { wie } \text { I, etwas } \\
\text { stärker }\end{array}$ \\
\hline Reaktion & alkalisch & alkalisch & alkalisch & alkalisch \\
\hline Rückstand & 290 & 340 & 280 & 285 \\
\hline Glühverlust & 160 & 160 & 140 & 145 \\
\hline Glührückstd. & 130 & 180 & 140 & 140 \\
\hline $\mathrm{H}_{2} \mathrm{~S}$ & 0 & 0 & 0 & 0 \\
\hline Chlor & 14 & 32 & 10 & 16 \\
\hline Ammoniak & 0 & $1 \cdot 36$ & 0 & 0 \\
\hline Salpetr. Säure & 0 & 0 & 0 & 0 \\
\hline Salpetersäure & 0 & 0 & 0 & 0 \\
\hline oxydierbark. & 6.3 & $11 \cdot 4$ & $4 \cdot 9$ & $5 \cdot 0$ \\
\hline $\begin{array}{c}\text { Freier } \\
\text { Sauerstoff }\end{array}$ & $5 \cdot 53$ & $2 \cdot 78$ & $4 \cdot 68$ & $6 \cdot 26$ \\
\hline $\begin{array}{c}\text { Sauerstoff- } \\
\text { defizitin Proz. }\end{array}$ & 25 Prozent & 62 Prozent & 35 Prozent & 13 Prozent \\
\hline $\begin{array}{l}\text { Suspendierte } \\
\text { Bestandteile }\end{array}$ & $31 \cdot 6$ & 82 & minimal & 16 \\
\hline $\begin{array}{l}\text { do. nach dem } \\
\text { Glühen }\end{array}$ & 12 & 46 & . & 14 \\
\hline Keimzahl & 1920 & 28400 & 1235 & 6320 \\
\hline
\end{tabular}


Tabelle V.

Freitag, 28. Oktober 1904.

In den vorangehenden Wochen oft geringer Regen; seit 2 Tagen Sonnenschein. Barometer 754.2; Lahnpegel 0.33.

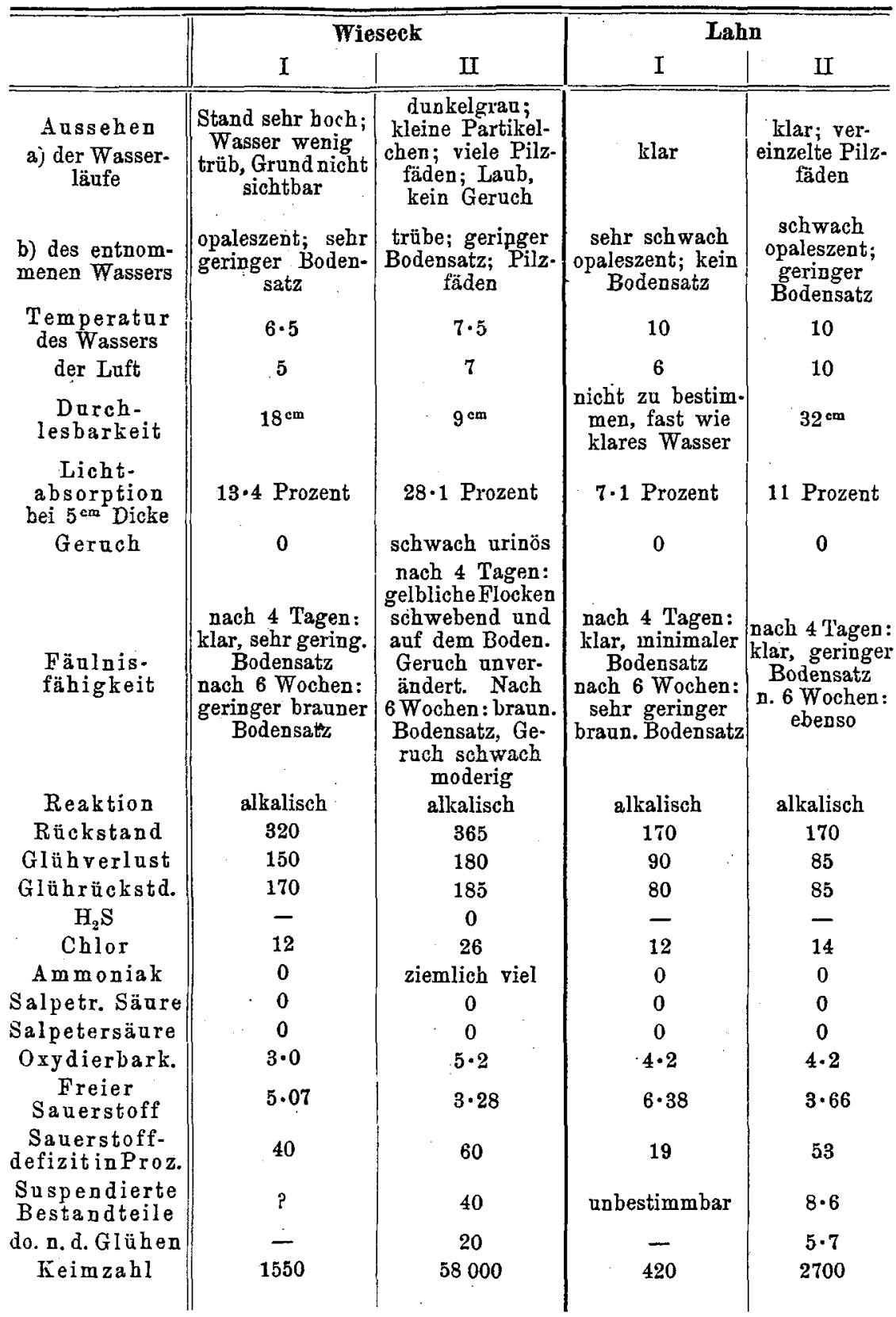


Tabelle VI.

Donnerstag, 17. November 1904.

Seit 4 Tagen schönes Wetter; vorher Regen. Barometer 758.5; - Lahnpegel 0.84 .

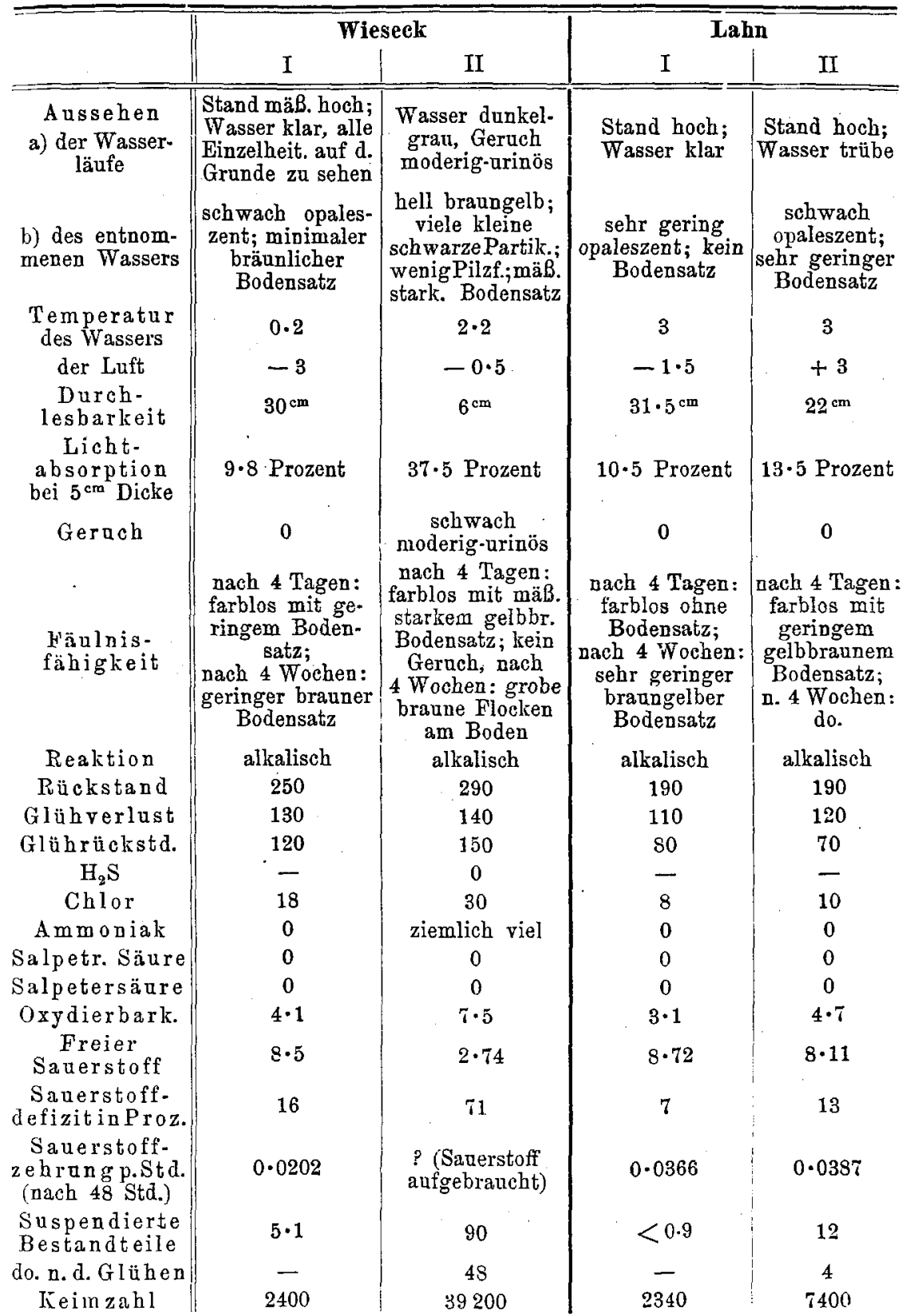


Tabelle VII.

Dienstag, 29. November 1904.

In der letzten Zeit abwechselnd Schnee und Regen. Der Schnee noch nicht weggeschmolzen. Barometer 745.3. Lahnpegel 0.59 .

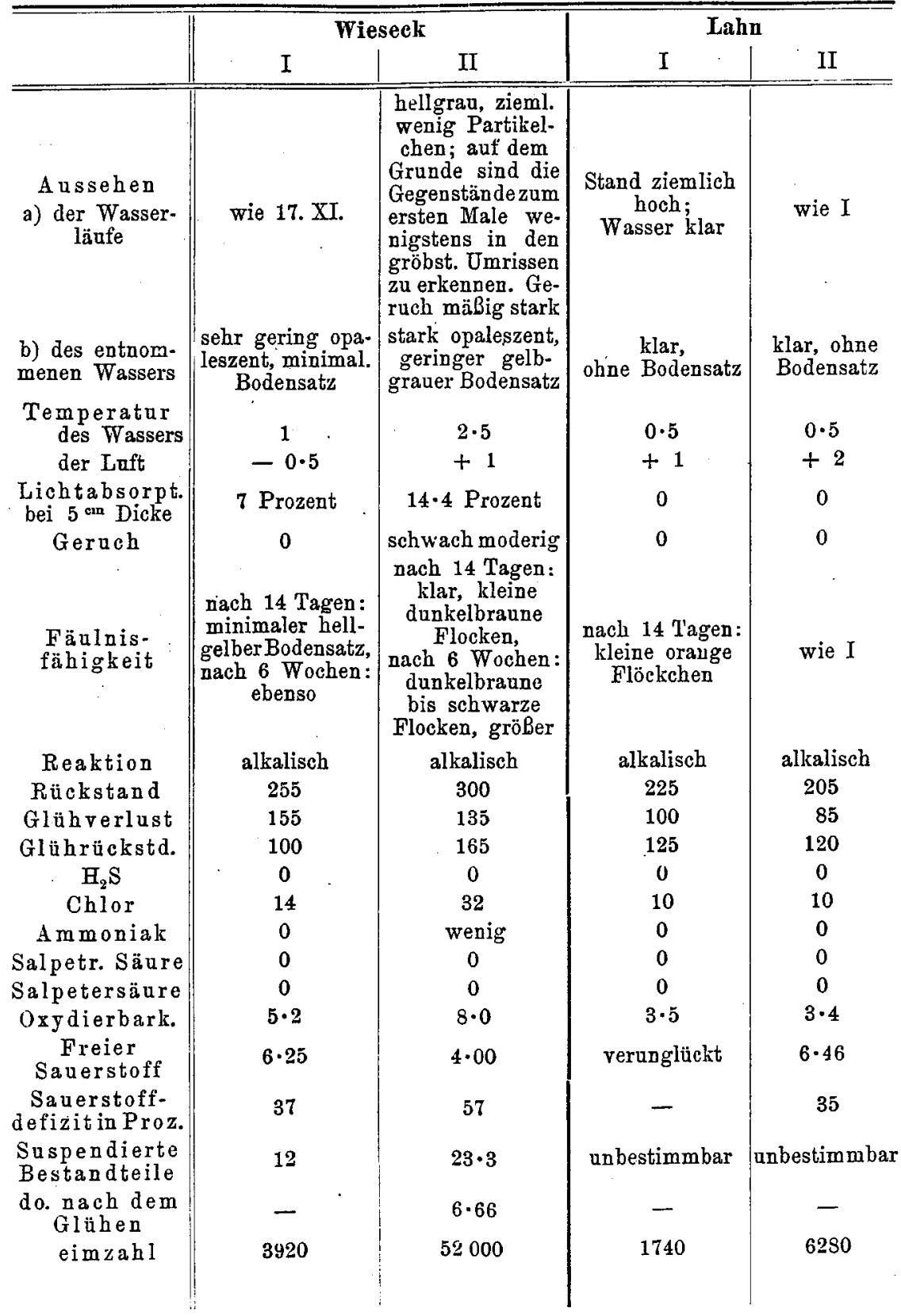


Tabelle VIII. Montag, 19. Dezember 1904.

Anfang Dezember Hochwasser infolge der Schneeschmelze. Dann fast täglich geringer Regen. - Bei dem Hochwasser hatte die Wieseck durch Anstauen seitens der Lahn ihr Bett stark überschritten. Bar. 760. Lahnpegel 1.02.

\begin{tabular}{|c|c|c|c|c|}
\hline & \multicolumn{2}{|c|}{ Wieseck } & \multicolumn{2}{|c|}{ Lahn } \\
\hline & I & II & $\mathrm{I}$ & II \\
\hline $\begin{array}{l}\text { Aussehen: } \\
\text { a) der Wasser- } \\
\text { läufe }\end{array}$ & $\begin{array}{l}\text { Stand hoch. } \\
\text { Wasser } \\
\text { schmutziggran; } \\
\text { Grund nicht } \\
\text { zu sehen }\end{array}$ & $\begin{array}{l}\text { Stand hoch. Am Ufer } \\
\text { Spurend.abgelaufenen } \\
\text { Hochwassers. Farbe } \\
\text { gelbgrau, viele Par- } \\
\text { tikelchen u. Pilzfäden. } \\
\text { Geruch urinös-moderig }\end{array}$ & $\begin{array}{l}\text { Stand hoch. } \\
\text { Wasser in } \\
\text { größerer Tiefe } \\
\text { schmutzig-grau }\end{array}$ & $\begin{array}{l}\text { Wasser trübe; an } \\
\text { dem jetzt unter } \\
\text { Wasser befind- } \\
\text { lichen Schilf } \\
\text { wächst } \\
\text { Leptomitus }\end{array}$ \\
\hline $\begin{array}{l}\text { b) des entnom- } \\
\text { menen Wassers }\end{array}$ & $\begin{array}{l}\text { zieml. stark opa- } \\
\text { leszent mit grau- } \\
\text { gelbl. Bodensatz }\end{array}$ & $\begin{array}{c}\text { stark opaleszent mit } \\
\text { starken graugelben } \\
\text { Bodensatz }\end{array}$ & $\begin{array}{c}\text { schwach opalesz. } \\
\text { mit minimalem } \\
\text { Bodensatz }\end{array}$ & wie I \\
\hline $\begin{array}{l}\text { Temperatur } \\
\text { des Wassers }\end{array}$ & 5 & $5 \cdot 25$ & 4 & 4 \\
\hline der Laft & $+1 \cdot 5$ & +2 & $+2 \cdot 5$ & +4 \\
\hline $\begin{array}{l}\text { Liehtabsorpt. } \\
\text { bei } 5 \mathrm{~cm} \text { Dicke }\end{array}$ & $25 \cdot 2$ Prozent & 58.1 Prozent & 10.5 Prozent & 12.9 Prozent \\
\hline Geruch & 0 & schwach urinös & 0 & 0 \\
\hline $\begin{array}{l}\text { Fäulnis - } \\
\text { fähigkeit }\end{array}$ & $\begin{array}{l}\text { nach } 48 \text { Stunden: } \\
\text { kleine hell- } \\
\text { braune Flocken } \\
\text { schwebend; } \\
\text { nach 4 Wochen: } \\
\text { gelbbrauner } \\
\text { Bodensatz }\end{array}$ & $\begin{array}{l}\text { nach } 48 \text { Std.: starker } \\
\text { hellbrauner Bodensatz; } \\
\text { gröBere hellbraune } \\
\text { Flocken schwimmend; } \\
\text { kein Geruch; } \\
\text { nach } 4 \text { Wochen: } \\
\text { gelbbrauner Bodensatz }\end{array}$ & $\left\{\begin{array}{c}\text { nach } 48 \text { Stunden: } \\
\text { keine } \\
\text { Veränderung; } \\
\text { nach } 4 \text { Wochen: } \\
\text { sehr geringer } \\
\text { gelbbrauner } \\
\text { Bodensatz }\end{array}\right.$ & $\begin{array}{l}\text { nach } 48 \text { Stunden: } \\
\text { geringer gelb- } \\
\text { brauner } \\
\text { Bodensatz; } \\
\text { nach } 4 \text { Wochen: } \\
\text { ebenso }\end{array}$ \\
\hline Reaktion & alkalisch & alkalisch & alkalisch & alkalisch \\
\hline Rückstand & 225 & 255 & $16 \check{\jmath}$ & 180 \\
\hline Glühverlust & 110 & 125 & 70 & 80 \\
\hline Glührückstd. & 115 & 130 & $9 \overline{5}$ & 100 \\
\hline $\mathrm{H}_{2} \mathrm{~S}$ & 0 & 0 & 0 & 0 \\
\hline Chlor & 14 & 28 & 10 & 10 \\
\hline Ammoniak & minimale Spur & ziemlich viel & Spur & $\begin{array}{l}\text { Spur etwas } \\
\text { stärker als I }\end{array}$ \\
\hline Salpetr. Säure & 0 & 0 & 0 & 0 \\
\hline Salpetersäure & 0 & 0 & 0 & 0 \\
\hline Oxydierbark. & $5 \cdot 9$ & $10 \cdot 0$ & $4 \cdot 3$ & $6 \cdot 2$ \\
\hline $\begin{array}{c}\text { Freier } \\
\text { Sauerstoff }\end{array}$ & $8 \cdot 073$ & $6 \cdot 240$ & $8 \cdot 282$ & $8 \cdot 738$ \\
\hline $\begin{array}{c}\text { Sauerstoff- } \\
\text { defizit in Proz. }\end{array}$ & 9 & 30 & 9 & 4 \\
\hline $\begin{array}{c}\text { Sauerstoff- } \\
\text { zehrung } \\
\text { Stunde ( } 24 \text { Sto St.) }\end{array}$ & 0.017 & $0 \cdot 239$ & 0.0429 & 0.0488 \\
\hline $\begin{array}{l}\text { Suspendierte } \\
\text { Bestandteile }\end{array}$ & $66 \cdot 8$ & 103 & unbestimmbar & unbestimmbar \\
\hline $\begin{array}{c}\text { do. nach dem } \\
\text { Glüben }\end{array}$ & $60 \cdot 8$ & $85 \cdot 8$ & - & - \\
\hline Keimzahl & 2060 & 28600 & 780 & 2160 \\
\hline Kolititer & 0.001 & $0 \cdot 0001$ & $0 \cdot 1$ & $0 \cdot 001$ \\
\hline Grad desselben & III & IV & I & III \\
\hline
\end{tabular}


Tabelle IX.

Freitag, 30. Dezember 1904.

Seit den letzten Untersuchungen meist trübes Wetter ohne Regen. Am Tage der Untersuchung anfangs geringer, zwischen der 3. und 4. Entnahme starker Regen. Barometer 743; Lahnpegel 0.62.

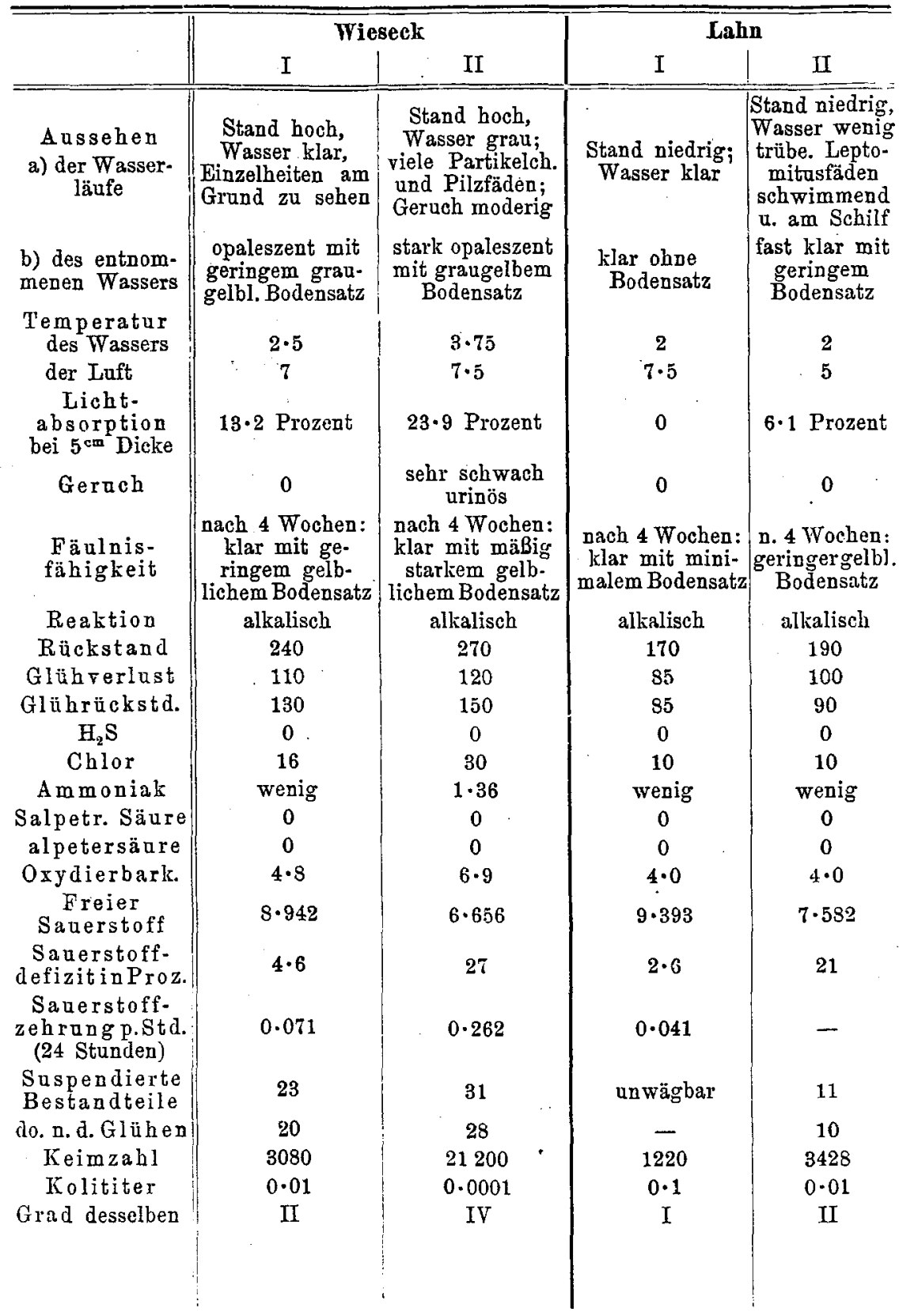


Tabelle X.

Donnerstag, 12. Januar 1905.

Seit der letzten Untersuchung Schnee, geringer Frost; einige Tage vorher

Hochwasser, das noch nicht ganz zurückgegangen ist.

Barometer 749.5; Lahnpegel 1.75.

\begin{tabular}{|c|c|c|c|c|}
\hline & \multicolumn{2}{|c|}{ Wieseck } & \multicolumn{2}{|c|}{ Lahn } \\
\hline & I & II & I & II \\
\hline $\begin{array}{l}\text { Aussehen } \\
\text { a) der Wasser- } \\
\text { läufe }\end{array}$ & $\begin{array}{c}\text { Stand hoch; } \\
\text { Wasser ziemlich } \\
\text { klar; Grund an } \\
\text { manchen Stellen } \\
\text { zu seben }\end{array}$ & $\begin{array}{c}\text { Stand hoch; } \\
\text { Wasser grad, } \\
\text { wenigPartikelch. } \\
\text { Geruch urinös }\end{array}$ & $\begin{array}{c}\text { Wasser ziemlich } \\
\text { klar }\end{array}$ & wie I \\
\hline $\begin{array}{l}\text { b) des entnom. } \\
\text { menen Wassers }\end{array}$ & $\begin{array}{c}\text { opaleszent mit } \\
\text { geringem braun- } \\
\text { gelbem Boden- } \\
\text { satz }\end{array}$ & $\begin{array}{c}\text { etwas stärker } \\
\text { opaleszent mit } \\
\text { stärkerem brau- } \\
\text { nem Bodensatz }\end{array}$ & $\begin{array}{c}\text { schwach opales- } \\
\text { zent m. geringem } \\
\text { brannem Boden- } \\
\text { satz }\end{array}$ & $\begin{array}{l}\text { etwas stärker } \\
\text { opaleszent mit } \\
\text { sehr geringem } \\
\text { Bodensatz }\end{array}$ \\
\hline Temperatur & & & & \\
\hline des Wassers & 0.2 & $1 \cdot 0$ & 0.8 & 0.8 \\
\hline der Luft & $2 \cdot 2$ & - & - & $4 \cdot 0$ \\
\hline $\begin{array}{c}\text { Licht: } \\
\text { absorption } \\
\text { bei } 5^{\mathrm{cm}} \text { Dicke }\end{array}$ & 10.4 Prozent & $\begin{array}{c}30 \cdot 1 \text { Prozent } \\
\text { (Filtrat 9.9 Proz.) }\end{array}$ & $7 \cdot 6$ & $6 \cdot 4$ \\
\hline Gerueh & 0 & schwach moderig & 0 & 0 \\
\hline $\begin{array}{l}\text { Fäulnis- } \\
\text { fähigkeit }\end{array}$ & $\begin{array}{c}\text { nach } 4 \text { Wochen: } \\
\text { klar, sonst un- } \\
\text { verändert }\end{array}$ & $\begin{array}{c}\text { nach } 4 \text { Wochen: } \\
\text { klar, geringe Zu- } \\
\text { nahme des } \\
\text { Bodensatzes }\end{array}$ & $\begin{array}{c}\text { nach } 4 \text { Wochen: } \\
\text { unverändert }\end{array}$ & $\begin{array}{l}\text { n. } 4 \text { Wochen: } \\
\text { geringer gelb. } \\
\text { Bodensatz }\end{array}$ \\
\hline Reaktion & alkalisch & alkalisch & alkalisch & alkalisch \\
\hline Rü ckstand & 210 & 235 & 140 & 140 \\
\hline Glühverlust & 80 & 100 & 70 & 70 \\
\hline Glührü ckstd. & 130 & 135 & 70 & 70 \\
\hline $\mathrm{H}_{2} \mathrm{~S}$ & 0 & 0 & 0 & 0 \\
\hline Chlor & 18 & 23 & 8 & 8 \\
\hline Ammoniak & wenig & 0.68 & wenig & wenig \\
\hline $\begin{array}{l}\text { Salpetrige } \\
\text { Säure }\end{array}$ & J. 0; E schwach & J. $0 ;$ E schwach & $\begin{array}{l}\text { J. 0; E sehr } \\
\text { schwach }\end{array}$ & $\begin{array}{l}\text { J. } 0 ; \text { E sehr } \\
\text { schwach }\end{array}$ \\
\hline Salpetersäure & 0 & 0 & 0 & 0 \\
\hline $\begin{array}{c}\text { Oxydierbark. } \\
\text { Freier }\end{array}$ & $6 \cdot 0$ & $7 \cdot 1$ & $5 \cdot 3$ & $5 \cdot 0$ \\
\hline Sauerstoff & $7 \cdot 676$ & $5 \cdot 013$ & $8 \cdot 969$ & $7 \cdot 104$ \\
\hline $\begin{array}{c}\text { Sauerstoff- } \\
\text { defizitinProz. } \\
\text { Sauerstoff- }\end{array}$ & 34 & 49 & 10 & 28 \\
\hline $\begin{array}{l}\text { zehrung p.Std. } \\
\text { (24 Stunden) }\end{array}$ & 0.0035 & $0 \cdot 1064$ & 0.0518 & - \\
\hline $\begin{array}{l}\text { Saspendierte } \\
\text { Bestandteile }\end{array}$ & 10 & 46.5 & 4 & $4 \cdot 5$ \\
\hline do.n. d. Glühen & $8 \cdot 75$ & 30 & 3 & $4 \cdot 5$ \\
\hline $\begin{array}{c}\text { Keimzahl } \\
\text { do. mit Jod. }\end{array}$ & 3920 & 29920 & 3668 & 5280 \\
\hline $\begin{array}{c}\text { kalium-Kar- } \\
\text { toffelgelatine }\end{array}$ & 180 & 6320 & 201 & 280 \\
\hline Kolititer & $0 \cdot 1$ & $0 \cdot 001$ & $0 \cdot 1$ & 0.01 \\
\hline $\begin{array}{l}\text { Grad desselben } \\
\text { Zeitschr. f. Hygie }\end{array}$ & ne. LIII. I & III & I & II \\
\hline
\end{tabular}


Tabelle XI.

Montag, 6. Februar 1905.

Seit 8 Tagen zuerst Tauwetter, dann Regen. Hochwasser.

Barometer 760.0; Lahnpegel 2.37.

\begin{tabular}{|c|c|c|c|c|}
\hline & \multicolumn{2}{|c|}{ Wieseck } & \multicolumn{2}{|c|}{ Lahn } \\
\hline & I & II & $I$ & II \\
\hline $\begin{array}{c}\text { Aussehen } \\
\text { a) der Wasser- } \\
\text { läufe }\end{array}$ & $\begin{array}{l}\text { Stand sehr hoch. } \\
\text { Strömung } \\
\text { schnell. Wasser } \\
\text { schmutziggelb- } \\
\text { grau }\end{array}$ & $\begin{array}{l}\text { Stand sehr hoch. } \\
\text { Wasser schmutz.- } \\
\text { gelbgrau, auf der } \\
\text { Oberfläche nur } \\
\text { wenige feine } \\
\text { Partikelchen, } \\
\text { kein Geruch }\end{array}$ & Wasser gelbgran & wie I \\
\hline $\begin{array}{l}\text { b) des entnom- } \\
\text { menen Wassers }\end{array}$ & $\begin{array}{c}\text { schwach opales- } \\
\text { zent mit gelb- } \\
\text { granem Boden- } \\
\text { satz }\end{array}$ & $\begin{array}{l}\text { schwach opales- } \\
\text { zent mit etwas } \\
\text { dunklerem } \\
\text { Bodensatz als I }\end{array}$ & $\begin{array}{l}\text { schwach opales- } \\
\text { zent m. braunem } \\
\text { Bodensatz }\end{array}$ & wie I \\
\hline $\begin{array}{l}\text { Temperatur } \\
\text { des Wassers }\end{array}$ & $3 \cdot 25$ & $3 \cdot 5$ & $3 \cdot 5$ & $3 \cdot 5$ \\
\hline der Loft & $4 \cdot 5$ & $5 \cdot 5$ & $5 \cdot 0$ & $6 \cdot 0$ \\
\hline $\begin{array}{l}\text { Lichtabsorpt. } \\
\text { bei } 5 \mathrm{~cm} \text { Dicke }\end{array}$ & 16.7 Prozent & 22.3 Prozent & 19.1 Prozent & 22.3 Prozent \\
\hline Gerach & 0 & 0 & 0 & 0 \\
\hline $\begin{array}{l}\text { Färlnis- } \\
\text { fähigkeit }\end{array}$ & $\begin{array}{l}\text { nach } 14 \text { Tagen: } \\
\text { Wasser klar mit } \\
\text { geringem gelb- } \\
\text { braun. Bodensatz }\end{array}$ & $\begin{array}{l}\text { nach 1 Tag: } \\
\text { kein Geruch; } \\
\text { nach 14 Tagen: } \\
\text { wie I, Bodensatz } \\
\text { etwas dunkler }\end{array}$ & $\begin{array}{l}\text { nach } 14 \text { Tagen: } \\
\text { Wasser klar mit } \\
\text { geringem gelb- } \\
\text { braun. Bodensatz }\end{array}$ & $\begin{array}{l}\text { nach } 14 \text { Tag.: } \\
\text { wie I, Boden- } \\
\text { satz etwas } \\
\text { dunkler }\end{array}$ \\
\hline Reaktion & alkalisch & alkalisch & alkalisch & alkalisch \\
\hline Rückstand & 190 & 200 & 135 & 140 \\
\hline Glühverlust & 70 & 80 & 60 & 60 \\
\hline Glührückstd. & 120 & 120 & 75 & 80 \\
\hline $\mathrm{H}_{2} \mathrm{~S}$ & 0 & 0 & 0 & 0 \\
\hline Chlor & 18 & 20 & 10 & 10 \\
\hline Ammoniak & sehr wenig & 0.45 & Spur & Spur \\
\hline Salpetr. Säure & J. 0; E. schwach & J. $0 ;$ E. + & J. $0 ;$ E. schwach & J. 0; E. Sprr \\
\hline Salpetersäure & 0 & 0 & 0 & 0 \\
\hline Oxydierbark. & $4 \cdot 8$ & $6 \cdot 2$ & $6 \cdot 0$ & $4 \cdot 5$ \\
\hline $\begin{array}{c}\text { Freier } \\
\text { Sauerstoff }\end{array}$ & $7 \cdot 5348$ & $6 \cdot 344$ & $9 \cdot 0294$ & $8 \cdot 0993$ \\
\hline $\begin{array}{c}\text { Sauerstoff- } \\
\text { defizitin Proz. }\end{array}$ & 20 & 30 & 1 & 11 \\
\hline $\begin{array}{l}\text { Suspendierte } \\
\text { Bestandteile }\end{array}$ & $18 \cdot 88$ & $18 \cdot 88$ & $24 \cdot 44$ & $17 \cdot 77$ \\
\hline do.n.d. Glühen & $15 \cdot 55$ & $17 \cdot 77$ & $21 \cdot 11$ & $13 \cdot 33$ \\
\hline Keimzahl & 5340 & 11900 & 5380 & 4080 \\
\hline $\begin{array}{c}\text { do. mit Jodkal.- } \\
\text { Kartoffel- } \\
\text { gelatine }\end{array}$ & 150 & 410 & 74 & 102 \\
\hline Kolititer & $0 \cdot 1$ & 0.01 & $0 \cdot 1$ & 0.01 \\
\hline Grad desselben & 1 & II & $\mathbf{I}$ & II \\
\hline
\end{tabular}


Tabelle XII.

Donnerstag, 9. März 1905.

Seit längerer Zeit täglich Regen. Barometer 741.5; Lahnpegel 1.84.

\begin{tabular}{|c|c|c|c|c|}
\hline & Wie: & seck & Lahr & \\
\hline & I & II & $\mathrm{I}$ & II \\
\hline $\begin{array}{c}\text { Ausseben } \\
\text { a) der Wasser- } \\
\text { läufe }\end{array}$ & $\begin{array}{l}\text { Stand sehr hoch. } \\
\text { Wasser ziemlich } \\
\text { klar, etwas gelb- } \\
\text { graa }\end{array}$ & $\begin{array}{c}\text { Stand hoch. } \\
\text { Wasser gelbgrau, } \\
\text { nicht sehr stark } \\
\text { getriibt }\end{array}$ & $\begin{array}{c}\text { Wasser graa, } \\
\text { am Ufer ziemlich } \\
\text { klar }\end{array}$ & wie I \\
\hline $\begin{array}{l}\text { b) des entnom- } \\
\text { menen Wassers }\end{array}$ & $\begin{array}{l}\text { fast klar; mini- } \\
\text { maler Bodensatz }\end{array}$ & $\begin{array}{l}\text { wenig opales- } \\
\text { zent; geringer } \\
\text { Bodensatz }\end{array}$ & $\begin{array}{l}\text { sehr wenig } \\
\text { opaleszent; mini- } \\
\text { maler Bodensatz }\end{array}$ & wie I \\
\hline $\begin{array}{c}\text { Te mperatur } \\
\text { des Wassers }\end{array}$ & $2 \cdot 5$ & $3 \cdot 5$ & 4 & 4 \\
\hline der Laft & $3 \cdot 5$ & 5 & 5 & 7 \\
\hline $\begin{array}{c}\text { Licht- } \\
\text { absorption } \\
\text { bei } 5 \text { cm Dicke }\end{array}$ & 9 Prozent & 31-1 Prozent & 17.2 Prozent & 23 Prozent \\
\hline Geruch & 0 & 0 & 0 & $\mathbf{0}$ \\
\hline $\begin{array}{l}\text { Fäulnis- } \\
\text { fähigkeit }\end{array}$ & $\begin{array}{l}\text { nach } 4 \text { Wochen: } \\
\text { klar, geringer } \\
\text { gelber Bodensatz }\end{array}$ & $\begin{array}{c}\text { nach } 4 \text { Wochen: } \\
\text { wie I }\end{array}$ & $\begin{array}{l}\text { nach } 4 \text { Wochen; } \\
\text { klar, sehr } \\
\text { geringer gelber } \\
\text { Bodensatz }\end{array}$ & $\begin{array}{l}\text { nach } \\
4 \text { Wochen: } \\
\text { wie I }\end{array}$ \\
\hline Reaktion & alkaliseh & alkalisch & alkalisch & alkalisch \\
\hline Rückstand & 155 & 125 & 135 & 125 \\
\hline Glühverlust & 55 & 50 & 65 & 75 \\
\hline GIührückstd. & 100 & 75 & 70 & 50 \\
\hline $\mathrm{H}_{2} \mathrm{~S}$ & 一 & 0 & - & - \\
\hline Chlor & 16 & 20 & 8 & 10 \\
\hline Ammoniak & Spur & 0.7 & 0 & 0 \\
\hline Salpetr. Säure & E. 0 & E. Spur & E. 0 & E. 0 \\
\hline Salpetersäure & 0 & 0 & 0 & 0 \\
\hline Oxy dierbark. & $5 \cdot 3$ & $7 \cdot 0$ & $4 \cdot 7$ & $4 \cdot 7$ \\
\hline $\begin{array}{c}\text { Freier } \\
\text { Sauerstoff }\end{array}$ & $8 \cdot 3214$ & $5 \cdot 8656$ & $8 \cdot 1810$ & $8 \cdot 8157$ \\
\hline $\begin{array}{c}\text { Sauerstoff- } \\
\text { defizitin Proz. } \\
\text { Sauerstoff- }\end{array}$ & 11 & 36 & 10 & $3 \cdot 6$ \\
\hline $\begin{array}{c}\text { zehrung pro } \\
\text { Stunde(n.48 Std.) }\end{array}$ & 一 & 0.0849 & 0.00465 & 0.01462 \\
\hline $\begin{array}{l}\text { Suspendierte } \\
\text { Bestandteile }\end{array}$ & $11 \cdot 1$ & $28 \cdot 8$ & 10 & 10 \\
\hline do.n. d. Glühen & 10 & 20 & $4 \cdot 4$ & $3 \cdot 3$ \\
\hline Keimzahl & 835 & 8250 & 1210 & 1285 \\
\hline $\begin{array}{c}\text { do. mit Jodkal. } \\
\text { Kartoffel- } \\
\text { gelatine }\end{array}$ & 94 & 346 & 30 & 68 \\
\hline Kolititer & 0.01 & 0.001 & 0.01 & $0 \cdot 01$ \\
\hline Grad desselben & II & III & II & II \\
\hline
\end{tabular}


Tabelle XIII.

Donnerstag, 13. April 1905.

Seit längerer Zeit tâglich geringer Regen; gestern und heute Sonne. Am Oberlauf der Lahn Regen. Barometer 748; Lahnpegel 2.33.

\begin{tabular}{|c|c|c|c|c|}
\hline & \multicolumn{2}{|c|}{ Wieseck } & \multicolumn{2}{|c|}{ Lahn } \\
\hline & I & II & I & II \\
\hline $\begin{array}{c}\text { Aussehen } \\
\text { a) der Wasser- } \\
\text { läufe }\end{array}$ & $\begin{array}{l}\text { Stand niedrig; } \\
\text { Wasser ziemlich } \\
\text { klar, Grund } \\
\text { aberall zu sehen } \\
\text { schwach opales- } \\
\text { zent mit gering. } \\
\text { graubraunem } \\
\text { Bodensatz }\end{array}$ & $\begin{array}{l}\text { Stand hoch } \\
\text { (durch die Lahn } \\
\text { angestant) Lauf } \\
\text { langsam, kein } \\
\text { Geruch } \\
\text { etwas stärker } \\
\text { opaleszent mit } \\
\text { geringem grau- } \\
\text { braunem } \\
\text { Bodensatz }\end{array}$ & $\begin{array}{l}\text { Stand sehr hoch } \\
\text { Wasser gelb }\end{array}$ & $\begin{array}{l}\text { Stand sehr } \\
\text { hoch; } \\
\text { Wasser gelb }\end{array}$ \\
\hline $\begin{array}{l}\text { Temperatur } \\
\text { des Wassers }\end{array}$ & $10 \cdot 5$ & 11 & 9 & 9 \\
\hline der Iuft & 9 & 12 & 9 & 15 \\
\hline $\begin{array}{l}\text { Licht: } \\
\text { absorption } \\
\text { bei } 5^{\mathrm{cm}} \text { Dicke }\end{array}$ & 15.9 Prozent & 19.8 Prozent & 21.7 Prozent & $20 \cdot 3$ Prozent \\
\hline Gerach & $\begin{array}{c}0 \\
\operatorname{nach} 4 \text { Wochen: }\end{array}$ & $\begin{array}{c}0 \\
\text { nach } 2 \text { Tagen. }\end{array}$ & & 0 \\
\hline $\begin{array}{l}\text { Fäulnis: } \\
\text { fähigleit }\end{array}$ & $\begin{array}{c}\text { nach } 4 \text { Wochen: } \\
\text { starker brauner } \\
\text { Bodensatz; } \\
\text { Wasser klar }\end{array}$ & $\begin{array}{c}\text { nach } 2 \text { Tagen: } \\
\text { kein Geruch } \\
\text { nach } 4 \text { Wochen: } \\
\text { wie I }\end{array}$ & $\begin{array}{c}\text { nach } 4 \text { Wochen: } \\
\text { wie Wieseck I }\end{array}$ & $\begin{array}{l}\text { n. } 4 \text { Wochen : } \\
\text { wie Wieseck I }\end{array}$ \\
\hline Reaktion & alkalisch & alkalisch & alkalisch & alkalisch \\
\hline Rüekstand & 193 & 209 & 127 & 140 \\
\hline Glüh verlust & 94 & 115 & 70 & 70 \\
\hline Glührückstd. & 99 & 94 & 57 & 70 \\
\hline $\mathrm{H}_{2} \mathrm{~S}$ & - & 0 & 0 & 0 \\
\hline $\mathrm{Chlor}$ & 20 & 24 & 10 & 10 \\
\hline Ammoniak & Spur & $1 \cdot 13$ & 0 & 0 \\
\hline $\begin{array}{l}\text { Salpetr. Säure } \\
\text { Salpetersäure }\end{array}$ & $\begin{array}{c}\text { J. } 0 ; \text { E. }+ \\
0\end{array}$ & $\begin{array}{c}\text { J. 0; E. + } \\
\text { Spur }\end{array}$ & $\begin{array}{c}\text { J. } 0 \text {; E. } 0 \\
0\end{array}$ & J.0; E. Spar \\
\hline Oxydierbark. & $4 \cdot 9$ & $6 \cdot 9$ & $4 \cdot 3$ & $4 \cdot 3$ \\
\hline $\begin{array}{c}\text { Freier } \\
\text { Sauerstoff }\end{array}$ & $5 \cdot 53$ & $5 \cdot 32$ & $5 \cdot 9994$ & $7 \cdot 6217$ \\
\hline $\begin{array}{c}\text { Sauerstoff- } \\
\text { defizit in Proz. }\end{array}$ & 28 & 31 & 26 & 5 \\
\hline $\begin{array}{c}\text { Sanerstoff- } \\
\text { zehrang p. Std. } \\
\text { (48 Stunden) }\end{array}$ & 0.0227 & $0 \cdot 0874$ & 0.0277 & 0.0339 \\
\hline $\begin{array}{c}\text { Suspendierte } \\
\text { Bestandteile }\end{array}$ & $21 \cdot 3$ & 17.2 & 12 & $8 \cdot 4$ \\
\hline Keimzahl & 2620 & 5910 & 4925 & 3820 \\
\hline $\begin{array}{l}\text { kaliam-Kar- } \\
\text { toffelgelatine }\end{array}$ & 177 & 1096 & 210 & 277 \\
\hline Kolititer & 0.001 & $0 \cdot 001$ & 0.01 & $0 \cdot 1$ \\
\hline Grad desselben & III & III & II & I \\
\hline
\end{tabular}


Tabelle XIV.

Donnerstag, 18. Mai 1905.

In letzter Zeit warmes Wetter, selten geringer Regen. Gestern und heute Sonne. - In der Stadt wird an den Rändern der Wieseck gegraben und dadurch Schmutz hineingebracht. - Barometer 748.5; Lahnpegel 0.45 .

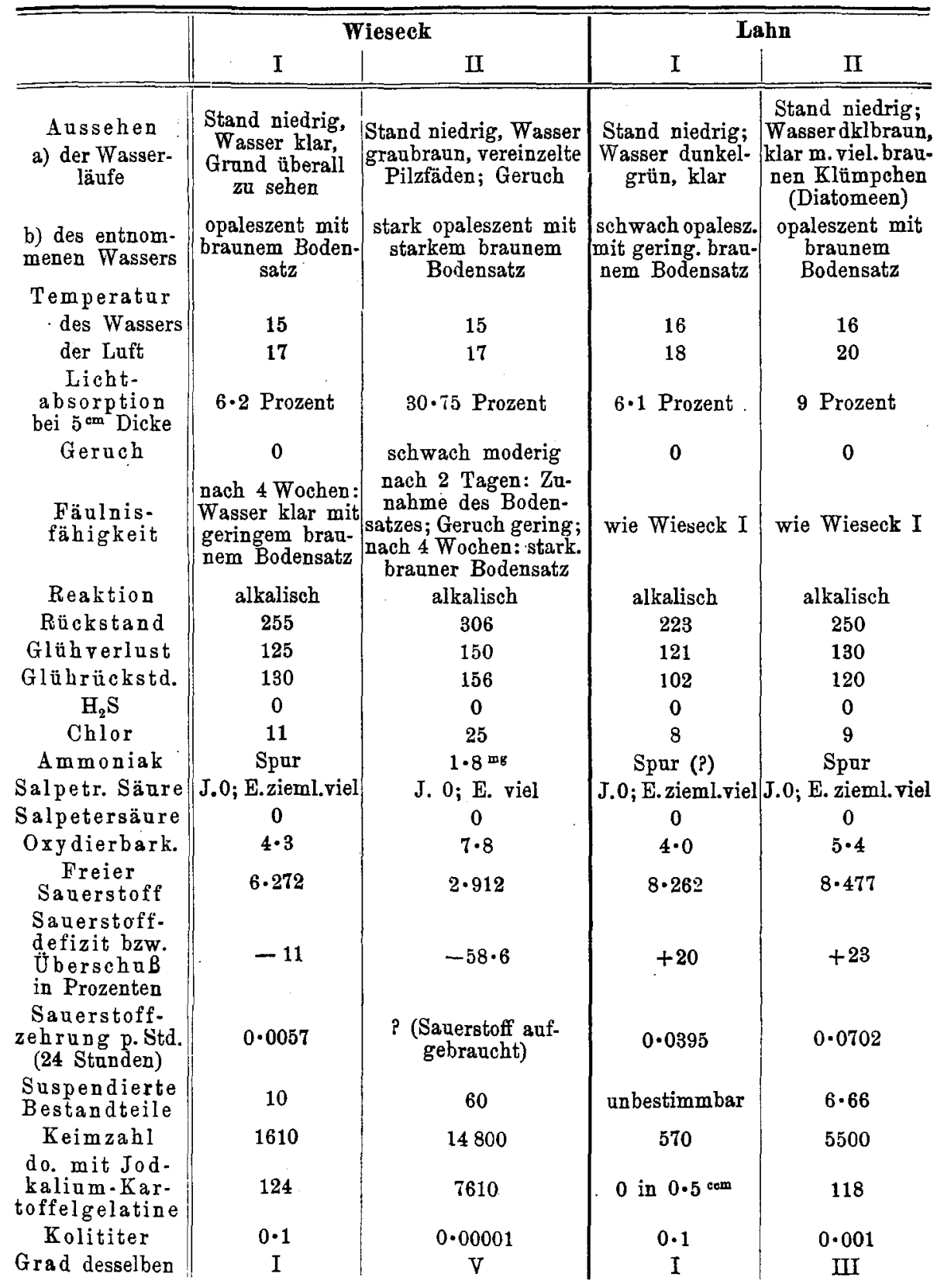




\section{Tabelle XV.}

Mittwoch, 31. Mai 1905, nachm. 3 Uhr.

Einige heiBe Tage vorangegangen; Wieseck stinkt besonders nachts in der Nähe des Ausgerinnes.

\begin{tabular}{|c|c|c|}
\hline & $\begin{array}{l}\text { Wieseck direkt oberhalb } \\
\text { des Aasgerinnes: schmutzig, } \\
\text { braungrau, einzelne } \\
\text { Schlammbrocken. } \\
\text { Gernch gering. }\end{array}$ & $\begin{array}{l}\text { Wieseck unterhalb des } \\
\text { Ausgerinnes (= Entnahme- } \\
\text { stelle II): Schmutz vermehrt, } \\
\text { Geruch stark }\end{array}$ \\
\hline & $1 \cdot 0$ & $4 \cdot 65$ \\
\hline $\begin{array}{l}\text { ierte } \\
\text { teile } . . .\end{array}$ & & $16 \cdot 8$ \\
\hline nach dem Glühen & & $7 \cdot 5$ \\
\hline
\end{tabular}

Dienstag, 6. Juni 1905, nachm. 2 Uhr

Am Tage vorher und am Vormittag starke Gewitterregen;

Wieseck sehr schmutzig.

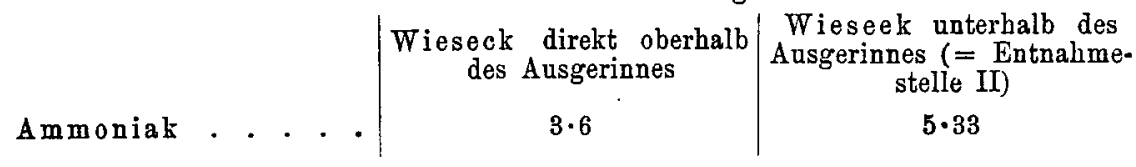

Tabelle XVI.

Mittwoch, 21. Juni 1905.

Seit 2 Tagen warmes Wetter; vorher vielfach Gewitter. - Somne.

Barometer 753.2; Lahnpegel 0.41.

\begin{tabular}{|c|c|c|c|c|}
\hline & Wie & eck & Lahn & \\
\hline & $I$ & II & I & II \\
\hline $\begin{array}{l}\text { Aussehen } \\
\text { a) der Wasser- } \\
\text { läufe }\end{array}$ & $\begin{array}{c}\text { Stand ziemlich } \\
\text { hoch; braun, } \\
\text { trüb }\end{array}$ & $\begin{array}{c}\text { Stand ziemlich } \\
\text { hoch; schwarz- } \\
\text { braun mit vielen } \\
\text { Pilzfäden, Kon- } \\
\text { glomerate bis } \\
\text { faustgroB. } \\
\text { Geruch kanm } \\
\text { wahrnehmbar }\end{array}$ & $\begin{array}{c}\text { braungrün, } \\
\text { stellenweise mit } \\
\text { feinem, fettigen } \\
\text { Überzug mit } \\
\text { Gasbläschen }\end{array}$ & $\begin{array}{l}\text { braun; viele } \\
\text { sehr kleine } \\
\text { Partikelchen. } \\
\text { Boden brann }\end{array}$ \\
\hline $\begin{array}{l}\text { b) des entnom- } \\
\text { menen Wassers }\end{array}$ & $\begin{array}{l}\text { opaleszent } \\
\text { mit braunem } \\
\text { Bodensatz }\end{array}$ & $\begin{array}{l}\text { etwas schwächer } \\
\text { opaleszent mit } \\
\text { etwas stärkerem, } \\
\text { braunem Boden- } \\
\text { satz; mikrosk.: } \\
\text { Sphaerotilus }\end{array}$ & $\begin{array}{l}\text { grün darch } \\
\text { Algen, die sich } \\
\text { beim Stehen za } \\
\text { Boden senken; } \\
\text { dann klar. AuBer- } \\
\text { dem geringer } \\
\text { brauner Bodens. }\end{array}$ & $\begin{array}{l}\text { wie I mit } \\
\text { starkem, } \\
\text { braunem } \\
\text { Bodensatz }\end{array}$ \\
\hline $\begin{array}{l}\text { Temperatur } \\
\text { des Wassers } \\
\text { der Luft. }\end{array}$ & $\begin{array}{c}18 \cdot 5 \\
21\end{array}$ & $\begin{array}{c}18 \cdot 5 \\
22\end{array}$ & $\begin{array}{l}22 \\
22\end{array}$ & $\begin{array}{l}22 \\
24\end{array}$ \\
\hline $\begin{array}{c}\text { Lichtabsorpt. } \\
\text { bei } 5 \text { om Dicke }\end{array}$ & $25 \cdot 7$ & $25 \cdot 3$ & $10 \cdot 5$ & $21 \cdot 3$ \\
\hline
\end{tabular}


Verdnkmintaung der LaHN UNd der Wieseck.

Tabelle XVI. (Fortsetzung.)

\begin{tabular}{|c|c|c|c|c|}
\hline & \multicolumn{2}{|c|}{ Wieseck } & \multicolumn{2}{|c|}{ Lahn } \\
\hline & $\mathrm{I}$ & II & $\mathrm{I}$ & $\mathrm{II}$ \\
\hline Gerach & 0 & schwach moderig & 0 & 0 \\
\hline $\begin{array}{l}\text { Fäulnis- } \\
\text { fähigkeit }\end{array}$ & $\begin{array}{l}\text { nach } 2 \text { Tagen: } \\
\text { klar mit grau- } \\
\text { braun. Bodensatz } \\
\text { nach } 4 \text { Wochen: } \\
\text { brauner Boden- } \\
\text { satz, an den } \\
\text { Wänden anch } \\
\text { Algen }\end{array}$ & $\begin{array}{c}\text { nach 24 Standen: } \\
\text { Geruch stärker; } \\
\text { nach } 2 \text { Tagen: } \\
\text { braune Flocken } \\
\text { anf dem Boden; } \\
\text { Geruch ebenso; } \\
\text { nach } 4 \text { Wochen: } \\
\text { starker brauner } \\
\text { Bodensatz }\end{array}$ & $\begin{array}{c}\text { nach } 2 \text { Tagen: } \\
\text { Flüssigkeit leicht } \\
\text { getrübt; braun- } \\
\text { grün. Bodensatz; } \\
\text { nach } 4 \text { Wochen: } \\
\text { brauner Boden- } \\
\text { satz, an den } \\
\text { Wänden anch } \\
\text { Algen }\end{array}$ & $\begin{array}{l}\text { nach } 2 \text { Tagen: } \\
\text { F'lüssigkeit } \\
\text { leicht getrïbt; } \\
\text { brauner } \\
\text { Bodensatz, an } \\
\text { den Wänden } \\
\text { auch Algen }\end{array}$ \\
\hline Reaktion & alkalisch & alkalisch & alkalisch & alkalisch \\
\hline Rückstand & 238 & 247 & 233 & 250 \\
\hline Glühverlust & 119 & 94 & 135 & 150 \\
\hline $\begin{array}{l}\text { Glüh. } \\
\text { rückstand }\end{array}$ & 119 & 153 & 98 & 100 \\
\hline $\mathrm{H}_{2} \mathrm{~S}$ & 0 & + & 0 & 0 \\
\hline Chlor & 12 & 27 & 12 & 13 \\
\hline Ammoniak & Spur & 0.9 & 0 & minimale Spur \\
\hline $\begin{array}{l}\text { Salpetrige } \\
\text { Säure }\end{array}$ & J. Spur; E. viel & $\begin{array}{c}\text { J. sehr deutlich; } \\
\text { E. viel }\end{array}$ & $\begin{array}{l}\text { J. sehr geringe } \\
\text { Spar; E. viel }\end{array}$ & J.Spur; E.viel \\
\hline Salpetersäure & 0 & 0 & 0 & 0 \\
\hline $\begin{array}{c}\text { Oxydierbar- } \\
\text { keit }\end{array}$ & $3 \cdot 9$ & $5 \cdot 9$ & $4 \cdot 5$ & $4 \cdot 5$ \\
\hline $\begin{array}{c}\text { Freier } \\
\text { Sauerstoff }\end{array}$ & $4 \cdot 554$ & $2 \cdot 2464$ & $8 \cdot 585$ & $7 \cdot 423$ \\
\hline $\begin{array}{c}\text { Sauerstoff- } \\
\text { defizit, bzw. } \\
\text { Überseha in } \\
\text { Prozenten }\end{array}$ & $-29 \cdot 25$ & $-65 \cdot 3$ & $+40 \cdot 41$ & $+21 \cdot 41$ \\
\hline $\begin{array}{c}\text { Sauerstoff* } \\
\text { zehrung pro } \\
\text { Stunde }(24 \text { Std. })\end{array}$ & 0.019 & $\begin{array}{c}\text { ? (Sauerstoff } \\
\text { aufgebraucht) }\end{array}$ & 0.0657 & 0.0523 \\
\hline $\begin{array}{l}\text { Suspendierte } \\
\text { Bestandteile }\end{array}$ & $38 \cdot 3$ & $38 \cdot 3$ & $36 \cdot 6$ & $48 \cdot 3$ \\
\hline Keimzahl & 3195 & 50180 & 686 & 10520 \\
\hline $\begin{array}{l}\text { do. mit Jod- } \\
\text { kalium- } \\
\text { Kartoffel- } \\
\text { gelatine }\end{array}$ & 0 in $0.5 \mathrm{cem}$ & 474 & 0 in $0.5 \mathrm{~cm}$ & 949 \\
\hline Kolititer & 0.1 & 0.0001 & $0 \cdot 1$ & $0 \cdot 00001$ \\
\hline Grad desselben & $I$ & IV & - $\mathbf{I}$ & $\mathrm{V}$ \\
\hline
\end{tabular}




\section{Tabelle XVII.}

Montag, 26. Juni 1905, nachm. 3 Uhr.

Seit einigen Tagen Regen; warme Witterung. Wasser dunkelgrau. Schwacher Geruch. Wieseck an der Entnahmestelle II: $1.82 \mathrm{mg}$ Ammoniak.

Donnerstag, 29. Juni 1905, nachm. $3 \mathrm{Uhr}$.

An den vorangegangenen Tagen täglich Gewitterregen.

Heute Sonne und sehr warm. Starker Geruch.

Wieseck an der Entnahmestelle II: $3 \cdot 25^{\mathrm{mg}}$ Ammoniak.

Montag, 3. Juli 1905, nachm. $3 \mathrm{Uhr}$.

Vorangegangene Tage heiß. Starker Geruch.

Wieseck an der Entnahmestelle II: $3.77 \mathrm{mg}$ Ammoniak.

Wie aus den Tabellen hervorgeht, wurde, abgesehen von den äuBersten Extremen, jede Art der Reinheit und der Verunreinigung untersucht, die ein FluB oder Bach ohne bedeutendere Zufuhr von Industrieabwässern erlangen kann. Zu Anfang, im Juli, herrschte seit längerer Zeit das heiße, trockene Wetter, das für den Sommer 1904 charakteristisch war. Andere Verhältnisse lagen im August vor; am Tage vor der in diesem Monat vorgenommenen Untersuchung war ein Witterungsumschlag eingetreten und die Temperatur gefallen, doch war ein Ansteigen des Lahnpegels nicht zu bemerken. Im Oktober sank die Temperatur allmählich, um schon im November und Dezember einen sehr niedrigen Stand zu erreichen; die Wassermenge schwankte unregelmäBig, ohne stark anzusteigen. Erst im Januar trat Hochwasser ein, das bis zum April fortdauerte; im Mai und Juni warde wieder ein niedriger Pegelstand notiert. Die Temperatur zeigte zu dieser Zeit andere Schwankungen: sie stieg rom Januar an langsam, vom April an schnell, um im Juni, wenigstens in der Lahn, fast dieselbe Höhe zu erreichen, die sie im Juli 04 gehabt hatte. Von anderen Zuständen sei noch notiert, daB im April 05 die Wieseck durch ein Hochwasser der Lahn an ihrem unteren Lauf allein angestaut wurde, während an der oberen Entnahmestelle der Stand mäBig hoch war; ferner, daB am Tag der Untersuchung im Mai 05 Reinigungsarbeiten an ihren Ufern vorgenommen wurden, wobei auch viel Schlamm aufgewirbelt wurde. Besser wäre es natürlich gewesen, wenn die Untersuchung auf andere Tage gefallen wäre; diese Umstände werden hier nur erwähnt, um einer falschen Beurteilung des an beiden Tagen erhaltenen Resultates vorzubeugen.

Die Untersuchungen ergaben ein rechtes Bild der Zustände, wie sie in der Lahn und in der Wieseck rom.Juli 04 bis Juni 05 herrschten, 
wie sie wohl stets in den letzten Jahren geherrscht haben und bis zur Beendigung der beabsichtigten Sanierung vorhanden sein werden. Wie aber am Anfang der Arbeit ausgeführt ist, sollten nicht nur diese Znstände untersucht, sondern es sollte zugleich festgestellt werden, inwieweit die hier gefundenen Tatsachen für Flüsse und Bäche, die durch städtische Abwässer verunreinigt werden, allgemeine Gültigkeit haben. Es sollte z. B. untersucht werden, welche Faktoren an der sichtbaren, welche an der riechbaren Verunreinigung schuld seien; welche die Vermehrung des Bakteriengehaltes, des Rückstandes, des Sauerstoffgehaltes bedingten; ferner welche Bedeutung für die Beurteilung der Bestimmung des Chlorgehaltes, des Gehaltes an oxydierbarer Substanz und den anderen, häufiger oder seltener herangezogenen Untersuchungsmethoden zukämen. Es sollte, mit einem Wort, das für alle derartigen Flüsse und Bäche typische aus den vielfältigen Befunden herausgeholt werden. Zu diesem Zwecke soll im folgenden der Versuch gemacht werden: I. die Ursachen zu erforschen, durch die der Gehalt der Flüsse an den verschiedenen Bestandteilen be. dingt ist, und II. zu sehen, welche Methoden zur Untersuchung von FluBverunreinigungen die geeignetsten sind.

\section{Die Zusammensetzung des Wassers der Lahn und der Wieseck in der Untersuchungsperiode und die darauf einwirkenden Faktoren.}

Das FluBwasser setzt sich zusammen aus dem reinen Wasser und den darin suspendierten und gelösten Stoffen; es kann daher in seiner Zusammensetzung verändert werden durch Veränderung der Wassermenge, durch Zunahme oder Abnahme dieser Stoffe und durch Umsetzungen, die im Wasser vor sich gehen. Die Wirkung dieser Faktoren läBt sich nie für sich allein beobachten. Wird z. B. durch einen Regen die Flüssigkeit verdünnt, so werden gleichzeitig yom Ufer aus Stoffe eingeschwemmt; oder es kann dadurch, noch bevor eine Veränderung des Pegelstandes zu bemerken ist, eine Erniedrigung der Temperatur und damit eine Verminderung der Umsetzungen eintreten. Durch Erhöhung der Temperatur wird nicht nur eine Vermehrung der Umsetzungen, sondern auch infolge der Verdunstung eine Verminderung des Wassers verursacht. Heiße Sommertage bewirken gleichzeitig eine Verminderung der Bakterien (Keimzahl) und eine Vermehrung der Algen (suspendierte Bestandteile).

Die Folgen dieser Begebnisse sind also getrennt voneinander klarzulegen. Nun erscheint es im ersten Augenblick einfach, die Wirkung eines Faktors experimentell darzustellen, indem man z. B. im Winter 
Wasser entnimmt, es bei höherer Temperatur stehen läßt und dann untersucht. Ein solches Vorgehen würde nicht immer richtig sein: es fehlen dabei zu viele Umstände, die nun in der Natur mitspielen: die Bewegung des Wassers, die stets reichliche Sauerstoffzufuhr, die Möglichkeit der Lösung neuer Stoffe aus dem Boden, die Tätigkeit vieler Lebewesen am Ufer und im Flusse, besonders im FluBschlamm. Immerhin ist zuzugeben, daB es in manchen Fällen gute Resultate zu geben vermag. Bei den vorliegenden Untersuchungen wurde es nicht angewendet. Dafür standen zu Gebote die Aufzeichnungen über die Temperatur und den Pegelstand, deren Schwankungen graphisch dargestellt wurden (Taf. III, Fig. 1), ferner die Aufzeichnungen über Wetter, Sonnenlicht und andere Verhältnisse und schlieBlich die in der Literatur niedergelegten und die selbstgemachten Erfahrungen über die Einwirkung aller dieser Faktoren auf die Umsetzungen in Flüssen.

1. Die Durchsichtigkeit des Wassers (hier soll nur auf die Methode der Bestimmung der Lichtabsorption, nicht auf die viel ungenauere der Durchlesbarkeit Rücksicht genommen werden) schwankt in weiten Grenzen (Taf. IV, Fig. 4). In der Lahn oberhalb GieBens ist sie ziemlich groB im Juli (Lichtabsorption in $5^{\mathrm{cm}}$ dicker Schicht $=11$ Prozent des Lichtes), steigt dann im August und Anfang Oktober (7.1 Prozent bzw. 4.5 Prozent), sinkt wieder auf den früheren Stand bis Mitte Oktober und hat diesen auch am 19. Dezember. Am 29. November und 30. Dezember ist das Wasser als vollständig rein anzusehen; dann nimmt die sichtbare Verunreinigung zu im Januar ${ }^{1} 05$ (7.6 Prozent), steigt stark an im Februar (19.1 Prozent), sinkt im März ganz gering und steigt im April wieder (21.7 Prozent). Im Mai ist das Wasser ziemlich rein, im Juni ist die Durchsichtigkeit dieselbe wie im Juli 04.

Vergleicht man diese Kurve mit der Temperaturkurve, so wird man wenig Ähnlichkeit herausfinden. Zwar zeigt auch diese Fallen im Herbst, Ansteigen am 19. Dezember, im Februar und im Juni an, doch damit ist die Ahnlichkeit zu Ende. Weder stimmt der übrige Verlauf, noch sind die Höhen einander proportional, sondern finden sich bei der einen im Februar bis April, bei den anderen im Hochsommer.

Ganz anders, wenn man zum Vergleich die Pegelkurve heranzieht. Hier zeigt sich bei beiden ein geringes Sinken vom August bis Oktober, Ansteigen Mitte November, Sinken Ende November, ebenso im Dezember, starkes Ansteigen im Januar, noch stärkeres im Februar, sehr geringes Abfallen im März, die alte Höhe im April, starkes Sinken im Mai. Soweit sind die Kurven bis in alle Einzelheiten identisch. Nur im Hoch-

1 Es ist natürlich nar der Tag der Untersuchung gemeint. 
sommer weichen sie voneinander ab. Hier erreicht bei niederem Wasserstand die Trübung eine, wenn auch nur geringe Höhe, um im August nach einem Regen mit Erniedrigung der Temperatur zu sinken, ohne daß im Pegelstand eine Veränderung eintritt.

Die Ursachen für dieses Parallelgehen und somit für die Entstehung der sichtbaren Verschmutzung sind leicht zu finden. Das Steigen des Wassers ist bedingt durch das Hochwasser, das das Flußbett aufwühlt und von den Ufern Schmutz hereinbringt. Mit dem Sinken des Pegelstandes hören diese Verunreinigungen auf. Mit dem Steigen der Temperatur beginnt unter Einwirkung des Lichtes in dem langsam fließenden Flusse ein kräftiges Algenwachstum, das wieder eine geringe Trübung des Wassers hervorruft.

Ganz ähnlich sind die Verhältnisse in der Wieseck oberhalb GieBens; nur ist dabei in Betracht zu ziehen, daß sie als Bach mit einer besonders im Sommer sehr geringen Wassermenge schon auf Einwirkungen reagiert, die auf die Lahn noch keinen EinfluB haben; das Maximum liegt daher bei der ersten Schneeschmelze (19. Dezember) nicht zur Zeit des höchsten Wasserstandes (Februar und März 05). Durch dieselben Momente ist auch die sichtbare Verschmutzung verursacht, die sie durch die Abwässer der Stadt empfängt: auch diese ist nicht am stärksten zur Zeit der Temperatur, der stärksten Zersetzung, sondern dann, wenn deren Produlte durch Regengüsse (August 04) und Hochwasser ausgewaschen werden; und zwar geschieht dies im Winter bei der ersten Schneeschmelze (19. Dezember) so gründlich, daß für die späteren wenig mehr übrig bleibt.

Die sichtbare Verunreinigung der Lahn unterhalb GieBens ist ein Produkt aus der, die sie oberhalb hat, und der, die sie dort, vor allem durch die Wieseck empfängt. $D a$ die Verdünnung, die letztere Wässer dabei erleiden, żiemlich stark ist, folgt ihre Kurve ebenfalls meist der des Pegelstandes, doch ist ein EinfluB der städtischen Abwässer selbst bei Hochwasser nie zu erkennen.

Uber die Durchsichtigkeit anderer Flüsse fehlen in der Literatur meist die Angaben; ich konnte nur die finden, daß die des Maines bei Hanau (13, S. 94) an trockenen Tagen vom März bis Juni meist über $20^{\mathrm{cm}}$, im August nur $10.4^{\mathrm{om}}$; bei Regen im April $10.6 \mathrm{bzw}$. über $20^{\mathrm{cm}}$, im Juli 12 bzw. über $20^{\mathrm{cm}}$, im September $14 \cdot 6^{\mathrm{cm}}$ betrug, also geringer ist als die der Lahn.

2. In ähnlichen Linien, wie die Kurve der Durchsichtigkeit, bewegt sich die der suspendierten Bestandteile (Taf. III, Fig. 3). Es ist dies leicht begreiflich: die suspendierten Bestandteile, die auf dem Filter zurückbleiben, bilden den Hauptbestandteil der Trübung, weun auch das 
Filtrat selten ganz klar ist: z. B. war am 12. Januar die Trübung zu $2 / 3$ durch abfiltrierbare, zu 1/3 durch nicht abfiltrierbare Bestandteile bedingt. Ahnlich fand Rubner, daB in manchen Fällen die Papierfiltration 30 Prozent des Suspendierten nicht zurückzuhalten vermag (14, S. 17). In der nicht verunreinigten Lahn ist ihre Menge gering im Juli 04, unwägbar von da an bis Dezember, steigt mit dem Wasser an bis April, sinkt im Mai auf 0 , steigt allerdings sehr auffallend im Juni. Auch in der reinen und der verunreinigten Wieseck verhalten sie sich wie die sichtbaren Trübungen überhaupt, nur sind die Ausschläge der Kurve viel heftiger. Die Ursachen für das Steigen und Sinken ihrer Menge dürften dieselben sein, da auch die Algen gröBtenteils auf dem Filter zurückbleiben; es ist daher den oben gemachten Ausführungen nichts hinzuzufügen.

Ähnliche Beobachtungen darüber wurden auch an anderen Flüssen: Elbe (15, S. 18), Maas, Rhein, Donau (16, S. 6), Regnitz (18, S. 30) gemacht; König faBt sie mit den Worten zusammen, daB ,die Flüsse bei hohem Wasserstand (im Winter) den höchsten Gehalt an Schwebestoffen aufweisen, wāhrend er bei niedrigem am geringsten ist". Dirksen und Spitta haben ihn allerdings in der Spree im Sommer am höchsten gefunden (19 u. 11, S. 176), doch findet sich unter ihren Untersuchungen auch keine bei Hochwasser vorgenommene; bei Niederwasser ist er, wie erwähnt, auch in unseren Untersuchungen im Sommer am höchsten.

Die Asche der suspendierten Bestandteile überwiegt den Glühverlust fast stets, doch im Winter mehr als im Herbst. Auch Spitta fand, daB der Aschegehalt des Plankton stark schwankt (zwischen 28.42 und 81.63 Prozent), und daB er im Sommer abnimmt (11). Ähnliche Schwankungen zeigt der Rhein, in dem oberhalb Mainz und oberhalb Wiesbadens bei Niederwasser im November der organische Teil der suspendierten Bestandteile etwas, bei Mittelwasser im September und bei Hochwasser im März der anorganische gewaltig überwiegt (20, S. 283 u. 292). In der Regnitz erreicht die Menge des Glühverlustes der suspendierten Bestandteile niemals die ihres Glührückstandes; doch sind die Differenzen im Sommer wesentlich geringer $(18$, S. 29).

3. Die Menge der gelösten Substanzen, der Gesamtrückstand schwankt weniger (Taf. III, Fig. 2); sie ist dem Pegelstand weder direkt noch umgekehrt genau proportional, sondern fällt im Herbst, während jener fast keine Veränderung zeigt, und sinkt nur gering bei Hochwasser. Eine etwas gröBere Ubereinstimmung findet sich dagegen mit dem Verlauf der Temperatur, ein Sinken im Winter, ein Steigen im Sommer: zieht man eine Grenze derart, daß eine Temperatur von $10^{\circ}$ und weniger als niedrig bezeichnet wird, so zeigt es sich, daß auch der Rückstand an 
solchen Tagen wesentlich geringer ist als bei hoher Temperatur. Einige Ausnahahmen kommen allerdings vor. - Die Kurve des Rückstandes in der Wieseck oberhalb und unterhalb Gießens zeigt im allgemeinen denselben Verlauf; doch spielen dabei noch andere Faktoren mit, indem der niederste Stand im März erreicht wird. - Der Rückstand der Lahn unterhalb GieBens weicht von dem oberhalb gefundenen nur wenig ab.

In der Literatur finden sich über eine Übereinstimmung zwischen Temperatur und Gesamtrückstand keine Angaben. Im Gegenteil behaupten L. Pfeiffer und Eisenlohr (21, S. 198), daB in der Isar mit sinkendem Wasserstand die Menge des Abdampfrückstandes (und des Chlors) steigt, bei hohem sinkt, da die durch das Grundwasser zugeführten anorganischen Bestandteile im letzteren Falle stärker verdünnt würden. Ähnlich scheinen sich die Elbe bei Königgrätz, die Donau bei Wien (15, S. 18) und die Mosel bei Trier (22, S. 564) zu verhalten. Dagegen nehmen die gelösten Stoffe des Rheines bei Hochwasser zu (16, S. 6) und für die Schwankungen im Pregel (23), in der Limmat (24) und in der Spree (25) kann nach den Tabellen weder Temperatur noch Wasserstand als Grund angegeben werden. ${ }^{l}$ Es kann daher auch der Satz keine allgemeine Gültigkeit haben, daB ein Anschwellen eines Flusses eine Abnahme der gelösten Stoffe zur Folge hat; es scheint dies mehr von örtlichen Verhältnissen abzuhängen und von der Jahreszeit, zu der das Hochwasser eintritt.

4. Glührückstand und Glühverlust zeigen fast genau dieselben Schwankungen wie der Gesamtrückstand.

5. Der Gehalt an Chloriden ändert sich in der Lahn im Laufe eines Jahres sehr wenig, und zwar unabhängig von Temperatur und Wassermenge. Etwas stärker sind die Schwankungen in der Wieseck oberhalb GieBens; hier scheint die Auswaschung des Bodens der Wiesen, die jedes Jahr gedûngt werden, mitzuspielen. An ihrer Mündung in die Lahn sind sie viel stärker, und zwar ist der Chlorgehalt um so gröBer, je geringer die Wassermenge ist; eine Zunahme durch Regen, wie sie Marsson, Spitta und Thumm im Main beobachtet haben (13, S. 79), findet nicht statt. Es konnten also die erwähnten Befunde von Pfeiffer und Eisenlohr (21) auch für die Chloride nicht bestätigt werden, ebenso wie sie auch für den Pregel oberhalb Königsberg (23, S. 354) wenigstens im Winter nicht zutreffen. Dagegen ist die Erklärung gültig für die Spree (25, S. 401) und für die Mosel (22, S. 564), wo die Differenzen ganz enorm sein sollen (Schwankungen zwischen 21.4 und $160^{\mathrm{mg}}$ in

1 Stets sind nur die oberhalb der betreffenden Städte gefundenen Zahlen berücksichtigt. 
1 Liter). Die Verhältnisse in verschiedenen Flüssen sind also verschieden; es ist möglich, daB sie auch mit dem Chlorgehalt des Bodens zusammenhängen, doch braucht ihre Menge der Auswaschung desselben nicht proportional zu sein, denn auch das Regenwasser führt den Flüssen Chloride zu. Sein Gehalt an Chlornatrium beträgt in Nantes (nach Bobierre) 5 bis $26.1^{\mathrm{mg}}$ in 1 Liter, in Manchester wurden bis $133^{\mathrm{mg}}$, in Landsend $950 \mathrm{mg}$ gefunden (15, S. 6).

6. Auch die für die Oxydierbarkeit gefundenen Zablen sind in der Lahn nicht sehr verschieden. Sie zeigen oberhalb Gießens ein Maximum rom Juli bis August 04, ein zweites im Januar bis Närz 05, sind also weder von Temperatur noch vom Wasserstand allein abhängig. Zieht man dagegen beide gleichzeitig in Betracht, so kann man finden, daB die Kurve hoch ist bei hoher Temperatur und hohem Pegelstand, niedrig, wenn keines von beiden der Fall ist. Die oxydierbaren Stoffe in der Wieseck oberhalb Gießens zeigen unregelmäBige, wohl zufällige Schwankungen, die nicht mit denen der Lahn übereinstimmen. OUber ibre Zunahme in der Stadt läBt sich soviel sagen, daB sie bei hoher Temperatur und niederem Wasserstand reichlich vorhanden sind (Juli 04), nach einem Regen sinkt ihre Menge, um dann (mit einer Ausnahme) wieder anzusteigen und nach der ersten Schneeschmelze (19. Dezember) für eine Zeit lang definitiv abzusinken. Ihr schlieBliches EinflieBen in die Lahn ist meist deutlich nachzuweisen.

Als Ursache des Ansteigens der organischen Substanzen in relativ reinen Flüssen wird von L. Pfeiffer und Eisenlohr (21) angenommen, daB sie im Gegensatz zu den anorganischen durch den Regen von der Oberfläche $a b$ - und in die Gewässer hineingeschwemmt werden; sie fanden auch in der Isar ein Ansteigen mit Ansteigen des Wasserstandes. Dasselbe wurde für den Pregel von Dräer konstatiert (23); ebenso steigen sie im Rhein bei Mainz (20, S. 283) bei steigendem Pegel an, ferner in der Regnitz oberhalb Erlangens (18), vielleicht auch in der Limmat oberhalb Zürichs (24); außerdem im Main oberhalb Hanau bei Regen (13, S. 79). Für die Spree dagegen trifft diese Regel nicht zu, auch nicht oberhalb Berlins (25, S. 377, Stralauer Wasserwerk); hier sind sie am höchsten bei niederem Pegelstand. Auch aus den ron Fränkel für die Lahn oberhalb Marburgs erhaltenen, dürfte eher das Gegenteil zu schließen sein (26). In der Mosel bei Trier (22) herrschen in dieser Beziehung überhaupt keine Gesetzmäßigkeiten.

In unseren Versuchen ist ebenfalls in der Lahn ein Ansteigen bei Hochwasser zu konstatieren, das durch Hereinschwemmen der organischen Substanzen vom Ufer aus bewirkt sein kann. Beim Fallen nehmen sie zunächst $a b$, doch geht dies nur bis zu einem gewissen Punkte weiter. 
Von da an nehmen sie wieder zu infolge der Konzentration, obwohl vom Ufer wenig oder nichts mehr eingeschwemmt wird: denn auch in reinen Flüssen werden sie ständig neugebildet durch Verwesung organischen Materials. Besonders aber tritt der Einfluß der Konzentration in der Wieseck unterhalb GieBens hervor, wo er fast allein maBgebend ist, da das Abschwemmen vom Jfer gegenüber der direkten Einleitung der Schmutzwässer stark zurūcktritt.

7. Ammoniak fehlte zunächst in der Lahn rom Juli bis Ende November. Zum erstenmal wurde es am 19. Dezember spurweise nachgewiesen. Dann nahm die Menge etwas zu, doch fehlte es schon vom Februar an wieder; nur im Mai wurde noch eine zweifelhafte Spur notiert. In der Wieseck oberhalb Gießens wurde es nachgewiesen Mitte Dezember 04 in Spuren, Ende Dezember und im Januar 05 in etwas größerer Menge, von da an wieder nur spurweise. - Wesentlich anders waren die Verhältnisse in der Wieseck unterhalb GieBens. Hier ist die Kurve hoch im Sommer 04 und bleibt dann bis zu einem Regen (August) auf der Höhe (zu bemerken ist, daB die Titrierung des Destillates damals nur mit $1 / 10$ Normalsäure vorgenommen wurde und daB daher keine genaueren Ausschläge erscheinen); im Oktober steigt sie wieder etwas an (im September waren keine Untersuchungen vorgenommen worden) und ist dann bis Mitte Mai 05 niedrig. Dann erhebt sie sich am 31. Mai nach einigen heiBen Tagen, noch mehr am 3. Juni, sinkt nach längerer Fortdauer der Gewitterregen am 21. und 26. Juni und steigt am 29. Juni und nach heiBen Tagen am 3. Juli. Ein EinfluB auf die Lahn ist selten und nur in geringem Maße nachzuweisen.

Dem Pegelstand ist die Kurve nie proportional; dagegen ist der EinfluB der Temperatur auf den Ammoniakgehalt offenbar. Allerdings genügt eine Steigerung. der Temperatur allein nicht, um sämtliche Verhältnisse zu erklären, da die Lahn z. B. Ammoniak nur im Winter enthält. Beror jedoch der Versuch gemacht werden kann, die anderen Ursachen zu finden, muß erst auseinandergesetzt werden, wie und wann der Gehalt an seinem Umsetzungsprodukt, der salpetrigen Säure, wechselt. Hier bietet sich allerdings die Schwierigkeit, daß diese nicht quantitativ bestimmt, sondern nur kolorimetrisch abgeschätzt wurde; daB ferner zunächst ein Reagens (Jodzinkstärke) angewendet wurde, das nicht imstande ist, sehr geringe Spuren nachzuweisen. Doch geben die Befunde auch so ein klares Resultat. - Salpetrige Säure wurde gleich das erste Mal gefunden, als mit dem Erdmannschen Reagens untersucht wurde, d. h. im Januar und Februar 05. Allerdings war ihre Menge damals sehr gering, und im März und April verschwand sie ganz. Sie trat dann wieder im Mai auf und war im Juni in so groBer Menge vorhanden, 
daß auch die Jodzinkstärkereaktion positiv war. Dasselbe Verhalten zeigte sie in der Wieseck oberhalb Gießens, nur daß sie in dieser schon im April gefunden wurde. In der verunreinigten Wieseck war sie am 18. Juli 04 in gröBerer Menge vorhanden; im Januar bis April 05 wurde sie mit dem Erdmannschen Reagens nachgewiesen; im Mai und Juni war ihre Menge groB. Manchmal zeigte sich eine Beeinflussung des Lahnwassers dadurch. Für ihre Kurve ist also die Wassermenge maBgebend, vor allem aber die Temperatur; erst bei erhöhter Temperatur wird sie in gröBerer Menge gebildet. - Nun wird auch die Kurve des Ammoniak völlig verständlich. Dieser tritt jederzeit auf, am meisten bei starker Verunreinigung und bei höherer Temperatur. Bei höherer Temperatur geschieht aber auch seine Oxydation so schnell, daB er als solcher nicht mehr nachweisbar ist, sondern nur seine höheren Oxydationsstufen. Bei starker Verunreinigung dagegen wird so viel gebildet, daB die vollständige Umwandlung nicht so schnell vor sich gehen kann.und es wird dann viel salpetrige Säure und viel Ammoniak gefunden. Im Winter wird zwar wenig Ammoniak gebildet, aber auch weniger umgewandelt; die Folge ist ein geringer Ammoniakgehalt und höchstens Andeutungen von salpetriger Säure. Selbstverständlich ist auch die Verdünnung durch Hochwasser für den Nachweis maßgebend. Übrigens wird auch nicht aller Ammoniak zu salpetriger Säure umgewandelt; ein Teil verdunstet, ein Teil wird von Algen direkt als Baustoff verwendet.

Salpetersäure wurde nur einmal spurweise gefunden. Dab sie trotz der Anwesenheit salpetriger Säure meist zu fehlen scheint, mag daher kommen, daß sie erst in 10 fach größerer Menge nachweisbar ist als letztere (16, S. 18).

$\mathrm{DaB}$ Ammoniak auch in reinem FluBwasser in Spuren vorkommen kann, wurde schon ofters konstatiert: so fand er sich in der Oder, in der Limmat, im Main oberhalb Hanau (und zwar besonders in dem nahe dem Grunde geschöpften Wasser), im Rhein oberhalb Mannheim, im. Mississippi (27, S. 455), manchmal im Pregel oberhalb Königsbergs und in der Lahn oberhalb Marburgs. Dagegen wurde er vermißt in der Isar, in der Regnitz, oberhalb Erlangen, im Rhein bei Mainz. - Salpetrige Säure wurde ebenfalls oft schon oberhalb von Städten gefunden, so in der Oder, im Main bei Hanau; im Sommer auch in der Isar (28, S. 43 bis 50) und in der Regnitz; dagegen waren die Befunde negativ in der Limmat, im Rhein bei Mainz und in der Lahn bei Marburg. Zum Teil dürften diese negativen Befunde freilich durch die Wahl eines ungeeigneten Reagens zu erklären sein. - Salpetersäure wurde unter denselben Umständen ebenfalls öfters nachgewiesen, z. B. in der Isar (28, S. 42) im Rhein bei Mannheim und Mainz, in der Oder, in der Limmat, der Mosel, 
der Spree (von Dirksen und Spitta), einmal auch in der Lahn bei Marburg; nicht dagegen im Main, dem Pregel und in der Spree (von Frank). - Unterhalb der betreffenden Städte nimmt der Ammoniakgehalt fast stets, der Nitrit- und Nitratgehalt öfters zu.

8. Freier Sauerstoff war stets vorhanden. Seine Kurve wurde in folgender Weise aufgestellt: es wurde zunächst nach den Winklerschen Tabellen berechnet, zu wieriel Prozent das Wasser damit gesättigt war, bzw. wieviel Prozent der UtberschuB über die von Winkler gefundenen Werte betrug. Die Zahlen wurden (Taf. IV, Fig. 5) eingetragen, und zwar das Sauerstoffdefizit über, der SauerstoffüberschuB unter dem Nullpunkt. Der Zweck dieser Anordnung war der, daß die Kurve bei zunehmender Verschmutzung in derselben Weise steigen sollte, wie bei den anderen Stoffen. - Das Ergebnis war folgendes: In der Lahn war im Juli 04 ein gewaltiger UberschuB vorhanden (42 und 61 Prozent); im Oktober war ein mäBig großes Defizit nachzuweisen, das im November sink; von da bis März war es gering, stieg im April noch etwas an und wandelte sich im Mai and noch mehr im Juni in einen starken ÜberschuB um. - In der Wieseck war der Sauerstoffgehalt fast stets wesentlich geringer; am 18. Juli 04 war ein geringes Defizit; am 25. Juli ein geringer UUberschuB nachzuweisen; von da an wird die Kurve stark zackig und schwankt unregelmäßig zwischen einem Defizit von 40 und $4 \cdot 6$ Prozent. Diese Linie geht weder einer Sauerstoff- noch einer anderen Linie parallel; es dürfte sich wohl um Zufälligkeiten handeln. Anders als diese beiden Linien verläuft die der Wieseck unterhalb GieBens: sie zeigt stets ein starkes Defizit an und zwar ist dies im allgemeinen um so stärker, je höher die Temperatur ist; ferner ist es niedriger im Februar und April, nachdem die verschmutzenden Stoffe wenigstens gröBtenteils durch die erste Schneeschmelze weggewaschen sind. Unterhalb Gießens zeigt das Lahnwasser im Sommer stets einen geringeren Sauerstoffgehalt; im Winter ist er bald größer, bald geringer. Letzteres spricht ebenfalls dafür, daß Zufälligkeiten eine ziemlich große Rolle spielen.

Die Veränderung des Sauerstoffgehaltes geschieht in verschiedener Weise. Bei der Berührung mit der Luft strebt das Wasser, seinen maximalen Sauerstoffgehalt zu erreichen, also bei einem Defizit Sauerstoff aufzunehmen, bei einem Utherschuß Sauerstoff abzugeben. Bei höherer Temperatur gewinnen zwei andere Momente große Wichtigkeit: das Wachstum der Wasserpflanzen und Algen, wodurch der Gehalt vermehrt wird (Knauthe beobachtete in einem Fall eine Vermehrung auf 24 Promille, Spitta von 23.05 Promille) (11, S. 207) und das Vorhandensein von Schmutzstoffen und Bakterien, wodurch er vermindert wird. Von einem gewissen Grade Zeitschr. f. Hygiene. IIII. 
der Verschmutzung an ist das Wachstum der Algen nicht mehr möglich; in diesem Fall tritt allein Sauerstoffzehrung ein. Daher zeigen die Tabellen in dem langsam strömenden, schön grünen Wasser der Lahn oberhalb Gießen im Sommer einen bedeutenden UberschuB, in der stinkenden Wieseck unterhalb Giebens ein bedeutendes Defizit, die vor allem bei Erhöhung der Temperatur hervortreten. Ein Parallelgehen mit der Bakterienkurve ist oft vorhanden, besonders in den Extremen; es tritt nicht durchweg hervor, weil der Bakteriengehalt auch durch Umstände bedingt ist, die keine Veränderung im Sauerstoffgehalt hervorrufen, z. B. Aufwirbeln des Schlammes.

Quantitative Bestimmungen des Sauerstoffs in Flüssen finden sich in der Literatur selten, und wo sie vorhanden sind, ist manchmal die Temperatur des Wassers nicht angegeben, so daB sich der Prozentsatz des Defizits nicht berechnen läBt. on älteren Angaben erwähnt Spitta (11, S. 220) die in der Donau, der Aare und der Seine ausgeführten. In letzterer sinkt der Gehalt in Paris ron 5.34 auf $1.02 \mathrm{cem}$. Seine eigenen Untersuchungen ergeben, daß das Spreewasser höchst selten einen ÜberschuB zeigt; meistens war ein Defizit vorhanden, das innerhalb Berlins stark zunahm und zwar besonders im Sommer; an Regentagen war es geringer. Das Rheinwasser war am Entnahmetage (September; Temperatur $14^{\circ}$ ) an keiner Stelle für die gegebene Temperatur gesättigt, doch war das Defizit ein ziemlich gleichmäßiges und schwankte zwischen 0.5 und $1.01 \mathrm{~cm}$ (29). Bei den Untersuchungen von Ohlmüller (20) schwankte der Sauerstoffgehalt des Rheines an verschiedenen Tagen aus unbekannten Gründen ziemlich stark, und zwar betrug das Defizit oberhalb Mainz zwischen 5.52 und $1.17 \mathrm{mg}$. Auch in der Regnitz war bei den Untersuchungen von Pren (18) stets ein Defizit vorhanden; allerdings wurde darauf nur bis Joni untersucht, und auBerdem scheint der Flub schon oberhalb Erlangens ziemlich stark verunreinigt zu sein, worauf auch die hohe Keimzahl im Juni und Juli hindeutet. Das Defizit war unterhalb der'Stadt stets größer als oberhalb.

9. Die Keimzahl (Taf.IV, Fig.6) ist in der Lahn sehr niedrig (318 und 132 Keime) im Juli 04, steigt gering bis Mitte November (bis 2340), nach einem Abfall im Dezember (780) stark, im Januar (3668), noch höher im Februar (5380), fällt im März (1210) ab, steigt im April wieder stark (4920), um im Mai (570) und Juni (686) wieder auf einen sehr niedrigen Stand zu sinken. Ähnlich ist der Verlauf in der Wieseck, nur ist sie hier in der warmen Jahreszeit höher (etwa 3000). In der verunreinigten Wieseck sind die Ausschläge überaus hohe: im Juli 04 betrăgt die Zahl bis 156000 , dann sinkt sie gering nach einem Regen im August 
(98 400), stärker im Oktober (28400), steigt wieder an, um unter starken Schwankungen im Junuar definitiv zu sinken (20000) und ihren niedersten Stand im April zu erreichen (5910). Im Mai und besonders im Juni erfolgt wieder ein starker Anstieg (bis 50000). - Es ist klar, daB die Lahn von dieser Menge stark beeinfluBt wird: ihr Keimgehalt ist unterhalb Gießen bis Dezember stets höher als oberhalb, und zwar ungefähr um so mehr, je höher der Keimgehalt der Wieseck ist. Vom Januar bis April sind die Zahlen ungefähr gleich, im Mai und Juni differieren sie wieder stark.

Vergleicht man die Kurve des Keimgehaltes der Lahn mit anderen Kurven, so findet man zu der der Temperatur keine Beziehungen. Sie steigt manchmal mit abnehmender Temperatur (Herbst 04), kann aber auch bei zunehmender Temperatur zunehmen (April 05). Dagegen ist es überraschend, zu sehen, wie innig die Beziehungen zum Pegelstand sind und zwar nicht etwa in der Art, daB durch Verdünnung die Keimzahl vermindert wird, sondern im Gegenteil: mit steigendem Pegelstand steigt, mit sinkendem sinkt die Keimzabl. Es liegen hier ganz ähnliche Verhältnisse vor, wie sie vorhin bei der Durchsichtigkeit und den suspendierten Bestandteilen auseinandergesetzt wurden: bei Hochwasser werden vom Boden und dem Ufer zahlreiche mit Keimen beladene Partikelchen mitgenommen. Ein einmaliger Regen dagegen ist ohne EinfluB. - Daneben kommen jedenfalls noch andere Faktoren in Betracht, besonders die bakterizide Wirkung des Lichtes; doch spielen diese bei den Resultaten eine so geringe Rolle, daß ihre Wirkung ganz vernachlässigt werden könnte. Wäre nicht die Einwirkung des Lichtes auf die Bakterien Gegenstand so eifriger Forschung gewesen - durch unsere Zahlen könnte man nicht auf seine bakterizide Wirkung aufmerksam werden. Es mag dies zum Teil daher kommen, daß das Licht das Wachstum der Algen begünstigt und durch diese wieder ein großer Teil des Lichtes absorbiert wird (durch eine nur $5^{\mathrm{cm}}$ dicke Schicht im Juli 04: 11 Prozent, im Juli 05: 10.5 Prozent). - Auch Praussnitz schätzt auf Grund seiner Untersuchungen die bakterizide Wirkung des Lichtes in Flüssen nicht hoch ein (30) ebensowenig Kruse (31). Wenn Buchner gefunden hat (32, S. 196), daB Typhusbazillen in der Tiefe von $1.6 \mathrm{~m}$ in $4 \frac{1}{2}$ Stunden vom Lichte abgetötet werden, so $m u B$ er ein auffallend reines Wasser gehabt haben (dasselbe zeigte bei $2 \mathrm{~m}$ hoher Schicht "schon" recht wahrnehmbare Trübung) und auBerdem dürfte es sehr ruhig gewesen sein (See), so daß nicht durch den Wellenschlag der gröBte Teil des Lichtes reflektiert wurde.

Etwas anders liegen die Verhältnisse betreffs der Zunahme der Keimzahl in kleinen Bächen, wie in der Wieseck. Zwar im Herbst, Winter 
und Frühjahr folgt ihre Kurve der der Lahn; im Sommer ist dagegen ihr Wasserstand so niedrig, daß die Keimzahl durch die Verunreinigungen von seiten der oberhalb gelegenen Dōrfer dauernd hoch bleibt. Durch Regen erfolgt eine starke Beeinflussung, die zu der höchsten beobachteten Keimzahl führt. Von einem bakteriziden Einflusse des Lichtes ist auch hier nichts zu bemerken.

In der verunreinigten Wieseck liegen wieder andere Verhältnisse vor: hier folgt die Keimzahl der Temperatur, hinkt ihr aber um einige Wochen nach. Niedrig wird sie besonders, nachdem durch die erste Schneeschmeize ein großer Teil des Schmutzes ausgeräumt ist. Im Mai wäre sie sicher niedriger gewesen, wenn nicht an und im Bach in der Stadt gearbeitet worden wäre. Der Anstieg im Frühjahr erfolgt aber sehr langsam. Eine Vermehrung der Wassermenge mag wohl mitwirken, doch tritt ihr EinfluB hinter dem der Temperatur weit zurūck. Speziell ist ein einmaliger Regen nur von geringem EinfluB. - Die Keimzahl in der Lahn unterhalb Gießens setzt sich zusammen aus dem ursprünglichen Gehalt und den zugeführten Keimen; die Zunahme ist stark. -

$\mathrm{DaB}$ die Keimzahl in relativ reinen Flüssen vor allem vom Wasserstand abhängig ist, hat zuerst Kabrhel (33) in monatelang täglich gemachten Untersuchungen gezeigt. Auch an anderen Flüssen zeigt sich diese Erscheinung, wie an der Limmat (24, S. 13 bis 25), dem Pregel (23), dem Main (13, S. 79), der bei Regen eine Vermehrung aufweist; dagegen nicht in der Regnitz (18), die schon oberhalb Erlangens ziemlich stark verunreinigt zu sein scheint, worauf auch andere Momente hindeuten. - Unterhalb der betreffenden Städte tritt in allen Fällen, die ich in der Literatur finden konnte, eine Vermehrung ein und zwar besonders stark im Sommer. Eine Ausnahme bildet nur der Rhein mit seiner enormen Wassermenge.

10. Die besonderen Arten von Keimen, die mittels Jodkaliumkartoffelgelatine gezählt wurden (im folgenden mit $\mathrm{J} \mathrm{K} \mathrm{K}$ bezeichnet) stimmen in ihrer Zu- und Abnahme mit der der Keimzahl nicht völlig überein. In der Lahn sinkt ihre Zahl vom Januar zum Februar, während die Keimzahl ansteigt; von da an gehen die Zahlen allerdings parallel. In der Wieseck ist der Verlauf ebenso, nur im Juni sinkt sie auf 0 , während die Gesamtkeimzahl steigt. Unterhalb GieBens gehen die Kurven anfangs parallel; dagegen folgt bei $\mathrm{J} \mathrm{K} \mathrm{K} \mathrm{im} \mathrm{April} \mathrm{(Anstauung} \mathrm{durch}$ das Hochwasser der Lahu) und noch vielmehr im Mai (niedriger Stand, aber Arbeiten im Bach) ein starker Anstieg, im Juni ein starker Abfall, der nach den abnormen Verhältnissen im Mai nicht weiter auffallen kann. - Die Schwankungen in der Lahn unterhalb GieBens entsprechen wieder ihren beiden Komponenten; nur am 21. Juni sind die Zahlen auf- 
fallend hoch. Eine Erklärung dafür konnte nicht gefunden werden; und da an diesem Tage dort auch eine abnorme Vermehrung der suspendierten Bestandteile, der Bakterienzahl und des Kolititers stattgefunden hat, so möchte ich annehmen, daß hier anormale Verhältnisse vorliegen, wahrscheinlich durch eine Aufwirbelung des Schlammes oberhalb der Entnahmestelle bedingt.

11. Anders verläuft die Kurve des Kolititers. In der Lahn findet sich Grad 2 im Dezember, 1 im Januar und Februar, 2 im März und April, 1 im Lai und Juni. In der Wieseck zeigt die Kurve den gleichen Verlauf, ist aber bei Steigerung um einen Grad höher. Die der verunreinigten Wieseck sinkt im Januar, steigt im Mai. Die der Lahn unterhalb GieBens zeigt zu keiner dieser Kurven eine Beziehung, geht dagegen dem Pegelstand umgekehrt parallel. - Auf die Ursachen und die Bedeutung dieser Zahlen soll später eingegangen werden.

12. Ebenso werden die Veränderungen der Reaktion, der „Fäulnisfähigkeit", der Sauerstoffzehrung und des Glührückstandes der suspendierten Bestandteile erst Besprechung später finden.

Die folgende Tabelle soll nochmals zusammenfassen, in welcher Weise Pegelstand und Temperatur auf den Gehalt an den einzelnen Bestandteilen einwirken.

Tabelle XVIII.

\begin{tabular}{|c|c|c|c|c|}
\hline & \multicolumn{2}{|c|}{ Pegelstand } & \multicolumn{2}{|c|}{$\mathrm{Tem}$ e eratur } \\
\hline & $\begin{array}{c}\text { direkt } \\
\text { proportional }\end{array}$ & $\begin{array}{l}\text { umgekehrt } \\
\text { proportional }\end{array}$ & $\begin{array}{c}\text { direkt } \\
\text { proportional }\end{array}$ & $\begin{array}{l}\text { umgekehrt } \\
\text { proportion. }\end{array}$ \\
\hline $\begin{array}{c}\text { Reiner FluB } \\
\text { (Lahn oberhalb } \\
\text { GieBen) }\end{array}$ & $\begin{array}{c}\text { sichtbare } \\
\text { Verschmutzung } \\
\text { suspendierte } \\
\text { Bestandteile } \\
\text { Keimzahl } \\
\text { Oxydierbarkeit }\end{array}$ & $\begin{array}{l}\text { Chlor }^{1} \\
\text { Gesamt- } \\
\text { rückstand }{ }^{1} \\
\text { Oxydierbarkeit } \\
\text { (Sommer) }\end{array}$ & $\begin{array}{l}\text { Gesamtrückstand } \\
\text { Glühverlust } \\
\text { Glührückstand } \\
\text { salpetrige Säure } \\
\text { freier Sacerstoff }\end{array}$ & Ammoniak \\
\hline $\begin{array}{c}\text { Ziemlich reiner } \\
\text { Bach } \\
\text { (Wieseck ober- } \\
\text { halb GieBen) }\end{array}$ & $\begin{array}{c}\text { sichtbare } \\
\text { Verschmutzung } \\
\text { suspendierte } \\
\text { Bestandteile } \\
\text { Keimzahl } \\
\text { (besond. Regen) } \\
\text { Oxydierbarkeit } \\
\text { (Winter) }\end{array}$ & $\begin{array}{c}\text { Chlor } \\
\text { Gesamtrückstand } \\
\text { Oxydierbarkeit } \\
\text { (Sommer) }\end{array}$ & $\begin{array}{l}\text { Gesamtrückstand } \\
\text { Glühverlust } \\
\text { Glührückstand } \\
\text { salpetrige Säure } \\
\text { freier Sauerstoff } \\
\text { (nicht immer) }\end{array}$ & Ammoniak \\
\hline
\end{tabular}

1 Nach Untersuchungen anderer Autoren. 
Tabelle XVIII. (Fortsetzung.).

\begin{tabular}{|c|c|c|c|c|}
\hline & \multicolumn{2}{|c|}{ Pegelstand } & \multicolumn{2}{|c|}{ Temperatur } \\
\hline & $\begin{array}{c}\text { direkt } \\
\text { proportional }\end{array}$ & $\begin{array}{l}\text { umgekehrt } \\
\text { proportional }\end{array}$ & $\begin{array}{c}\text { direkt } \\
\text { proportional }\end{array}$ & $\begin{array}{l}\text { umgekehrt } \\
\text { proportion. }\end{array}$ \\
\hline $\begin{array}{c}\text { Stark } \\
\text { verunreinigter } \\
\text { Bach } \\
\text { (Wieseck } \\
\text { unterhalb } \\
\text { GieBen) }\end{array}$ & $\begin{array}{l}\text { sichtbare } \\
\text { Verschmutzung } \\
\text { suspendierte } \\
\text { Bestandteile }\end{array}$ & $\begin{array}{c}\text { Oxydierbarkeit } \\
\text { Chlor } \\
\text { Ammoniak } \\
\text { Kolititer }\end{array}$ & \begin{tabular}{|c|} 
sichtb. Verschmutzung \\
suspend. Bestandteile \\
Gesamtrückstand \\
Glühverlust \\
Glührückstand \\
Oxydierbarkeit \\
Ammoniak \\
salpetrige Säure \\
Keirazahl
\end{tabular} & $\begin{array}{c}\text { freier } \\
\text { Sauerstoff }\end{array}$ \\
\hline $\begin{array}{c}\text { Gering } \\
\text { verunreinigter } \\
\text { FluB } \\
\text { (Lahn } \\
\text { unterhalb } \\
\text { GieBen) }\end{array}$ & $\begin{array}{c}\text { sichtbare } \\
\text { Verschmatzung } \\
\text { suspendierte } \\
\text { Bestandteile } \\
\text { Keimzahl } \\
\text { (Winter) } \\
\text { Oxydierbarkeit } \\
\text { (Winter) }\end{array}$ & $\begin{array}{l}\text { Chlor }^{1} \\
\text { Gesamt- } \\
\text { rückstand }{ }^{1} \\
\text { Oxydierbarkeit } \\
\text { (Sommer) } \\
\text { Kolititer }\end{array}$ & \begin{tabular}{|} 
sichtb. Verschmutzung \\
suspend. Bestandteile \\
Gesamtrückstand \\
Glühverlust \\
Glührückstand \\
Orydierbarkeit \\
(Sommer) \\
Amroniak (Sormer) \\
salpetrige Säure \\
freier Sauerstoff \\
Keimzahl (Sommer)
\end{tabular} & $\begin{array}{l}\text { Ammoniak } \\
\text { (Winter) }\end{array}$ \\
\hline
\end{tabular}

\section{Kritik der Mothoden.}

Wie aus der Tabelle und den darauffolgenden Ausführungen hervorgeht, sind nicht alle Methoden gleichartig: manche geben bei starker Verschmutznng einen starken, andere einen geringen Ausschlag. Es soll daher im folgenden auf Grund der Tabellen und der vorhandenen Literatur untersucht werden, welche Methoden zur Beurteilung einer FluBverunreinigung geeignet, welche ungeeignet sind.

Die Urteile über den Wert der gewöhnlich angewandten Methoden gehen weit auseinander. Während Weyl (27, S. 387) angibt, daB die Methoden die auch zur Prüfung des Trinkwassers benutzten seien, führt $\mathrm{R}$ ubner $(14$, S. 9) aus, daB FluBwasseruntersuchungen nach ganz anderen Gesichtspunkten vollzogen werden und ihren Ausgang ron den Sielwasseruntersuchungen nehmen müBten.

Bevor ich die Ergebnisse meiner eigenen Untersuchungen bringe, möchte ich einen Vorschlag machen, der sich auf die Anordnung der

${ }^{1}$ Nach Ontersuchungen anderer Autoren. 
Nethoden bezieht. Sie werden meist eingeteilt in chemische und bakteriologische. Eine solche Einteilung entspricht allerdings der angewandten Technik, doch werden in den beiden Gruppen Stoffe von ganz verschiedener Bedeutung zusammengefaBt. Besser wäre es, die Einteilung nach dem Zweck der Untersuchung vorzunehmen.

Der Zweck der Untersuchung ist der, die Übelstände festzustellen, die durch das Einfübren der verunreinigenden Substanzen in einen FluB entstanden sind oder entstehen werden. Diese sind verschiedener art: Schädigung der Gesundheit durch Infektionskeime, Belästigung der Sinne, Schädigungen der Landwirtschaft, der Industrie, der Schiffahrt, der Fischzucht. Letztere Größen sind der Berechnung zugänglich; infolgedessen ist ein Abwägen der Vorteile, die die Einleitung der Abwässer bietet, gegenüber den dadurch gesetzten Schädigungen möglich. Wesentlich schwerer kann dies bezüglich der ersteren Punkte sein. Man mag immerhin sagen, daB FluBwasser kein Trinkwasser, ist und dab, wer es dennoch trinkt, dies auf eigene Gefahr tut: der Schiffer, der sich dadureh den Typhus zuzieht, hat dadurch nicht allein den Schaden, sondern kann auch eine Infektionsquelle für andere Personen bilden. Beim Baden im Fluß wird, besonders von Knaben, sicher mehr Wasser hinuntergeschluckt als man im allgemeinen annimmt; oft ist dies durch Aufwirbeln des FluBbodens besonders stark verunreinigt. In vielen Städten wird die Wäsche noch im FluB gewaschen; mir selbst ist ein Fall bekannt, wo noch in jüngster Zeit das Waschschiff direkt unterhalb der Ausmündung von Kanälen angelegt wurde. DaB ferner die üblen Gerüche, die nach Einleitung von Abwässern in Flüsse entstehen, zu Gesundheitsschädigungen AnlaB geben, ist bekannt; und es ist sehr erfreulich, daß sich die Rechtsprechung dieser Anschauung angeschlossen hat und daraus die Konsequenzen zieht. Aber auch ästhetische Bedenken verdienen Beachtung. Dabei kommt besonders der enge Zusammenhang zwischen Reinlichkeit und Gesundheit in Betracht. Die Erziehung des Volkes zur Reinlichkeit macht schon jetzt Mühe; wird auch die freie Natur zur Ablagerungsstätte des Unrates umgewandelt, so wirkt dies wie ein schlechtes Beispiel den Bemühungen entgegen. Es ist derselbe Grund, aus dem die Hygiene auch die Rauchbelästigung bekämpft: nicht weil dadurch Infektionskrankheiten übertragen oder verschlimmert würden, sondern weil sonst der Schmutz als etwas Unvermeidliches angesehen und nicht mehr bekämpft würde. - Daß der Staat übrigens manchmal die Verpflichtung hat, rein ästhetische Interessen zu schützen, hat Preußen durch sein Gesetz gegen die Verunstaltung landschaftlich hervorragender Gegenden rom 2. Juni 1903 bewiesen.

Trotz dieser so verschiedenen Gesichtspunkte lassen sich die Methoden zur Untersuchung von Flußverunreinigungen in vier Gruppen einteilen: 
Die erste Gruppe bilden die Methoden zur Untersuchung der Infektiosität. Es kann vorkommen, daB ein Gewässer keine Spur von Fäulnis darbietet, dab auch mit chemischen Methoden keine Verunreinigung nachgewiesen werden kann, und daß es doch imstande ist, Krankheiten hervorzurufen: z. B. ein klarer Bach, der durch den Urin eines Typhusrekonvaleszenten verunreinigt ist. Die Methoden, mit denen die Infektiosität nachgewiesen wird, müssen daher eine Gruppe für sich bilden. (S. 360.)

Die zweite Gruppe ist die der Methoden, die die vorhandene Zersetzung des Wassers nachweisen. Den Ausdruck Fäulnis möchte ich hier vermeiden, da man diesen auf sehr geringe Grade, die ohne Bildung übelriechender Gase verlaufen und nur chemisch nachweisbar sind, nicht anwenden könnte. In diese Gruppe fallen bedeutend mehr Methoden; auch werden durch sie eine größere Zahl von Übelständen nachgewiesen: nämlich alle diejenigen Zustände, die die Zersetzung zur Folge hat, Entziehung des Sauerstoffs einerseits, Bildung von giftigen oder die Sinne belästigenden, meist ekelerregenden Stoffen andererseits. Die Infektionsgefahr für den Menschen muß dabei nicht erhöht sein, im Gegenteil, je mehr das Gewässer verschmutzt ist, desto mehr wird es vom Trinken abschrecken - in dieser Hinsicht ist ein sehr geringer Grad von Verunreinigung gefährlicher. Sehon das Bewußtsein, daß in das Wasser „etwas Unrechtes" hineingekommen ist, hat diese Wirkung, wie unter anderem die Beobachtung dartut, daß seit der Einleitung der Abwässer der Zellulosefabriken in den Main die Schiffer weit unterhalb kein Mainwasser mehr genießen (13). Doch kommt bei stark verunreinigten Gewässern vielleicht die Gefahr der Übertragung durch die massenhaft schwärmenden Fliegen in Betracht. (S. 345.)

Die dritte Gruppe von Methoden dient zur Untersuchung der Zersetzungsfähigkeit eines Wassers, die erst dadurch gefährlich wird, daß sie zu den oben besprochenen Zuständen führt. An sich ist sie nicht zu beanstanden - ihre Folgen können z. B. hintangehalten werden, wenn das betreffende Wasser bald mit einer großen Menge reinen Wassers verdünnt wird. (S. 353.)

Eine vierte Gruppe umfabt die Methoden, die Stoffe nachweisen, welche als Indikatoren für den EinfluB der Abwässer dienen, obne direkt Zersetzung oder Zersetzungsfähigkeit anzuzeigen. Zwar werden auch durch die vorher erwähnten Methoden nicht immer die Stoffe bestimmt, die die Belästigungen hervorrufen: Wenn z. B. der Ammoniak später als Indikator für Zersetzung nachgewiesen wird, so bedeutet dies nicht, daß durch den Ammoniak der Gestank hervorgerufen wird, sondern nur, daB sich aus der Menge des Ammoniaks auf die Stärke des Geruches schließen läßt. 
Die Chloride dagegen stehen in keiner direkten Beziehung dazu und zeigen nur den Grad der Verdünnung an. (S. 349.)

Diese Gruppen genügen zur Einteilung bei der Untersuchung städtischer Abwässer. Bei der Cntersuchung mancher industrieller Abwässer kommen noch die Stoffe hinzu, die, ohne Zersetzung hervorzurufen, belästigen, z. B. die Salze der Abwässer der Kaliindustrie.

Nach dieser Einteilung soll nun der Wert der einzelnen Methoden für die Beurteilung von FluBverunreinigungen besprochen werden. Doch ist zunächst eine kurze Auseinandersetzung nötig, welche Anforderungen an eine Methode zu stellen sind, damit sie für gut gelten kann. Die Methoden sind fast nur quantitative, da die gesuchten Stoffe sämtlich schon in reinem FluBwasser vorkommen können - abgesehen von Arsen usw. und von saproben Abwässermikroorganismen und anderen nur mikroskopisch nachweisbaren Bestandteilen. Eine quantitativ arbeitende Methode darf aber als Ausschlag nicht eine einfache Steigerung anzeigen, sondern diese muB so beschaffen sein, daB man aus der Zunahme der Zahlen direkt auf die Zunahme der Stoffe schließen kann. Sie muB in einem stark verunreinigten Wasserlauf die in Betracht kommenden Stoffe mindestens in mehrfach gröBerer Menge angeben als in reinem Wasser. Je stärker dieser Ausschlag ist, desto besser ist sie, ceteris paribus.

Wie früher erwähnt, traf es sich günstig, daß zur Untersuchung sowohl reines als auch stark verunreinigtes Wasser kam; denn durch eine Vergleichung der Resultate konnte die Güte einer Methode leicht ermittelt werden. Am geringsten schien die Verunreinigung in der Lahn zu sein; gab also eine Methode bei Vergleichung des oberhalb und unterhalb Gießens geschöpften Lahnwassers noch einen kräftigen Ausschlag, so war sie als sehr gut anzusehen. Viel stärker war die Wieseck verunreinigt: hier mußte jede Methode unbedingt einen starken, das mehrfache betragenden Ausschlag ergeben, wenn sie als brauchbar gelten sollte.

I.

Methoden zur Untersuchung der Zersetzung. 1. Die erste Methode, die angewendet werden sollte, ist die Inspektion: in jedem Falle ist eine Besichtigung durch den Untersucher selbst nötig. - In der Wieseck wurden die am meisten Anstob erregenden Gegenstände, geformte Fäkalien, nicht gesehen; dagegen schwammen darauf 'Zündhölzer, Korke und ähnliches. - Einen besonders unangenehmen Eindruck machten die Schlammbrocken, die schon lange vor Einmündung des Stadtbaches darin auftraten, während sie oberhalb GieBens nicht vorkamen. Ferner flottierten darin Konglomerate von Abwässerpilzen, die im Sommer bis faustgroß wurden. Kleinere derartige Pilz- 
haufen werden manchmal von Laien für unverdaut abgegangene Sehnen gehalten. - Doch braucht das Vorkommen von Pilzfäden noch nieht auf stärkere Verunreinigung hinzudeuten: auch in reinem Flusse können Zersetzungsvorgänge vorkommen, die ihr Wachstum hervorrufen: so wurden sie im Winter in der Lahn an abgestorbenem Schilfe gefunden. Von Wichtigkeit ist die Bestimmung der Art. - Aus dem Boden aufsteigende Gasblasen bilden ebenfalls einen Indikator für sichtbare Verunreinigung, ebenso ein fettiger Überzug in verdächtigen Gewässern. Die letztere Erscheinung allerdings darf nicht falsch gedeutet werden. Sie wurde auch in der Lahn oberhalb GieBens beobachtet und zwar im Hochsommer, als die Entwicklung der Algen eine sehr starke war: dabei wurden auch kleine Gasbläschen gesehen, die selbstverständlich aus Sauerstoff bestanden. Besondere Wichtigkeit kommt der Farbe des Gewässers zu (über die Ursache der normalen Färbung vgl. besonders Forel [6]). Ein klare Farbe darf auch rom reinsten Flusse nicht verlangt werden. Ein farbloses Gewässer ist eine Wüste; besonders im Sommer bestimmen grüne Algen und braune Diatomeen die Farbe des Gewässers. Bei Hochwasser erhălt der Flub noch eine bestimmte, von der Beschaffenheit des durchstrōmten Geländes abhängige Farbe. Sogar schwarze Farbe kommt bei manchen Flüssen und Strömen in der Natur vor und ist dann bei fast vollständigem Fehlen suspendierter Bestandteile durch huminsaures Alkali bedingt (34). Doch ergeben sich darans für die Beurteilung der Verunreinigung nur geringe Schwierigkeiten. GröBer werden diese dadurch, dab eine Veränderung der Farbe eintreten kann, wenn sonst eine Verunreinigung nur in geringem Grade vorhanden ist, besonders, daB Farbstoffe schon in minimaler Menge Veränderungen hervorrufen. Daraus darf aber nicht geschlossen werden, daß in diesem Falle erst eine stärkere Verunreinigung zu beanstanden ist, sondern umgekehrt, daB eine Verunreinigung durch gefärbte Abwässer viel leichter eintritt als durch andere Stoffe und deshalb noch viel sorgfältiger zu rermeiden ist.

AuBer von der Eigenfarbe des Wassers ist die Farbe des Flusses abhängig von der scheinbaren Farbe (Oberflächenreflexion) und der Farbe des FluBbodens. Erstere bewirkt, daB der FluB die Farbe des reflektierten Körpers anzunehmen scheint, daß z. B., wenn am Ufer Bänme stehen, sein Wasser grün, andernfalls blau, grau usw., je nach der Farbe der Umgebung und des Fimmels aussehen kann. Die Farbe des FluBbodens spielt eine Rolle bei seichten Gewässern, und am Ufer tieferer Flüsse. Ihre Mitwirkung ist teilweise von der Helligkeit abhängig, indem in manchen Fällen nur intensives Licht auf den Grund und zurück ins Auge zu dringen vermag, wobei sich der Farbe des Wassers die Farbe des Bodens beimischt - während weniger helles Licht nicht bis auf den 
Grund dringt und infolgedessen nur die Farbe des Wassers zurückbringt. Daher mag es kommen, daß das Wasser eines mäßig tiefen Flusses ron einer Brücke aus gesehen, im Reflex der Brücke eine andere Farbe haben kann, als direkt daneben; das von der Unterseite des Brückenbogens reflektierte Licht ist nicht vermögend, bis auf den Grund zu dringen das Wasser erseheint hier rein grün; daneben fällt das Licht rom Himmel direkt ein - daher hier eine Beimischung brauner Farbe.

In unseren Untersuchungen war die Farbe der Lahn von allen drei Faktoren abhängig. Die Eigenfarbe war im Hochsommer grün, bei Hochwasser gelbbraun, in dem gröBten Teile des Jahres fehlte sie. Die scheinbare Farbe spielte eine groBe Rolle; die Farbe des FluBbodens (braun), kam besonders unterhalb GieBens in Betracht, da die Ufer hier nicht so steil waren wie oberhalb. Bei der Wieseck oberhalb Gießens konnte man von einer bestimmten Färbung meist nicht sprechen; unterhalb GieBens spielte allein die in dickerer Schicht schwarzgraue Eigenfarbe eine Rolle.

DaB die Resultate der Untersuchung durch die Inspektion gute sind, ist selbstverständlich; manche Beanstandungen treten nur deshalb ein, weil die Vorgänge im FluB zu einer Belästigung der Sinne geführt haben; die Inspelition ist daher nicht nur als Methode zur Untersuchung der Ubelstände, sondern auch als Prüfstein anderer Methoden aufzufassen.

2. Über die Beurteilung nach Aussehen des entnommenen Wassers, speziell dessen Durchsichtigkeit, ist im vorhergehenden schon einiges gesagt. Sie bietet bei subjektiver Beurteilung (stark - schwach opaleszierend usw.; stärkerer - geringerer Bodensatz) einen sehr weiten Spielraum. Zur objektiven Prüfung kommen zwei Methoden in Betracht: die Bestimmung der Durchlesbarkeit und die Bestimmung der Lichtabsorption. Schon früher (5) wurde auseinandergesetzt, welche Nachteile erstere hat. Vor allem pflegen sich die gröberen Bestandteile in den unteren Schichten des Zylinders anzusammeln; läßt man das Wasser unten ab, so werden sie vor allem mitgerissen und das Resultat erscheint zu günstig; gießt man oben $a b$, so wird es zu ungünstig. Man kann sich zwar dadurch helfen, daß man nicht durch Ablassen, sondern durch Zugießen die Durchlesbarkeit des Wassers zu bestimmen sucht; doch kann auch dann durch das Vorhandensein gröberer Partikelchen die Untersuchung gestört werden, da diese nur einzelne Buchstaben verdecken und somit vernachlässigt werden, da die Buchstaben von dem Lesenden aus dem Zusammenhang ergänzt werden. Außerdem ist stets gleichmäBige Beleuchtung nötig, wie sie nur in einem künstlich erhellten Zimmer vorhanden sein kann; dann muB der Untersuchende bei jedem Versuche seine Augen erst an das künstliche Licht gewöhnen. Werden alle diese MaBregeln eingehalten, so ist das Resultat zwar für denselben Untersucher konstant, aber bei 
verschiedenen Untersuchern kann es differieren. Daher verdient die ganz objektive Methode der Bestimmung der Lichtabsorption den Vorzug. In den vorliegenden Tabellen ist nicht der Absorptionskoeffizient angegeben, sondern der Prozentsatz des Lichtes, das von einer $5^{\mathrm{cm}}$ dicken Schicht des zu untersuchenden Wassers absorbiert wurde. $5^{\mathrm{cm}}$ erwies sich als am geeignetsten; stark verschmutzte Wässer können natürlich vorher verdünnt werden.

Die Untersuchungen wurden eine Zeitlang nach beiden Methoden vorgenommen, und auch dabei ergab sich, daß die Methode der Lichtabsorption die genauere ist, da hierbei der Abstand der Kurve des Wassers der Wieseck unterhalb GieBens von den anderen bedeutend gröBer ist, was mit den anderweitig erhobenen Befunden übereinstimmt.

Die Resultate, die mit der Bestimmung der Lichtabsorption erhalten wurden, sind sehr gute. Die Methode gibt einen starken Ausschlag bei Vergleichung der reinen und unreinen Wässer, der manchmal das fünffache, meist bedeutend mehr als das doppelte beträgt und, was die Hauptsache ist, dem subjektiven Eindruck, den der Untersucher hat, parallel geht. Ja, sie ist nicht nur objektiver als die Beurteilung mit dem Auge, sondern dieser auch noch überlegen: das beweist ein Vergleich des Lahnwassers oberhalb und unterhalb Gießens, wobei mit dem Auge oft keine Veränderung nachgewiesen werden konnte, während die Vermehrung der Lichtabsorption $1 / 3$ bis $1 / 2$, oft noch mehr betrug.

Es war von Interesse zu untersuchen, in welchen Beziehungen die dabei erhaltenen Zahlen zu der sichtbaren Verunreinigung eines Flusses ständen, bei welcher Trübung z. B. bestimmte Gegenstände noch oder nicht mehr im Flusse erkannt werden könnten. Ohne weiteres ist dies nicht möglich: die Durchsichtigkeit eines Flusses ist nicht allein von der Durchsichtigkeit seines Wassers abhängig, sondern auch von der Art und Farbe der Gegenstände, der Geschwindigkeit der Strömung, der Helligkeit, der Wellenbewegung. Immerhin mögen hier einige Untersuchungen angeführt sein, die im Laufe der letzten Monate vorgenommen wurden. Die Oberfläche des Wassers. war bei allen ziemlich glatt.

a) 13. IV. 05. Lichtabsorption 15.9 Prozent. Wasser ziemlich klar. Sonne. Tiefe des Wassers $40^{\mathrm{cm}}$. Geschwindigkeit $34^{\mathrm{m}}$ pro Minute: Grund überall zu sehen.

b) 13. IV. Lichtabsorption 19.8 Prozent. Farbe gelbbraun. Geschwindigkeit $20^{\mathrm{m}}$ pro Minute: Gras in $23^{\mathrm{cm}}$ Tiefe noch zu sehen.

c) 18. V. Lichtabsorption 6.2 Prozent. Wasser klar. Sonne. Geschwindigkeit $30^{\mathrm{m}}$ pro Minute: in $34^{\mathrm{cm}}$ Tiefe weiBe Steinchen von ca. $1 \mathrm{~cm}$ Durchmesser noch gut sichtbar; in $27 \mathrm{~cm}$ Tiefe Sand in Einzelheiten schlecht sichtbar. 
d) 18. V. Lichtabsorption 9 Prozent. Wasser klar. Sonne. Geschwindigkeit $29^{\mathrm{m}}$ pro Minute: in eiuer Tiefe von $45^{\mathrm{cm}}$ sind große Steine (10 ${ }^{\mathrm{mm}}$ Durchmesser) nur schlecht $\mathrm{zu}$ erkennen.

e) 21. VI. Lichtabsorption 25.7 Prozent; Wasser trüb. Sonne. Geschwindigkeit $12^{\mathrm{m}}$ pro Minute: flottierendes Gras in 11 und $13 \mathrm{~cm}$ Tiefe nur undeutlich, in $18^{\mathrm{cm}}$ Tiefe kaum noch zu sehen.

f) 21. VI. Lichtabsorption 21.3 Prozent. Wasser besonders durch braune Partikelchen getrübt. Sonne. Geschwindigkeit $20^{\mathrm{m}}$ pro Minute: in $28^{\mathrm{cm}}$ Tiefe sind groBe Steine (20 $\mathrm{cm}$ Durchmesser) eben noch zu sehen.

3. Ànliches, wie von der sichtbaren Verunreinigung, gilt auch von dem Geruch. Seine Abschätzung ist nicht so sehr als Methode zu betrachten, wie als Prüfstein der Methoden. Wahrgenommen wurde er nur im Sommer an der Wieseck in GieBen. Die Prüfung des Geruches des entnommenen Wassers hat kaum Vorteile; am Bache war er meist stärker. Er wechselt übrigens nach rerschiedenen Umständen: Wind vermindert ihn, hohe Temperatur vermehrt ihn. In der Nacht wird er deutlicher wahrgenommen, da dann die Sinne für Eindrücke empfänglicher sind. Auch die Umgebung ist von 'Wichtigkeit, indem er an Stellen, wo sich die Bäche in ihren Untergrund tief eingeschnitten haben, deutlicher zu bemerken ist. Auch die Art des Geruches ist in Betracht zu ziehen, denn auch reine, langsam fließende Bäche können im Sommer einen schwachen Geruch entwickeln.

4. Schwefelwasserstoff wurde nur einmal gefunden; er fehlte zu einer Zeit, wo der Zustand der Wieseck schon stark AnstoB erregen muBte. Sein Fehlen läBt also nicht den Schluß zu, daB ein Gewässer nicht verunreinigt ist; sein Vorhandensein beweist unerträgliche Zustände. Andere Untersucher scheinen ihn selten gefunden zu haben; z. B. Lehmann in der stark verunreinigten Saale bei Hof (35, S. 171-175).

5. Im Gegensatz dazu findet sich Ammoniak auch in reinem FluBwasser in sehr geringer Menge, besonders im Winter. In größerer Menge wurde es nur in der verunreinigten Wieseck nachgewiesen und zwar in um so größerer Menge, je stärker die Verunreinigung war. Gleichzeitig mit der Zunahme des Ammoniaks traten auch die Belästigungen durch den Geruch auf und schwankten ungefähr mit seiner Zu- und Abnahme. Da auBerdem beide aus demselben Material - stickstoffhaltige Substanzen - entstehen, so möchte ich annehmen, daB der Ammoniak speziell für das Auftreten und die Stärke von Gestank in verunreinigten Gewässern den besten Indikator abgibt.

Der Ausschlag, den die Methode gibt, ist stark: in der verunreinigten Wieseck schwanken die Zahlen ron Bruchteilen eines Milligramm bis zu 
$5.33^{\mathrm{mg}}$; bei Vergleich mit der Lahn ergeben sich natürlich noch gröBere Differenzen, da hier die untere Grenze bei 0 liegt. Die Methode der quantitativen Ammoniakbestimmung leistet also alles, was von einer guten Methode verlangt werden kann; ihre Anwendung dürfte daher bei der Untersuchung von FluBverunreinigungen unbedingt nötig sein.

Ähnliche vorzügliche Resultate lassen sich bei Durchsicht fast der gesamten Literatur über FluBverunreinigung erkennen. Die englische Rivers Pollution-Kommission erhielt damit so hohe Ausschläge wie mit keiner anderen Methode: so stieg z. B. der Ammoniakgehalt des Irwell von 0.04 auf $3.71^{\mathrm{mg}}$ pro Liter (36, S. 414), der des Bradford Beck in Bradford von 1.05 auf 12.2 (S. 412), der des Sankeybaches von 0.1 auf 3.5 (37, S. 286). Der Gehalt der Oder in Breslau steigt nach Hulwa (16, S. 222) von 0.07 auf 1.124 , also um das 16 fache; der Gehalt einiger Bäche bei Freiburg von 0 auf $35 \mathrm{mg}$ in 1 Liter (38, S. 44) (da letztere Zahl ganz enorm ist und höchstens von Kanalinhalt erreicht wird, möchte ich annehmen, daB in der ganzen Rubrik durch einen Druckfehler das Komma um eine Stelle verrückt worden ist. Die Zahlen würden dann. meiner Erfahrung und den in der Literatur vorhandenen Zahlen nach eher den geschilderten Zuständen entsprechen). Auch in der Limmat (24) zeigt sich oft eine Zunahme um mehr als das 10 fache, in der Spree um das 3- bis 4 fache (25). Ahnliche günstige Resultate sind da zu vermuten, wo eine Zunahme von "Spur" auf „stark" bzw. "sehr stark" konstatiert wird, wie in der Leine bei Göttingen (15, S. 117), der Spree 1896 (19), besonders im Sommer. Wenigstens eine geringe Zunahme zeigt sich in der Lahn bei Marburg (26) und in dem Pregel. Die Probe versagt erst in großen Strömen.

Es soll schlieBlich noch versucht werden, anzugeben, bei welchem Ammoniakgehalt gleichzeitig Geruchsbelästigungen vorhanden sein können. Wie oben auseinandergesetzt wurde, sind letztere allerdings noch von anderen Faktoren abhängig. Die Grenze dürfte nahe bei $1^{\mathrm{mg}}$ in 1 Liter, eher darunter als darüber liegen. Wenigstens bezeichnet Preu (18) den Geruch eines Wassers mit 3 bis $4^{\mathrm{mg}}$ als ,faulig, bzw. ,etwas faulig“; Stahl (38, S. 44, Tabelle, unter Berücksichtigung obiger Korrektur), den von 0.45 bis $3.25^{\mathrm{mg}}$ als muffig, von $3.5^{\mathrm{mg}}$ als stinkend (16, S. 222), den von $1.12^{\mathrm{mg}}$ als faulig, bzw. fremdartig, ein Wasser mit $0.48^{\mathrm{mg}}$ als geruchlos. Der Stadtgraben von Güstrow, der sich im Zustand hochgradigster Zersetzung befand, hatte einen Gehalt von $3 \cdot 17^{\mathrm{mg}}$ in 1 Liter (59). In unseren Untersuchungen fehlte der Geruch bei $1.13^{\mathrm{mg}}$, war jedoch ein andermal bei $0.9^{\mathrm{mg}}$ schwach moderig, ebenso bei $1.17^{\mathrm{mg}}$, bei $1.82 \mathrm{mg}$ schwach, von $3 \cdot 25^{\mathrm{mg}}$ an stinkend. 
6. Salpetrige Säure wurde nicht quantitativ bestimmt; einen Anhaltspunkt für ihre Menge gab der Umstand, ob sie schon mit Jodzinkstärke oder erst mit dem Erdmannschen Reagens nachweisbar war, ferner die bei letzterer Probe erhaltene Farbe. Sie wurde auch in reinem Wasser nachgewiesen, und zwar im Sommer in einer Menge, die die im Winter in den verschmutzten Gewässern gefundene übertraf. - Vielleicht könnte ihre quantitative Bestimmung unter kritischer Verwertung der Zahlen brauchbare Resultate ergeben. - In anderen Flüssen zeigt sie fast stets bei Verunreinigung eine Zunahme, doch fehlen quantitative Angaben.

7. Salpetersäure wurde nur einmal nachgewiesen; ihre Zunahme ist auch in anderen Gewässern bei Verschmutzung gering. Eine Untersuchung darauf dürfte also höchstens bezüglich der Selbstreinigung von Bedeutung sein.

8. Dagegen ist die Bestimmung des Gehaltes an freiem Sauerstoff sehr wertvoll. Zwar ist auch in reinem Wasser im Winter oft ein beträchtliches Defizit nachzuweisen; doch ist es in dem reinsten Wasser, der Lahn oberhalb Gießens, am geringsten; am höchsten, meist bedeutend höher als in allen anderen, in der Wieseck unterhalb GieBens. Noch größer sind die Unterschiede im Sommer, und zwar erhält man das beste Bild, wenn man nicht nur die Höhe berücksichtigt, sondern auch die Umstände, unter denen Steigen und Fallen eintritt. Die Differenzen sind zwischen der Lahn oberhalb und der Wieseck unterhalb GieBens im Juli 04 und Juni 05 ganz auBerordentlich - auf der einen Seite ein ÜberschuB von 42 Prozent, 61 Prozent und $40 \cdot 41$ Prozent, auf der anderen Seite ein Defizit von 81 Prozent, 95 Prozent und 65.3 Prozent. Diese Differenzen, bedingt auf der einen Seite durch Produktion, auf der anderen Seite durch Zehrung, treten bei ungefähr gleicher Temperaturerhöhung auf und sind nur abhängig vom Schmutzgehalt des Wassers. Man kann daher für die vorliegenden Untersuchungen sagen: In reinen Gewässern nimmt der Sauerstoffgehalt bei steigender Temperatur zu, in unreinen ab. Sollte sich diese Regel auch für andere Gewässer bestätigen, so wäre damit ein wichtiger Anhaltspunkt für die Beurteilung von Flußwasser gefunden.

Die vorhandene Literatur scheint für seine Richtigkeit zu sprechen. So nahm in der Spree in Berlin der Sauerstoffgehalt im Sommer meist stärker ab als im Winter (11); da trotz der langsamen Strömung ein Sauerstoffüberschub niemals nachweisbar war, so dürfte sie wohl an der Grenze dessen sein, was sie vertragen kann. - Die Verunreinigung einer Stelle des Schweriner Sees ließ sich sehr gut durch die Sauerstoff bestim- 
mung nachweisen (40). Der Sauerstoffgehalt der Regnitz nimmt unterhalb Erlangens stets ab (18). Im Hochsommer wurde nicht untersucht. Dagegen zeigt die nur sehr gering verunreinigte Elbe in Dresden im August sogar eine geringe Zunahme (41, S. 473).

9. Die suspendierten Bestandteile haben eine doppelte Bedeutung: erstens als Hauptursache der sichtbaren Verunreinigung, zweitens als Träger von in Zersetzung begriffenen Stoffen. Letztere sind allerdings nur in geringer Menge darin enthalten. Auf ihre absolute Menge ist kein Gewicht zu legen: wie erwähnt ist sie in gröBeren Flüssen am gröBten zur Zeit des Hochwassers. Ihre Bedeutung wird aber da groB, wo sie nicht durch Regen und Hochwasser aufgewirbelt oder vom Ufer losgerissen sind, sondern wo sie auch in trockenen Perioden in langsam flieBenden Gewässern in grober Menge vorkommen. Sie sind dann ein sehr guter Indikator für stattfindende Zersetzung, besonders wenn sie chemisch untersucht werden (14). Für sichtbare Verunreinigung wären sie es nur dann, wenn ihr Volumen, nicht ihr Gewicht, bestimmt werden könnte; denn beim Trocknen wird ersteres gerade bei den so wichtigen organischen Bestandteilen (Pilzfäden usw.) in ganz unverhältnismäBiger Weise reduziert. Ihre Bedeutung in dieser Hinsicht ist auch deshalb gering, weil es bessere Methoden zu deren Bestimmung gibt. - In der mir zugänglichen Literatur finden sich wenige Angaben über starkes Steigen der suspendierten Bestandteile in verunreinigten Flüssen; ziemlich hohe Zahlen haben Dirksen und Spitta erhalten (19), wesentlich geringer sind die von Preu (18).

10. Die Reaktion des Wassers war stets alkalisch. Auf eine genauere Bestimmung wurde nicht geachtet. Sie dürfte bei industriellen Abwässern eine größere Rolle spielen als bei städtischen.

11. Die Bestimmung der Keimzahl ist ebenfalls unter die Methoden zur Untersuchung der Zersetzung, nicht unter die zur Untersuchung der Infektiosität $\mathrm{zu}$ rechnen. Mit letzterer steht sie nur in oberflächlichem Zusammenhang, indem ein Wasser, das Träger von Infektionskeimen ist, meist überhaupt viele Bakterien enthält. Ein offenes Wasser ist stets dem Hineingelangen von Keimen ausgesetzt und es kommt nur auf die Menge der zersetzungsfähigen Stoffe an, wie schnell sie sich darin vermehren können. Es wäre daher auch falsch, bei der bakteriologischen Untersuchung die Platten in den Brütschrank zu stellen, sondern sie müssen bei der Temperatur aufbewahrt werden, die in der Natur in derartigen Gewässern höchstens vorzukommen pflegt; die üblichen $\mathbf{2 3}^{\circ}$ dürften das richtige sein. Doch ist auch die GröBe der Zersetzung nicht immer in erster Linie für die Keimzahl maßgebend, sondern in reinen Gewässern die 
Wassermenge. In einem Flusse läßt also ein Ansteigen der Keimzahl nur dann auf Zersetzungsvorgänge schließen, wenn der Pegelstand gleich bleibt oder sinkt.

Bei richtiger Verwertung ist die Bedeutung dieser Methode eine sehr große. Dazu kommt noch, daß die Ausschläge, die sie gibt, außerordentlich hohe sind, so hoch, wie sie andere nicht im entferntesten geben. Die gröBten Differenzen sind 132 und 156000 Keime (beide an demselben Tage). Besonders für die Beurteilung der Verunreinigung der Lahn gibt es keine Methode, die dieser an die Seite gestellt werden kann. Die Differenzen oberhalb und unterbalb Gießens sind an einem Tage 132:10400, an einem anderen 686:10520. - Es wäre merkwürdig, wenn eine Methode, die so starke Ausschläge gibt, nicht auch mit Fehlerquellen behaftet wäre. Die wichtigste ist die, daß die Keime im Wasser nicht gleichmäBig verteilt sind. Sehr groB kann jedoch dieser Fehler nicht sein; wie erwähnt, wurden an beiden Ufern der Lahn unterhalb Gießens stets ungefähr dieselbe Zahl gefunden, und im Frühjahr, wenn die Wieseck ohne Einfluß ist, differieren die Zahlen oberhalb und unterhalb GieBens um weniger als die Hälfte. Dies ist ein Fehler, der einem Ausschlag bis zum 1200 fachen gegenüber kaum in Betracht kommt.

Unser Resultat, daß die Methode der Keimzählung die stärksten Ausschläge bei der Prüfung auf Verunreinigung gibt, steht im Einklang mit sämtlichen Angaben, die ich in der Literatur auffinden konnte. Diese Einstimmigkeit läßt es überflüssig erscheinen, die einzelnen Stimmen hier anzuführen. Leider lassen sich die absoluten Zahlen der einzelnen Autoren nicht miteinander vergleichen, da die Zählung unter zu verschiedenen Bedingungen (Nährboden, Beobachtungsdauer) vorgenommen wurde. Es wäre sehr zu wünschen, daß diesem Übelstande durch ein allgemeines Übereinkommen abgeholfen würde. Als Nährboden dürfte sich die von Prall (42) angegebene Agargelatine wohl allgemein eingeführt haben. Als Tag der Zählung möchte ich nach meinen Erfahrungen schon den zweiten Tag empfehlen. Sämtliche Keime zur Entwicklung zu bringen, wird ja doch nicht möglich sein, und an späteren Tagen kommt es oft vor, daß sich Keime, die andere an der Entwicklung verhindern, über den größten Teil der Platte ausgebreitet haben und zu einer Fehlerquelle werden, der nur durch frühere Zählung abgeholfen werden kann.

II.

1. Von Methoden zur Untersuchung auf Zersetzungsfähigkeit scheint a priori die Bestimmung der "Fäulnisfähigkeit" in stehengelassenem Wasser die einfachste zu sein. Diese Annahme wird Zeitschr. f. Hygiene. LIII. 
durch unsere Untersuchungen nicht bestätigt. Geruch konnte nur in Wasser lronstatiert werden, das ihn schon vorher zeigte; auch verschwand er nach kurzer Zeit. Schwarzer Bodensatz bildete sich nur zweimal. Sonst bestand der ganze Unterschied darin, daß der braune Bodensatz in stark verschmutztem Wasser stärker wurde als in reinem. Vielleicht sind die Resultate besser, wenn man 1 Liter und mehr nimmt, wie es König (43, S. 605-6) und Proskauer (44, S. 576) empfehlen; leider konnten von uns größere Mengen nicht transportiert werden.

2. Die Oxydierbarkeit ist, wie erwähnt, abhängig von der Wassermenge. DaB sie eine Probe auf Zersetzungsfähigkeit, nicht auf Zersetzung ist, beweisen die Untersuchungen über Reinigung der Abwässer, bei denen die Bestimmung der Oxydierbarkeit ein sehr gutes Reagens auf Fäulnisfähigkeit bildet. Sie nimmt in der Laln bei niederem Wasserstand durch Einfluß der Wieseck meist merklich zu, ist also zur Erkennung einer schwachen FluBverunreinigung noch brauchbar. In der Wieseck beträgt die Zunahme meist 50 Prozent, manchmal das Doppelte, einmal sogar noch mehr. Das mag ziemlich viel erscheinen; wenn man aber bedenkt, was oben gesagt wurde über die Anforderungen, die an eine quantitativ arbeitende Methode zu stellen sind, so sieht man, daB ihre Leistungen doch recht geringe sind. Die Wieseck z. B. kommt nach Gießen als relativ reiner Bach und verläBt es im Sommer als stinkendes Gewässer, in dem Schlammbrocken und Pilzfäden massenhaft schwimmen. Sollte man diese mit den Sinnen wahrnehmbaren Differenzen in Zahlen ausdrücken, so müBte man eine Veruureinigung um mindestens das 10 fache angeben. Solche und noch höhere Differenzen finden sich auch bei der Benutzung anderer Methoden, z. B. der Bestimmung des Ammoniaks; der Keimzahl; wenn sie bei der Bestimmung der Oxydierbarkeit fehlen, so folgt daraus, daB sie Ungenügendes leistet. - Auch aus der Literatur geht dasselbe hervor. So hatte die Nebel oberhalb Güstrow einen Sauerstoffverbrauch von $6.3^{\mathrm{mg}}$ (an einem anderen Tage 5.4 $\mathrm{mg}$ ); der Stadtgraben, in den sich fast die gesamten Abwässer der Stadt ergießen und der sich im Zustand hochgradigster Zersetzung befand, einen solchen von $9 \cdot 3 \mathrm{mg}$; die Nebel, nachdem sie dieses Wasser aufgenommen hatte, an dem betreffenden Ufer eine solche von $6.5 \mathrm{mg}$, am anderen ron $6.1(5 \cdot 8)^{\mathrm{mg}}(39)$. Der Sauerstoffbedarf der Regnitz steigt an einer Stelle, wo sich das Kanalwasser noch nicht vollständig mit ihr gemischt hat, nur von 7.8 auf 16.8 (bzw. von 6.04 auf 18.1); der Geruch wird an letzterer Stelle als ,faulig" bezeichnet, während oberhalb keiner vorhanden war (18). In der Spree nimmt nach Frank (zitiert nach 16, S. 227) im Sommer die Oxydierbarkeit von 5.03 auf $5.4 \mathrm{zu}$, der Ammoniakgehalt von 0.09 auf 0.93 , die Keimzahl von 6771 auf 451826 ; nach Dirksen und Spitta (19, 
S. 118) Von 6.6 auf 7.1. Die Oder unmittelbar vor Eintritt in die Stadt Breslau hat einen Sauerstoff bedarf von $4.22 \mathrm{mg}$, in einiger Entfernung unterhalb der Kanäle, wo die Mischung noch nicht erfolgt ist (Geruch meist faulig) von $5.77 \mathrm{mg}$ (Zunahme des Ammoniak von 0.076 auf $1.12 \mathrm{mg}$ ) (16, S. 222). Auch in der Limmat ist die Zunahme meist gering, während der Ammoniakgehalt oft um das 10 fache steigt. Etwas gröBer ist sie in der Isar bei München (28 und 45, S. 278); dagegen ist ein Anstieg in der Lahn bei Marburg (von 1.6 auf 1.7), in der Elbe bei Dresden (von 8.02 auf 8.06) und im Pregel bei Königsberg kaum zu konstatieren, noch weniger im Rhein. - Größer scheint der Ausschlag zu sein, wenn industrielle Abwässer stark in Betracht kommen; so steigt die Oxydierbarkeit in der Saale bei Hof von 5.7 auf 18.1 (35, S. 109) bzw. von 3.9 auf 29.7 (S. 116) wobei auf eine einzige Fabrik 7.4 (bzw. 20.4) der Zunahme trafen.

Ist somit die relative Zunahme der oxydierbaren Substanzen kein gutes Merkmal zur Beurteilung von Flußverunreinigungen, so ist es der absolute Gehalt des Wassers daran noch viel weniger. Darüber, wie viel oxydierbare Substanzen ein Flußwasser überhaupt enthalten darf, scheint noch kein Übereinkommen zu herrschen: doch ist nach Du n bar (46, S. 200) ein Abwasser, das nur 4 bis $7.5^{\mathrm{mg}}$ Sauerstoff verbraucht, der stinkenden Fäulnis nicht mehr zugänglich. - Sehen wir zunächst, wieviel der Gehalt der Flüsse vor dem Passieren der betreffenden Städte betrug. In manchen Flüssen ist er sehr gering; so betrug er in der Isar 1887/89:0.76 bis $2.04^{\mathrm{mg}} 0$ in 1 Liter $(28, \mathrm{~S} .43), 1901: 1.5$ bis $2^{\mathrm{mg}}(45, \mathrm{~S} .278)$; in der Limmat 1.0 bis $1.66(24)$, in der Lahn oberhalb Marburgs 1.2 bis $2 \cdot 35$, in verschiedenen Bächen bei Freiburg in ihrem obersten Laufe 1.4 bis 3.0 (hier wurde schon direkt vor der Brunnenstube eine Zunahme nachgewiesen) und im Rhein bei Mainz 1.26 bis $\mathbf{5 . 0}(\mathbf{2 0}, \mathrm{S} . \mathbf{2 8 3})$. Hōher ist er in der Oder: $4 \cdot 22$; in der Spree 1886/7: 3.4 bis $8 \cdot 5$ (25, S. 377), 1896: $5 \cdot 25$ bis $8.5(19)$ in der Saale bei Hof 3.9 bis 5.7 ; in der Nebel 5.4 bis 6.3 ; in der Kinzig 2.75 bis $6.0(13$, S. 75) und in der Lahn oberhalb GieBens: 3.1 bis 7.8. Hoch ist er in der Elbe bei Dresden: 8.02, und im Main bei Hanau: 9.5. Manche dieser Flüsse können dort allerdings nicht mehr als rein gelten. - Ganz auffallend sind die Schwankungen in der Regnitz: $3 \cdot 85$ bis $\mathbf{1 7 . 9}$, und besonders in der Mosel: $\mathbf{5} \cdot 1$ bis 47.4 .

Wurden diese Flüsse durch städtische Abwässer verunreinigt, so nahm, wie erwähnt, die Oxydierbarkeit meist $\mathrm{zu}$; doch ist es unmöglich, aus den Zahlen auf die dort herrschenden Zustände zu schließen. Allerdings beweisen Zahlen, wie 29.7 (35) und 43.3 (47, S. 355) wohl stets hochgradige Verunreinigungen; doch zeigt umgekehrt die Oder schon bei einem Gehalt von 5.77 fauligen Geruch; der Stadtgraben von Güstrow 
besitzt bei hochgradiger Zersetzung eine Oxydierbarkeit von 9.3 und die Wieseck in einem ähnlichen Zustande von 14.4. Dagegen steigt die Oxydierbarkeit der Regnitz bis 19.9 , ohne daß ein Geruch nachweisbar wäre, und Zahlen, wie die eben genannten, sind oben bei den „reinen" Flüssen mehrfach überschritten.

Daraus folgt, daß die absoluten Zahlen der Oxydierbarkeit für die Beurteilung der Verschmutzung eines Flusses nicht maßgebend sind, so wenig, wie dies bei der Beurteilung der Abwässer der F'all sein kann, wie dies Dunbar kürzlich (46) auseinandergesetzt hat. Während aber hier das Verhältnis zwischen dem unreinen und dem gereinigten $\mathrm{Ab}$ wasser einen guten MaBstab zur Beurteilung abgibt, fehlt dieser bei Flußverunreinigungen: wenn auch stets eine Zunahme der Oxydierbarkeit stattfindet, so geht diese ibr doch nicht in ähnlicher Weise parallel wie z. B. die des Ammoniaks und der Keimzahl, sondern bleibt weit dahinter zurück. Man darf daher nicht, wie es manchmal geschieht, eine Flußverunreinigung als gering ansehen ,weil die Zunahme der oxydierbaren Substanzen nur 50 Prozent beträgt", sondern man sollte sich in einem solchen Falle lieber auf die Beurteilung durch die Sinne und auf andere Methoden verlassen und sich eventuell damit bescheiden, daß die Methode der Oxydierbarkeit nicht genügend ist, um eine Beurteilung der Verunreinigung zu ermöglichen.

3. Die Methode der Sauerstoffzehrung wurde von Spitta angegeben; sie ist noch . verhältnismäßig neu und vielleicht deshalb noch mit einigen Fehlern behaftet. Einer der unangenehmsten ist der, daB sich im Winter im Zimmer das kalte Wasser ausdehnt und mit großer Gewalt den Stöpsel herausdrückt. - Das Prinzip der Methode ist, daB durch die Wirkung der Bakterien der freie Sauerstoff des Wassers aufgezehrt wird, und zwar soll die Sauerstoffabnahme der Menge der verunreinigenden Stoffe entsprechen. Das Resultat ist also abhängig von den dabei oxydierbaren Stoffen, der Sauerstoffmenge, der Temperatur, der Keimzahl und den oxydierenden Fähigkeiten der vorhandenen Bakterien. - Auch durch die groBe Zahl der mitwirkenden Faktoren sind Mißstände vorhanden. Ein Wasser, das stark verschmutzt ist, enthält schon in der Natur wenig Sauerstoff; die Schnelligkeit der Zehrung ist zwar in diesem Falle die gleiche (11, S. 245), doch wird der Nullpunkt schon nach wenigen Stunden erreicht. Um wenigstens zu sehen, nach wie langer Zeit dies eintritt, wurde Methylenblau oder Neutralrot zu Kontrollen zugesetzt, doch zeigte es sich, daß die Entfärbung erst einige Zeit nach völligem Verschwinden des Sauerstoffs eintritt. - Bessere Resultate gibt ein Verfahren, das auch den erstgenannten Übelstand rermeidet: Das Wasser wird auf $23^{\circ} \mathrm{er}$ wärmt, dann kräftig mit Luft geschüttelt und nun die Hälfte sofort, die 
andere Hälfte nach dem Stehenlassen untersucht. - Die in den Tabellen XII und XIII angegebenen Resultate sind auf diese Weise gewonnen. Eine andere Modifikation des Verfahrens hat Preu angegeben (18, S. 47): er füllt die Flaschen nur teilweise mit Wasser, und bestimmt nach einiger Zeit den Sauerstoffgehalt der überstehenden Luft. Das Verfahren scheint zwar den Vorteil zu haben, daB man die Proben längere Zeit stehen lassen kann, ohne daB der Sauerstoff ganz aufgezehrt wird, doch sind die Differenzen zwischen Schmutzwasser und reinem Wasser viel geringere als nach der alten Methode.

Uberblickt man die in den Tabellen verzeichneten Resultate, so findet man, daB die Sauerstoffzehrung in der Wieseck unterhalb Gießens bedeutend höher ist als in den übrigen Wässern. Ferner ist fast stets eine Zunahme in der Lahn unterhalb der Einmündung der Gießener Abwässer zu konstatieren. In reinem Wasser ist die gefundene Abnahme des Sauerstoffs in der Flasche meist sehr gering, manchmal schien sogar eine Zunahme einzutreten; dies kann dadurch erklärt werden, daß der Sauerstoff im Flusse nicht gleichmäßig verteilt ist.

Die Größe der Zunahme der Sauerstoffzehrung in der Wieseck innerhalb GieBens ist eine bedeutende; an einem Tage beträgt sie das 3.7 fache, an anderen das 4 fache, das 14 fache, das 35 fache, an den Tagen, wo wegen des niedrigen Standes der Wieseck am meisten zu erwarten war, ist eine quantitative Bestimmung überhaupt nicht möglich, da die Zehrung $\mathrm{zu}$ schnell vor sich ging.

Daraus ist zu schlieBen, daß die Methode trotz allem eine gute ist. Es wäre nur wünschenswert, daß die Grenzen der Fehlerquellen besser bekannt wären, und daB mehr absolute Zahlen zur Verfügung stünden, aus denen man ersehen kann, bei welcher Zehrung ein Gewässer als verunreinigt zu gelten hat. Was die Zeit betrifft, so wird es am günstigsten sein, verschiedene Proben 1, 2 und 7 Tage stehen zu lassen; die an verschiedenen Tagen erhaltenen Werte dürfen allerdings nicht untereinander verglichen werden. Betreffs der Verwertung der erhaltenen Zahlen läBt sich aus unseren Resultaten schließen, daß die Grenze der Verunreinigung etwa bei 0.08 pro Stunde liegt; denn diese Zahl wurde in reinem Wasser nie erreicht, in unreinem stets überschritten. In der Spree beträgt sie bei rersehieden langer Beobachtungszeit 0.011 bis 0.07 , bei Speien der Notauslässe $\mathbf{0 . 2 5 5}$; in der Regnitz, allerdings mit der modifizierten Hethode ermittelt, 0.15 bis 0.64 (bei Abwasser war die höchste Zahl nur 2.82).

4. Der organisch gebundene Stickstoff wurde nicht bestimmt; die Methode scheint keine sehr guten Resultate zu geben: Preu z. B. beobachtete einmal eine Steigerung ron 1.3 auf 2.9 , an anderen Tagen 
bedeutend weniger. Günstiger sind die Resultate der Rivers PollutionKommission (36); allerdings untersuchte diese hochgradig verunreinigtes Wasser. Ein besonderer Nachteil der Methode ist, daß schon kleine Versuchsfehler bedeutende prozentuale Fehler geben können.

Derselbe Mangel haftet der Bestimmung des Albuminoid-A mmoniaks an: hier können Irrtümer um 100 Prozent schon bei der Untersuchung von Abwasser vorkommen (46, S. 200). Die Ausschläge scheinen nicht hoch zu sein: in der Oder bei Breslau (16, S. 222) zeigte sich eine Zunahme von 0.24 auf 0.422 ; in der Limmat beträgt der Gehalt 0.06 bis $0 \cdot 16$, eine Zunahme hinter Zürich ist selten zu bemerken. Ähnlich ist es in amerikanischen Flüssen (27, S.396/7). Uber den Wert der Bestimmung des organischen Kohlenstoffes und die Untersuchùng mit der Berthelotschen Bombe fehlen mir die Erfahrungen; doch dürfte sich letztere wegen ihres hohen Preises kaum allgemein einführen.

5. Als Methode zur Untersuchung auf zersetzungsfähige Stoffe wird von manchen Seiten die Bestimmung des Glühverlustes angesehen. Nach unseren Resultaten ist dies nicht richtig: er nimmt bei Verschmutzung durchaus nicht in dem Maße zu, wie man erwarten sollte: z. B. in der Wieseck um höehstens 50 Prozent, meistens bedeutend weniger. Es gilt daher von dieser Probe in erhöhtem Maße, was oben von der Oxydierbarkeit gesagt wurde. Auch das Verhältnis des Glühverlustes zum Gesamtrückstand ist nicht verwertbar, da, wie die Kurve ergibt, sich die beiden fast genau parallel gehen.

Auch andere Autoren hatten schlechte Resultate mit seiner Bestimmung: das Wasser der Nebel oberhalb Güstrow z. B. hatte einen solchen von 81 bzw. $99^{\mathrm{mg}}$, das des dortigen Stadtgrabens, der einer Jauche ähnlich war, von $127 \mathrm{mg}$ - also weniger als in unseren Versuchen die Lahn manchmal hatte. Das der Oder hat vor Eintritt in die Stadt Breslau $131 \cdot 1^{\mathrm{mg}}$, an einer Stelle, an der es infolge unvollständiger Vermischung mit dem Kanalwasser noch faulig riecht, $138 \cdot 3^{\mathrm{mg}}$ (der Ammoniak hatte an derselben Stelle um das 16 fache zugenommen). - ̊̈hnlich, weun auch. nicht ganz so charakteristisch, sind die Resultate in anderen Flüssen: stärkeres Steigen, auf mehr als das Doppelte, beobachtet man nur bei enormer Verunreinigung.

Wie man sieht, ergibt keine der Methoden zur Untersuchung auf Zersetzungsfähigkeit vollkommen befriedigende Resultate. Es handelt sich bei den zersetzungsfähigen Substanzen anscheinend um Stoffe, von denen schon eine sehr geringe Menge genügt, um groBe Unzuträglichkeiten hervorzurufen. Diese Stoffe müßte man allein fassen; bei den bisher an. gewendeten Methoden wird aber noch eine große Menge harmloser Stoffe mitbestimmt. 
III.

Die dritte Gruppe bilden die Methoden, die zur Messung der Verdünnung dienen.

1. Die Messung der Temperatur ist oft das einfachste Verfahren zu ihrer Ermittelung. Unterschiede traten nur in der Wieseck im Winter hervor, wo die Abwässer eine Erhöhung bis zu $2^{\circ}$ bewirken, auch wenn die Lufttemperatur viel niedriger lag. Eine solche Steigerung ist selbstverständlich von hoher Bedeutung.

2. Die Chloride geben einen noch besseren Indikator ab. Da ihre Gesamtmenge im Sommer und im Winter gleichbleibt, so lassen sie gute Schlüsse auf die Verdünnung der Schmutzstoffe in der Wieseck zu; und es zeigt sich auch, daB der Chlorgehalt um so höher, je niedriger ihr Wasserstand ist; die größten Differenzen betrugen oberhalb und unterhalb Gießens $18: 54^{\mathrm{mg}}$; die geringsten $18: 20^{\mathrm{mg}}$. In der Lahn tritt die Differenz weniger deutlich hervor; doch ist immerhin eine Steigerung fast stets nachweisbar.

3. Die Menge des Gesamtrückstandes läBt ebenfalls auf die Verdünnung Schlüsse ziehen. Er nimmt in der Wieseck stets (mit einer Ausnahme) zu, am meisten im Sommer: hier steigt er einmal von 230 auf $360^{\mathrm{mg}}$. In der Lahn ist die Zunahme sehr gering, doch fast stets deutlich nachzuweisen.

4. Die Bestimmung des Calcium und Magnesium empfiehlt besonders Weyl (27, S. 387), da ,diese stets in den menschlichen Effluvien nur in kleiner Menge vorhandenen Stoffe sich benützen lassen, um den Verdünnungsgrad der mensehlichen Fäkalien durch das Flußwasser festzustellen". Von uns wurden derartige Bestimmungen nicht vorgenommen; auch wird diese Ansicht durch keine der durchgesehenen Tabellen bestätigt; meistens schwankt der Kalkgehalt ganz unregelmäßig.

Es bleibt also zur Beurteilung der Verdünnung, abgesehen von der Temperatur, nur Chlor und Rückstand übrig, von denen uns ersteres bessere Resultate ergeben hat. Auch König (16, S. 233) empfiehlt vor allem die Chlorbestimmung; derselben Ansicht ist Ohlmüller (20, S.283). Auch in der Oder (16, S.222) ist die Zunahme des Chlorgehaltes stärker als die des Gesamtrückstandes (8.78:10.99 gegen $168 \cdot 9: 185 \cdot 6)$, ebenso in der Lahn bei Marburg (8.5:9.7 gegen 139.7:142.5) (26). In der Isar (28) ist es ebenfalls noch $\mathrm{zu}$ benutzen, wenn die Bestimmung des Rückstandes versagt. - Wenn demnach der Chlorbestimmung auch zur Beurteilung der Verdünnung eine größere Bedeutung zukommt, so is selbstrerständlich auch stets der Gesamtrückstand zu bestimmen, schon wegen der industriellen und auch anderweitigen Verwendung des Flubwassers. 
IV.

Nachdem, wie oben auseinandergesetzt, die Keimzahl keinen unmittelbaren RückschluB auf die Infektiosität zuläBt, bleiben zu deren Ermittelung besonders zwei Methoden übrig: die Bestimmung des Kolititers nach Petruschky und Pusch (12) und die der Zahl der auf Jodkaliumkartoffelgelatine wachsenden Keime (im folgenden mit JKK bezeichnet).

Die Methoden gehen von folgenden Erwägungen aus: Bacterium coli ist normalerweise nur oder fast nur in der direkten Umgebung des Menschen vorhanden und stammt stets aus dessen Darmkanal. In der freien Natur vermehrt es sich nicht wesentlich, sondern geht nach einiger Zeit zugrunde. Es stimmt darin überein mit den Bakterien, die rom Darmkanal aus krankheiterregend wirken, z. B. mit dem Typhusbazillus, kommt aber stets in viel gröBerer Menge vor und ist daher leichter nachzuweisen. Man wird daher schließen dürfen, daß, wo viel Bact. coli vorhanden sind, auch die Gefahr einer Infektion mit Typhus- und āhnlichen Bazillen eine entsprechend größere ist.

Da die beiden erwähnten Methoden das gleiche leisten sollen, so wäre es natürlich wünschenswert, wenn man nur eine anzuwenden brauchte, und es fragt sich nur, welche die bequemere ist und ob beide gleichviel leisten, d. h. ob sie einerseits alle Kolibazillen, andererseits nur diese angeben.

Bei den vorliegenden Untersuchungen hat sich gezeigt, daB die Bestimmung mittels J K K, nachdem einmal der Nährboden hergestellt war, weit bequemer ist: sie erfordert nicht mehr als das GieBen der Platten - auf die Wassermenge braucht nicht viel Rücksicht genommen zu werden - und das Zählen, das bei der geringen Zahl der Keime sehr einfach ist. - Bei der Bestimmung des Kolititers ist zwar die Bereitung der Nährböden einfacher, aber schon die Verdünnung und die Verteilung in die Bouillon erfordern mehr Zeit als das einfache PlattengieBen. Am nächsten Tage sieht man, daß einzelne Röhrchen, nämlich die mit der stärksten Verdünnung, nur oben und unten getrübt und in der Mitte klar sind. Diese können ohne weiteres ausgeschaltet werden, da Koli die Bouillon gleichmäBig trübt; sie beweisen aber, daB der Mesophilentiter durchaus nicht immer mit dem Kolititer zusammenfällt, wie Petruschky und Pusch (12) und auch Preu (18, S.44) behaupten. Damit stimmt auch überein, daB in den nicht getrübten Röhrchen sich niemals mehr Wachstum zeigte, wenn sie bei Zimmertemperatur aufbewahrt wurden. - Die übrigen wurden auf Drigalskiplatten ausgestrichen; auf einigen von diesen wuchsen keine roten Kolonien. Die roten Kolonien wurden auf Gelatine ausgestrichen; zeigte sich nach 2 Tagen keine Verflüssigung, so wurden sie auf Zuckervergärung geprüft. Verfüssigten sie nach 5 Tagen nicht und 
vergoren sie Zucker, so wurden sie für B. coli gehalten. Um einen Überblick zu geben, sei im folgenden das Gesamtresultat der Untersuchung von 16 Wässern angeführt: Nach Ausscheidung der nur teilweise getrübten waren es 55 Bouillonröhrchen, da bei den am stärksten verschmutzten nur die 4 niedersten Konzentrationen untersucht wurden. Bei 14 davon zeigten sich auf Lackmusagar keine roten Kolonien. Von den übrigen verflüssigten 7 die Gelatine, weitere 3 vergoren Zuckeragar nicht, so daB nur 31 übrigblieben. Man sieht, daB die Methode mehr Zeit erfordert als einfache Plattenzählung.

Die zweite Frage ist die, ob beide Wethoden sämtliche Kolibazillen angeben. Dabei zeigte sich zunächst, daß bei Bestimmung des Kolititers niemals eine stärkere Verdünnung Koli ergab, wenn sie eine schwächere nicht ergeben hatte: es scheint also, daß im Brutschrank ein Überwuchern der Koli durch andere Keime nicht stattfindet. Im übrigen lassen die Zahlen aber keinen SchluB zu, da merkwürdigerweise bald die eine, bald die andere Probe mehr Keime ergab. Einmal ergab sich sogar anscheinend eine höhere Zahl von Koli als von Keimen überhaupt: die Probe hat eben den großen Nachteil, daß die Angabe immer erst bei der zehnfachen Steigerung erfolgt, so daß z. B. nicht zu ersehen ist, ob 11000 oder 100000 Coli in $1 \mathrm{cem}$ vorhanden siud.

Da auf jene Frage aus den Tabellen keine Antwort zu erhalten ist, so ist es um so wichtiger, zu untersuchen, ob bei beiden Methoden auch wirklich nur B. coli gezählt wird. $\mathrm{DaB}$ beim Kolititer nur dieses in Betracht kommt, ist klar, da die Probe darauf zugeschnitten ist. Bei J KK muB der Nachweis erst geliefert werden. Nach Proskauer (48) wachsen außer ihnen nur einige verflüssigende und Hefekolonien darauf, die leicht zu unterscheiden sind. Letztere wurden von uns nicht gefunden; erstere erscheinen als kleine, graue, fast ausschließlich oberflächliche Kolonien, die diesen Nährboden nicht rerflüssigen, jedoch gewöhnliche Gelatine, wenn sie auf solche übergeimpft werden, Diese Kolonien wurden nicht mitgezählt (doch zur Kontrolle stets auf Gelatine geimpft). Wurden mit einer Reinkultur von Fluorescens liquefaciens JKK-Platten gegossen, so wuchsen darauf dieselben kleinen, grauen Kolonien, doch trat Verflüssigung nur da ein, wohin große Brocken von Reinlzultur gelangt waren. Es scheint also, daß peptonisierendes Ferment auf diesem Nährboden nicht gebildet wird, dab aber noch anhaftendes Ferment imstande ist, ihn zu verflüssigen. - $\mathrm{Um}$ zu sehen, ob außer diesen noch verflüssigende auf den Nährböden waren, wurden im ganzen 114 andere Kolonien auf gewöhnliche Nährgelatine abgeimpft: keine von diesen verflüssigte, alle wuchsen koliähnlich. - Damit ist aber noch nicht bewiesen, daß die Probe als Indikator auf Infektiosität aufgefaBt und der Bestimmung des Kolititers 
auch mit Hinblick auf die Erfolge als gleichwertig erachtet werden darf: dazu muß erst der Beweis geliefert werden, daß die gezählten Keime die Eigenschaft besitzen, die den typischen Darmkoli als Indikator wichtig macht, nämlich daB sie sich im Wasser nicht wesentlich vermehren. Es wurden daher drei der Wässer 24 Stunden nach der ersten Untersuchung nach gründlichem Umschütteln nochmals untersucht. Das Ergebnis ist in der folgenden Tabelle aufgezeichnet; die eingeklammerte Zahl zeigt die sofort - die nicht eingeklammerte die nach 24 Stunden ermittelte Zahl an.

Tabelle XIX.

\begin{tabular}{l||c|c|c}
\hline & I. & II. & III. \\
\hline \hline Keimzahl . . & $(3195)$ & $(50180)$ & $(686)$ \\
& 11880 & 325140 & 12784 \\
desgl. auf J K K & $(0)$ & $(474)$ & $(0)$ \\
& 24 & 12640 & 24 \\
Kolititer . . . & (Grad I) & (Grad IV) & (Grad I) \\
& 0 & Grad III & Grad I
\end{tabular}

Es zeigt sich also, daB die Gesamtkeimzahl bedeutend steigt, der Kolititer einmal gleichbleibt und zweimal abnimmt, die Zahl der JK K dagegen jedesmal ansteigt. Letztere Probe zeigt also auch Keime an, die zwar zur Koligruppe gehören, aber in hohem Maße die Fähigkeit besitzen, sich außerhalb des Körpers zu vermehren.

Damit gewinnt die Bestimmung des Kolititers eine erhöhte Bedeutung; jetzt $m u B$ die Tatsache, daß sich dabei offters noch Keime zeigen, wenn auf JKK keine mehr wachsen, so gedeutet werden, daB die JKK nicht nur andere Keime, sondern auch B. coli in geringem Grade hemmt. Es ist ja auch aus anderen Versuchen bekannt, daB flüssige Nährböden noch Keime zur Entwicklung bringen, wo feste versagen.

Nach diesen Versuchen scheint also die Bestimmung des Kolititers die bessere Probe zu sein. Sehen wir nun, wie diese Resultate mit denen der Untersuchung der Gewässer übereinstimmen. Hier haben wir einen gewissen Maßstab, wenn wir annehmen, daß die Zahl der hineingelangenden Koli in der Zeit vom Dezember bis Juni wenigstens ungefähr gleich bleibt: dann muß cet. par. bei hohem Stande des Wassers die Zahl der Koli niedrig, bei niedrigem hoch sein. Dies trifft nur für die Bestimmung des Kolititers zu: besonders ein Vergleich des Gehaltes der Wieseck unterhalb Gießens im Dezember und Mai einerseits, im Januar, Februar, März, April andererseits zeigt, daß die ermittelte Zahl ungefähr umgekehrt proportional der Wassermenge ist. Ảhnliches zeigt sich in dor Lahn unter- 
halb Gießens. Aus den Zahlen der Lahn und der Wieseck oberhalb GieBens lassen sich keine Schlüsse ziehen, da die Schwankungen relativ gering sind. - Anders wechseln die Zahlen bei JKK. Hier sinken sie in der verunreinigten Wieseck nicht mit steigendem Wasserstand (Januar), sondern sind da noch recht hoch: umgekehrt steigen sie in der Lahn und Wieseck unterhalb GieBens nicht mit sinkendem Wasserstand, sondern schon vorher. Es zeigt sich also, was nach dem Ergebnisse der Experimente zu erwarten war: durch diese Methode werden auch Keime angezeigt, die fähig sind, sich außerhalb des Körpers wesentlich zu vermehren.

Es folgt also daraus, daB die Bestimmung des Kolititers vorzuziehen ist. Sie ist nicht sehr bequem, die Fehlerquelle bei der Zählung ist nicht gering, trotzdem muB sie für die beste Methode zur Prüfung auf Infektiosität gelten. Die Untersuchung mittels JKK dagegen wird da bessere Dienste leisten, wo es nicht so sehr darauf ankommt, durch Bestimmung der Zahl der typischen Darmkoli die Infektiosität eines Flußwassers anzugeben, sondern nur einen Überblick zu gewinnen, wie sich Bakterien, die den Darmkoli nahestehen, z. B. zu einem Desinfektionsmittel verhalten. Hier ist sie besonders wegen ihrer Bequemlichkeit zu empfehlen.

Die Methode zur Bestimmung des Kolititers wurde bisher erst selten auf FluBverunreinigungen angewendet, z. B. von Petruschky und Pusch (12), die den Koligehalt der Wasserläufe in der Nähe von Danzig auf Grad I bis III (10 bis 1000 in $1{ }^{\mathrm{cm}}$ ) bestimmten; ferner von Preu (18), der als Kolititer der Regnitz oberhalb Erlangens Grad III (1000 in $1^{\mathrm{cm}}$ ), unterhalb Grad IV (10000) angab; der Schmutzstreifen des Kanalwassers im Flusse hatte Grad V (100000), das Kanalwasser selbst Grad VI (1000000). In England wurden ähnliche Untersuchungen besonders mit Rücksicht auf die Verbreitung des Typhus durch Austern angestellt: Houston (49) fand in der Themse oberhalb Londons meist 10, oft 100 Koli pro Kubikzentimeter; 3 bis $11^{\mathrm{km}}$ unterbalb des Finlaufes der Abwässer Londons 100 bis $1000 ; 20^{\mathrm{km}}$ unterhalb 10 bis 1000 (meist 100); $35^{\mathrm{km}}$ unterhalb meist $10 ; 43^{\mathrm{km}}$ unterhalb 1 in $10^{\mathrm{com}}$ bis 1 in $1^{\mathrm{cm}}$. Der Gehalt der chemisch gereinigten Abwässer betrug 100000 , der des Klärschlammes von einer bis zu zehntausend Millionen. In $100^{\mathrm{ccm}}$ reinen Meerwassers fehlten sie vollständig. Wesentlich ungünstiger waren die Resultate Hammerls (50), der Koli im FluBwasser unterhalb Graz nicht nachweisen konnte, obwohl die Siele in den FluB einmündeten; allerdings untersuchte er zunächst auf Gelatineplatten. Nach Vincent (51) hat das Wasser der Seine in Paris nur 1 bis 60 Koli pro Kubikzentimeter; seine Methode besteht zunächst in Vorzüchtung in 0.75 Promille Karbolbouillon bei $41^{\circ}$. 
Eine andere Methode zur Bestimmung der Infektiosität ist die von Blachstein (27, S. 388), der das zu untersuchende Wasser in verschieden groBen Mengeh Mäusen, Kaninchen und Tauben injiziert. Die Methode dürfte sich schon wegen der hohen Kosten kaum allgemein einführen. AuBerdem sind die Lebensbedingungen für menschen- und tierpathogene Keime zu verschieden, als daB sich aus dem Vorhandensein der letzteren irgendwelche Schlüsse ziehen ließen.

\section{SchluB.}

Nachdem im vorhergehenden die Ergebnisse der Untersuchung der Lahn und der Wieseck an vielen Stellen einzeln besprochen worden sind, sind noch einige Worte über ihre Verunreinigungen im Zusammenhang zu sagen. - Eine Verunreinigung ist bei beiden vorhanden; in der Wieseck ist sie stark, in der Lahn gering. In der Wieseck ist sie mit allen Methoden leicht nachzuweisen und mit vielen quantitativ zu bestimmen. In der Lahn ist sie bei Besichtigung nicht bemerkbar und wird auch unter günstigen Bedingungen nur durch einzelne Methoden deutlich: die Keimzahl ist zum Zeichen der stärkeren Zersetzung vermehrt, der freie Sauerstoff vielleicht aus demselben Grunde vermindert, Ammoniak und salpetrige Säure zeigen ebenfalls manchmal eine Zunahme. Eine Trübung des Wassers ist durch die Bestimmung der suspendierten Bestandteile und noch besser durch die der Durchsichtigkeit nachweisbar. $\mathrm{DaB}$ auch die Zersetzungsfähigkeit zugenommen hat, beweist das Ansteigen der Sauerstoffzehrung und vielleicht auch das der Oxydierbarkeit. Durch die Erhöhung des Kolititers ist eine höhere Infektiosität angedeutet. Die Verunreinigung wechselt in beiden Gewässern nach der Wassermenge: in der Wieseck ist sie bei Hochstand vermindert, in der Lahn fast aufgehoben, da dann - ganz abgesehen von der Verdünnung - die natürliche Verunreinigung so stark wird, daB die künstliche dagegen stark zurücktritt. Dagegen nimmt im Sommer die Verschmutzung der Wieseck und besonders der Stadtbäche in unerträglicher Weise zu. Hier wird die begonnene Kanalisation großen Segen stiften. In der Lahn ist die Verunreinigung auch im Sommer so gering, daß höchstens mit Rücksicht auf die rermehrte Bakterienzahl und die vergröBerte Wahrscheinlichkeit des Hineingelangens krankheitserregender Keime, die sich durch die Erhöhung des Kolititers kundgibt, das Wasser zum Trinken, Waschen und Baden eine Strecke weit unbrauchbar wird. $O b$ und wie die dortigen Zustände sich nach der Kanalisation verändern werden, dies zu untersuchen wird Sache einer weiteren Arbeit sein, die sofort nach deren Vollendung unternommen werden soll. 
Die Ergebnisse der Arbeit lassen sich in folgender Weise zusammenfassen:

1. Die Veränderungen der Zusammensetzung reiner und verunreinigter Flüsse sind von der Temperatur und der Wassermenge in der Weise abhängig, wie es in Tabelle XVIII angegeben ist.

2. Zum quantitativen Nachweis vorhandener Zersetzung gibt sebr gute Resultate die quantitative Bestimmung der Durchsichtigkeit (Lichtabsorption), des Ammoniaks, des freien Sauerstoffs und der Keimzahl; weniger leistet die Bestimmung des Schwefelwasserstoffes, der salpetrigen Säure und der suspendierten Bestandteile.

3. Eine vollkommene Methode zum Nachweis der Zersetzungsfähigkeit wurde nicht gefunden. Von den untersuchten scheint am meisten die Bestimmung der Sanerstoffzehrung zu leisten; die Bestimmung der Oxydierbarkeit ist für Flußwasser wenig brauchbar, die des Glühverlustes völlig unbrauchbar.

4. Zur Bestimmung der Infektiosität ist die Ermittlung des Kolititers die beste Methode.

5. Nach den Ergebnissen der Untersuchungen ist die Lahn als gering, die Wieseck als stark verunreinigt anzusehen. 


\section{Literatur-Verzeichnis.}

1. Kossack, Das Staatsrecht d. Großherzogt. Hessen. Freiburg u. Leipzig 1894.

2. Baumeister, Vergleich von FluBverunreinigungen. Vierteljahrsschrift für öfentl. Gesundheitspflege. 1892. Bd. XXIV. S. 467.

3. Verhandlungen der zweiten Kammer der Landstände des Großherzogtams Hessen in den Jahren 1903/06. 32. Landtag. Protolcolle. Bd. III. S. 2416. - Drucksachen. Bd. TV. Nr. 509.

4. Mez, Mikroskopische Wasseranalyse. Berlin 1898.

5. Kisskalt, Eine neue Methode zur Bestimmung der sichtbaren Vernnreinigung ron FluB. und Abwasser. Hygien. Rundschau. 1904. Bd. XIV. S. 1036.

6. Forel, Handbuch der Seenkunde. Stuttgart 1901.

7. Fischer, Untersuchnngen über die Verunreinigung des Kieler Hafens. Diese Zeitschrift. 1896. Bd. XXIII. S. 1.

8. Farnsteiner, Buttenberg und Korn, Leitfaden für die chem. Untersuchung von Abwasser. München und Berlin 1902.

9. Lehmann, Die Methoden der praktischen Hygiene. 2. Aufl. Wiesbaden 1901.

10. Emmerich u. Trillich, Anleitung zu hygienischen Untersuchungen. 3. Aufl. München 1902.

11. Spitta, Untersuchungen über die Verunreinigung und Selbstreinigung der Flüsse. Archiv für Hygiene. 1900. Bd. XXXVIII. S. 160.

12. Petruschky und Pusch, Bacterium coli als Indikator für Fäkalverunreinigang von Wässern. Diese Zeitschrift. 1903. Bd. XLIII. S. 304.

13. Marsson, Spitta und Thumm, Gutachten über die Zulässigkeit der Fäkalienabschwemmang der Stadt Hanau in den Main. Mitteilungen a. d. Prüfungsanstalt. für Wasserversorgung und Abwässerbeseitigung. 1905. Hft. 5. S. 60.

14. Rubner, Das städtische Sielwasser und seine Beziehung zur Flabverunreinigung. Archiv fïr Hygiene. 1903. Bd. XLVI. S. 1.

15. Fischer, Das Wasser. 3. Anfl. Berlin 1902.

16. König, Die Verunreinigung der Gewässer. Berlin 1899. Bd. I.

17. Derselbe, Ebenda. Bd. II.

18. Prea, Das Abwasser von Erlangen und die Regnitz an der Einmündung des Hauptsiels. Inaug.-Diss. Erlangen 1905.

19. Dirksen und Spitta, Die Verändernngen des Spreewassers auf seinem Laufe durch Berlin in bakteriologischer und chemischer Hinsicht. Archiv f. Hygiene. 1899. Bd. XXXV. S. 83.

20. Ohlmüller, Gutachten des Reichsgesundheitsrates über die Einleitung des Mainzer Kanalwassers einschlieBlich der Fäkalien in den Rhein. Arbeiten aus dem Kaiserl. Gesundheitsamte. 1903. Bd. XX. S. 258.

21. Pfeiffer a. Eisenlohr, Zur Frage der Selbstreinigung der Flüsse. Archiv für Hygiene. 1892. Bd. XIV. S. 191. 
22. Brandenburg, Uther die Verunreinigung des Moselflusses durch die Stadt Trier. Hygien. Rundschau. 1898. Bd. VIII. S. 561.

23. Dräer, Das Pregelwasser oberhalb, innerhalb und nnterhalb Königsbergs. Diese Zeitschrift. 1895. Bd. XX. S. 323.

24. Thomann, Untersuchungen über den gegenwärtigen Stand der Frage der Verunreinigung der Limmat durch die Abwässer der Stadt Zürich. Ebenda. 1900. Bd. XXXIII. S. 1.

25. Frank, Die Veränderungen des Spreewassers innerhalb und unterhalb Berlins in bakteriologischer und chemischer Hinsicht. Ebenda. 1888. Bd. III. S. 355 .

26. Fränkel, Die Einleitung der Abwässer Marburgs in die Lahn. Vierteljahrs. schrift für gerichtl. Medizin. 1892. 3. Folge. Bd. VII. S. 321.

27. Weyl, Handbuch der Hygiene. Jena 1897. Bd. II. Abtlg. I.

28. Praussnitz, Der EinfluB der Münchener Kanalisation auf die Isar. Bygien. Tagesfragen. IX. München 1890.

29. Spitta, Weitere Untersuchungen über Flußverunreinigung. Archiv für Hygiene. 1903. Bd. XLVI. S. 64.

30. Goldschmidt, Luxembarger, Franz, Hans und Ludwig Neumayer und W. Praussnitz, Das Absterben der Mikroorganismen bei der Selbstreinigung der Flüsse. Hygien. Rundschau. 1898. Bd. VIII. S. 161.

31. Kruse, Beiträge zur praktischen Hygiene. II. Über Verunreinigung und Selbstreinigung der Flüsse. Centralblatt für allgemeine Gesundheitspflege. 1899. Bd. XVIII. S. 16.

32. Buchner, Über den Einfuß des Lichtes auf Bakterien und über die Selbstreinigung der Flüsse. Archiv für Hygiene. 1893. Bd. XVII. S. 179.

33. Kabrhel, Bakteriologische und kritische Studien über die Verunreinigung und Selbstreinigung der Flüsse. Ebenda. 1897. Bd. XXX. S. 32.

34. Reindl, Die schwarzen Flüsse Südamerikas. Naturwissenschaftl. Wochenschrift. 1905. Neue Folge. Bd. IV. S. 353.

35. Lehmann, Die Verunreinigung der Saale bei u. in der Stadt Hof. Hof 1895.

36. Der dritte Bericht der im Jahre 1868 in England eingesetzten Rivers Pollution Commission. Vierteljahrsschrift für öffentl. Gesundheitspflege. Bd. IV. S. 409.

37. Der erste und zweite Bericht der im Jahre 1868 in England eingesetzten Rivers Pollution Commission. Ebenda. Bd. III. S. 278.

38. Stahl, Bakteriologische a. chemische Untersuchungen über Verunreinigung und Selbstreinigung kleinerer FluBläufe in der Umgebung von Freiburg i. Br. Inaug.Diss. Freiburg 1904.

39. Ohlmüller, Gutachten, betreffend die Entwässerung der Stadt Güstrow. Arbeiten aus dem Kaiserl. Gesundheitsamte. 1891. Bd. VII. S. 255.

40. Derselbe, Weiteres Gutachten, betreffend die Beseitigung der Kanalwässer der Residenzstadt Schwerin. Ebenda. 1904. Bd. XX. S. 243.

41. Gärtner und Rabner, Gutachten des Reichsgesundheitsamtes über die Einleitung der Abwässer Dresdens in die Elbe. Ebenda. 1903. Bd. XIX. S. 458.

42. Prall, Beitrag zur Kenntnis der Nährböden zur Bestimmung der Keimzahl im Wasser. Ebenda. 1902. Bd. XVIII. S. 436.

43. König, Die Untersuchung landwirtschaftlich u. gewerblich wichtiger Stoffe. Berlin 1891.

44. Proskaqer u. Croner, Die Kläranlage für die Kolonie und Arbeitsstätten der Berliner Maschinenbau-Aktiengesellschaft, vorm. L. Schwartzkopff in Wildau bei Berlin. Festschrift für Koch. Jena 1903. 
368 K. Kisskatt: Verungeinigung Der LahN UND DeR Wieseck.

45. Praussnitz, Der Einfluß der Münchener Kanalisation auf die Isar. Hygien. Rundschau. 1903. Bd. XIII. S. 273.

46. Dunbar, Zur Beurteilung der Wirkung von Abwasserreinigungsanlagen. Gesundheits-Ingenieur. 1905. Bd. XXVIII. S. 157.

47. Lehmann, Die Verunreinigung des Kanalhafens von Frankenthal. Ver. handlungen der phys.-med. Gesellschaft zu Würzburg. 1903. N. F. Bd. XXXV.

48. Proskaner u. Elsner, Über die hygienische Untersuchung des Kohlebreiverfabrens zur Reinigung von Abwässern auf der Kläranstalt in Potsdam. Vierteljahrsschrift für gerichtl. Mledizin. 3. Folge. BI. XVI. Suppl.-Heft.

49. Bouston, The bacteriological examination of oysters and estuarial waters. Journal of Hygiene. 1904. Bd. IV. S. 173.

50. Hammerl, Über das Vorkommen des Bacterium coli im Flußwasser. Eygien. Rundschau. 1897. Bd. VII. S. 528.

51. Vincent, Sur la signification du „Bacillus coli“ dans les eaux potables. Annales de l'Institut Pasteur. 1905. 'T. XIX. p. 233.

\section{Erklärung der Abbildungen.}

(Taf. III u. IV.)

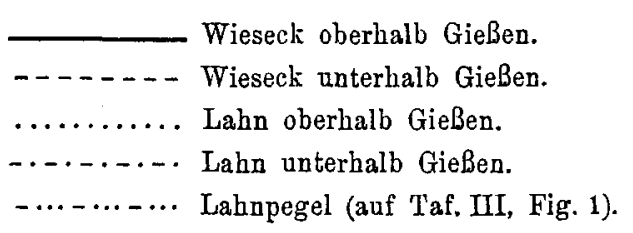

Tafel III.

Fig. 1. Temperatur und Lahnpegel. $1^{\mathrm{cm}}$ Höhe entspricht $2^{\circ}$ bzw. $0 \cdot 25^{\mathrm{m}}$.

Fig. 2. Gesamtrückstand. $1^{\mathrm{cm}}$ Höhe entspricht $25^{\mathrm{mg}}$.

Fig. 3. Suspendierte Bestandteile. $1^{\mathrm{cm}}$ Höhe entspricht $5^{\mathrm{mg}}$.

\section{Tafel IV.}

Fig. 4. Durchsichtigkeit. $1^{\mathrm{cm}}$ Höhe entspricht 5 Prozent Lichtabsorption.

Fig. 5. Freier Sauerstoff. $1^{\mathrm{cm}}$ Höhe entspricht 10 Prozent Defizit oder ÜberschuB. Das Defizit ist über, der ÜberschuB unter der Mittellinie angegeben.

Fig. 6. Keimzahl. $1^{\circ \mathrm{m}}$ Höhe entspricht bei „Wieseck oberhalb GieBens" und „Lahn oberbalb und unterhalb GieBens“ 1000, bei „Wieseck unterhalb GieBens“ 2000 Keimen; bei letzterer ist die Höhe anfangs nur durch einen Pfeil angedeutet, da auf der Tafel kein Platz war. 

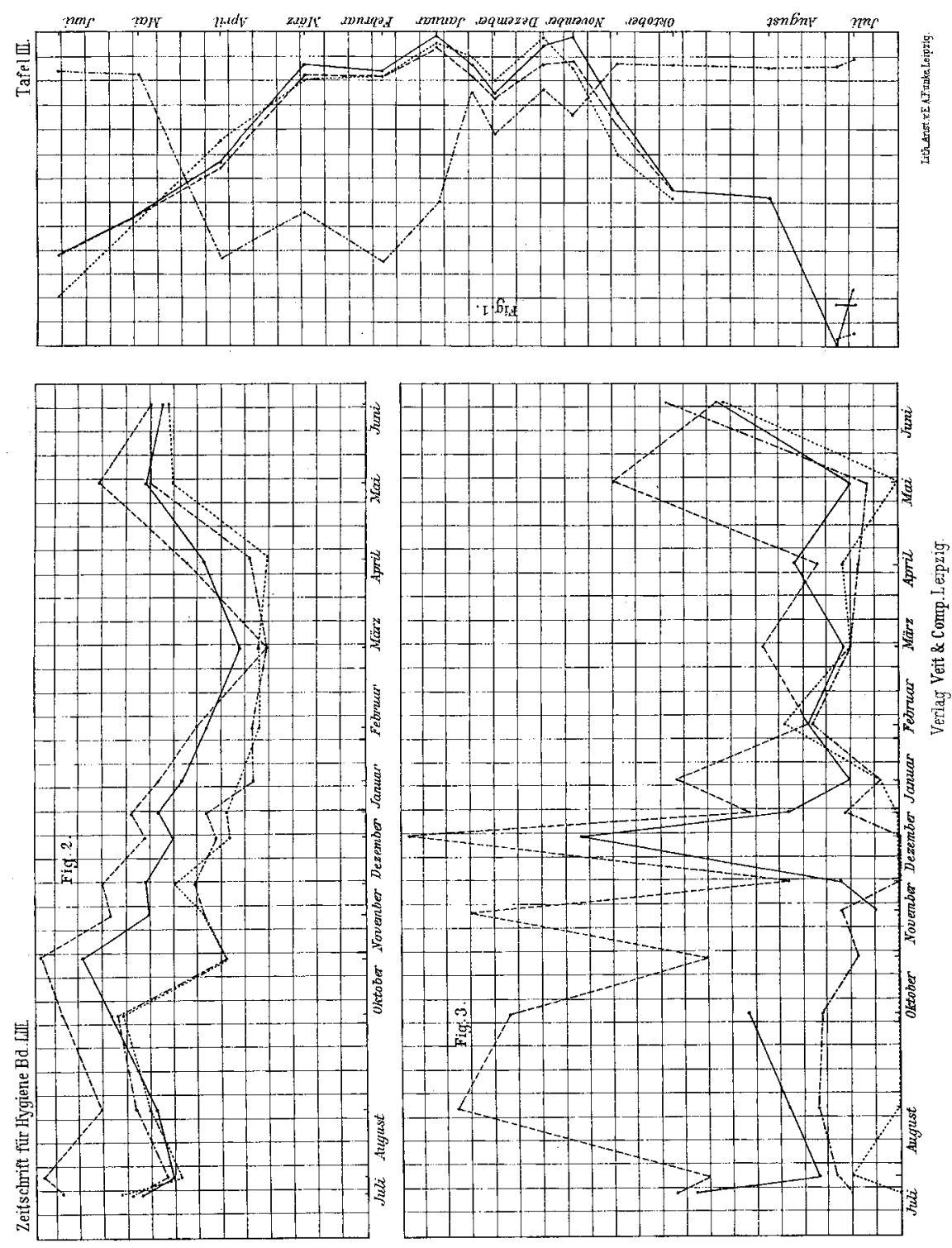


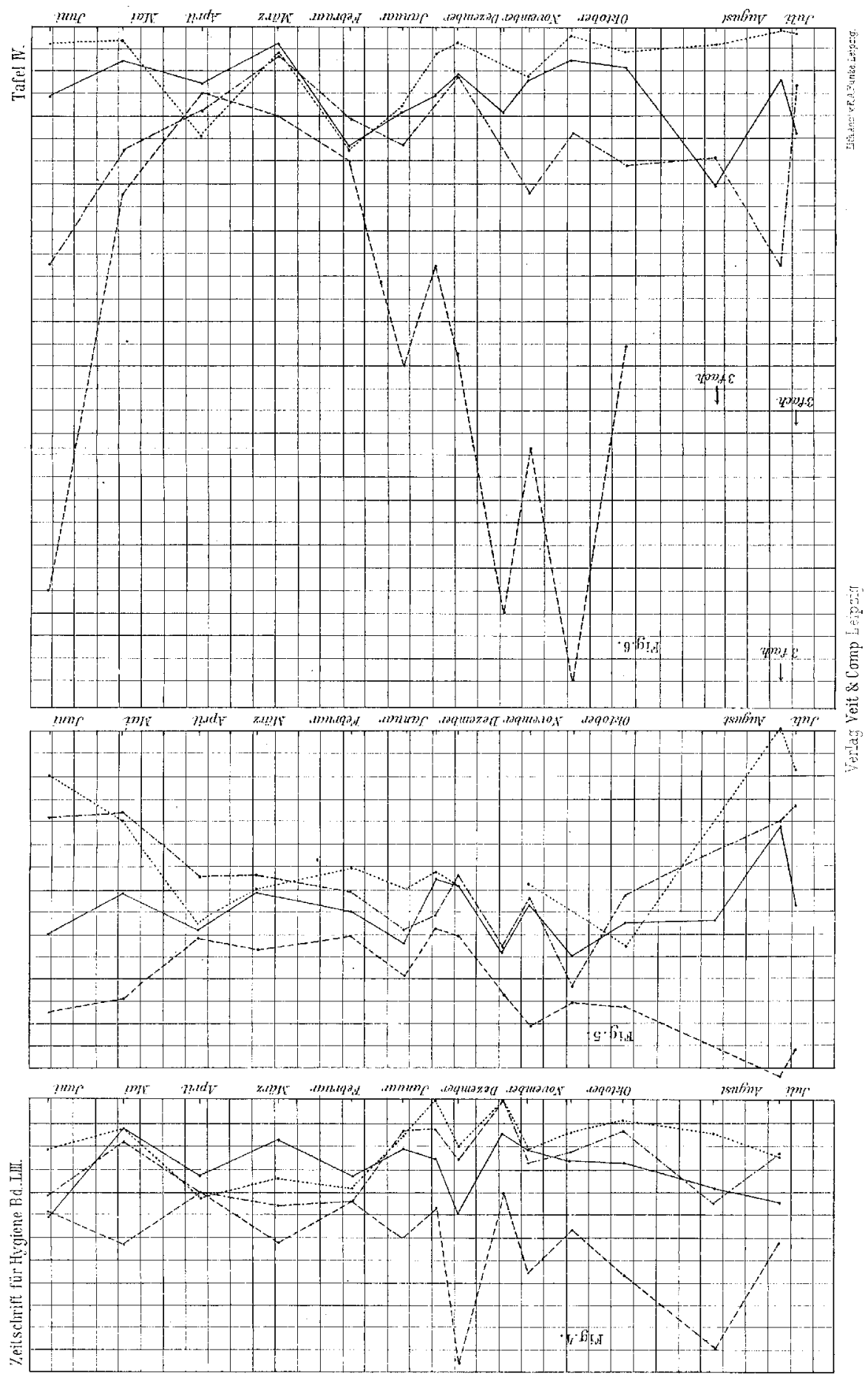

